Universidade de São Paulo

Faculdade de Medicina de Ribeirão Preto

\title{
2020
}

Avaliação eletrofisiológica (P300) e de percepção de fala em indivíduos com perda auditiva antes e após adaptação de AASI

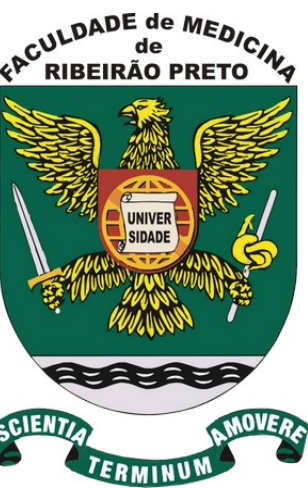

Victor Goiris Calderaro

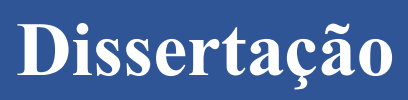




\section{Avaliação eletrofisiológica (P300) e de percepção de fala em indivíduos com perda auditiva antes e após adaptação de}

\section{AASI}

\section{Versão corrigida}

Dissertação de Mestrado apresentada para o Programa de Pós-Graduação em Reabilitação e Desempenho Funcional da Faculdade de Medicina de Ribeirão Preto FMRP/USP para obtenção do título de Mestre em Ciências.

Área de concentração: Fonoaudiologia

Orientadora: Profa. Dra. Ana Cláudia Mirândola Barbosa Reis 
Autorizo a reprodução e divulgação total ou parcial deste trabalho, por qualquer meio convencional ou eletrônico, para fins de estudo e pesquisa, desde que citada a fonte.

FICHA CATALOGRÁFICA

Calderaro, Victor Goiris

Avaliação eletrofisiológica (P300) e de percepção de fala em indivíduos com perda auditiva antes e após adaptação de AASI. Ribeirão Preto, 2020.

78 p.: il. $18,30 \mathrm{~cm}$.

Dissertação de Mestrado, apresentada à Faculdade de Medicina de Ribeirão Preto/USP. Área de concentração: Fonoaudiologia.

Orientadora: Reis, Ana Cláudia Mirândola Barbosa.

1. Audição; 2. Potencial Evocado P300; 3. Perda Auditiva; 4. Auxiliares de audição 
Nome: CALDERARO, Victor Goiris

Título: Avaliação eletrofisiológica (P300) e de percepção de fala em indivíduos com perda auditiva antes e após adaptação de AASI.

Dissertação apresentada à Faculdade de Medicina de Ribeirão Preto da Universidade de São Paulo junto ao Departamento de Ciências da Saúde para obtenção do título de Mestre em Ciências pelo Programa de Pós-Graduação em Reabilitação e Desempenho Funcional.

Aprovado em: 20 / 02 / 2020.

\section{Banca examinadora}

Profa. Dra. Elaine Caldeira de Oliveira Guirro

Instituição: Faculdade de Medicina de Ribeirão Preto da Universidade de São Paulo Julgamento:

Prof. Dr. Eduardo Tanaka Massuda

Instituição: Faculdade de Medicina de Ribeirão Preto da Universidade de São Paulo Julgamento

Profa. Dra. Maria Cecília Martinelli

Instituição: Universidade Federal de São Paulo - UNIFESP

Julgamento: 


\section{DEDICATÓRIA}

Aos meus pais, José Armando e Estela, que com muito carinho e apoio não mediram esforços para que eu chegasse até essa etapa da minha vida. 


\section{AGRADECIMENTOS}

À Profa. Dra. Ana Claudia Mirândola Barbosa Reis, em especial, pela confiança depositada em mim, por ter orientado esta dissertação de mestrado e a quem devo toda minha formação científica. Agradeço pela disposição em compartilhar comigo momentos de conhecimento e por ser, além de orientadora, uma pessoa em quem posso confiar.

Sou grato a todos os profissionais, funcionários e colaboradores do serviço, que me ajudaram de forma direta ou indiretamente nesta pesquisa, para que este trabalho pudesse ser executado e concluído. Humberto de Oliveira Simões, Carla Aparecida de Urzedo Fortunato Queiroz, Francine Raquel dos Santos, Daniela Soares Fonseca da Costa, Carla Dias, Sthella Zanchetta, Adriana Ribeiro Tavares Anastasio, Maria Stella Arantes do Amaral, Miguel Angelo Hyppolito, Juliana Reche, Ana Maria Rufato Furukawa, Vera Lucia Valladares, Sandra Regina de Souza Maximo, Denny Marcos Garcia, Sarah Carolina Bernal e Andreia Romeu Faria, agradeço imensamente.

A todos meus familiares e amigos próximos, que sempre me incentivaram e que viveram comigo cada momento.

Ao Programa de Pós-graduação em Reabilitação e Desempenho Funcional, por ter me recebido de forma acolhedora neste desafio. Em especial ao Samuel Ribeiro Filipini, Marília dos Reis Pereira V. Prioli e Edvaldo F. Gonçalves, pela prontidão em ajudar e esclarecer minhas dúvidas.

E, finalmente, a todos os pacientes que compuseram a amostra deste estudo. Meu sincero agradecimento por todo esforço e colaboração para a concretização deste estudo. 
"A tarefa não é tanto ver aquilo que ninguém viu, mas pensar o que ninguém ainda pensou sobre aquilo que todo mundo vê."

(Arthur Schopenhauer) 


\section{RESUMO}

CALDERARO, Victor Goiris. Avaliação eletrofisiológica (P300) e de percepção de fala em indivíduos com perda auditiva antes e após adaptação de AASI. 2020. 78 p. Dissertação (Mestrado). Faculdade de Medicina de Ribeirão Preto Universidade de São Paulo, Ribeirão Preto, 2020.

Introdução: A audição é um dos sentidos fundamentais para que o ser humano possa se comunicar. Sendo ela deficiente, uma das condutas apropriadas para minimizá-la, quando não é possível tratamento médico ou cirúrgico, é o uso de aparelho de amplificação sonora individual (AASI). Uma maneira efetiva de verificar se os aparelhos estão trazendo benefícios para o paciente é avalia-lo por meio de testes de percepção de fala, questionários e exames eletrofisiológicos Objetivo: Verificar as possíveis adaptações a nível funcional após a estimulação auditiva com uso de AASI em indivíduos com perda auditiva sensorioneural de grau moderado e severo. Material e métodos: Foram avaliados 24 indivíduos, de ambos os sexos, com média de idade de 58,9 anos (DP+$15,0)$, com perda auditiva sensorioneural de grau moderado ou severo, os quais receberam AASI bilateral. Foram realizadas a avaliação comportamental e eletrofisiológica da audição e aplicação de questionário de auto percepção da deficiência auditiva. A primeira fase da coleta foi realizada no período da adaptação dos aparelhos, constituindo-se da avaliação com o teste Listas de Sentenças em Português e da avaliação eletrofisiológica (P300). A segunda fase após seis meses, constituindo-se das mesmas avaliações da fase um, acrescidas da aplicação do questionário Hearing Handicap for Inventory for Elderly (HHIE) or Adults (HHIA), semelhante à terceira fase, que ocorreu após 12 meses da adaptação. Resultados: O limiar auditivo médio em campo sonoro foi de $55,1 \mathrm{~dB}$ na fase $1,36,1 \mathrm{~dB}$ na fase 2 e 36,9 dB na fase 3. A média de latência do P300 para os estímulos tone burst e fala foram, respectivamente, 348,85 e 326,08 ms na fase 1; 334,84 e 330,72 ms na fase 2 e 337,01 e 318,62 ms na fase 3, já a média de amplitude foram, respectivamente, 3,38 e 4,25 $\mu \mathrm{V}$ na fase $1 ; 4,12$ e 4,26 $\mu \mathrm{V}$ na fase 2 e 4,35 e 3,70 $\mu \mathrm{V}$ na fase 3. Não houve diferença estatística de latência e amplitude entre as fases. As médias de acertos no teste de reconhecimento de sentenças no silêncio ( $\mathrm{F} 1=79 \%$, F2 $=85,4 \%$ e $\mathrm{F} 3=86,6 \%)$ mostram diferença estatística $(\mathrm{p}=0,0003)$ com o uso de AASI quando comparadas as fases 1 e 2 e as fases 1 e 3. A aplicação do questionário HHIE ou HHIA apontou resultados favoráveis ao uso dos aparelhos auditivos, mostrando redução de restrição de participação do indivíduo. Conclusão: Não houve diferenças nas medidas de latência e amplitude da componente P3 nas três fases do estudo, evidenciou-se melhora das respostas dos indivíduos para os testes de percepção de fala nas três fases do estudo. Houve correlação da variável grau da perda auditiva com os resultados do teste de percepção de fala. Os escores do questionário de autoavaliação demonstraram redução da percepção de restrição de participação, após uso do AASI, tanto no âmbito emocional quanto no social.

Palavras-Chave: Audição; Potencial Evocado P300; Perda Auditiva; Auxiliares de audição. 


\begin{abstract}
CALDERARO, Victor Goiris. Electrophysiological assessment (P300) and speech perception in people with hearing loss before and after hearing aid fitting. 2020. 78 p. Dissertation (Master degree). Ribeirão Preto Medical School - University of São Paulo, Ribeirão Preto, 2020.
\end{abstract}

Introduction: Hearing is one of the fundamental meanings for human beings to communicate. If it is deficient, one of the appropriate conducts to minimize it, when medical or surgical treatment is not possible, is the use of an individual hearing aid (hearing aid). An effective way to check if the devices are bringing benefits to the patient is to evaluate them through speech perception tests, questionnaires and electrophysiological exams Objective: To verify possible adaptations at the functional level after hearing stimulation with hearing aid use in individuals with moderate and severe sensorineural hearing loss. Material and methods: Twenty-four individuals of both sexes, with a mean age of 58.9 years (SD +-15.0 ), with moderate or severe sensorineural hearing loss, who received bilateral hearing aids, were evaluated. Behavioral and electrophysiological assessment of hearing and a self-perception questionnaire for hearing loss were performed. The first phase of the collection was carried out in the period of adaptation of the devices, consisting of the evaluation with the Portuguese Sentence List test and the electrophysiological evaluation (P300). The second phase after six months, consisting of the same assessments as in phase one, plus the application of the Hearing Handicap for Inventory for Elderly (HHIE) or Adults (HHIA) questionnaire, similar to the third phase, which occurred after 12 months of adaptation. Results: The mean auditory threshold in the sound field was $55.1 \mathrm{~dB}$ in phase $1,36.1 \mathrm{~dB}$ in phase 2 and $36.9 \mathrm{~dB}$ in phase 3. The mean P300 latency for tone burst and speech stimuli were, 348.85 and $326.08 \mathrm{~ms}$ in phase 1, respectively; 334.84 and $330.72 \mathrm{~ms}$ in phase 2 and 337.01 and $318.62 \mathrm{~ms}$ in phase 3, whereas the mean amplitude was, respectively, 3.38 and $4.25 \mu \mathrm{V}$ in phase $1 ; 4.12$ and $4.26 \mu \mathrm{V}$ in phase 2 and 4.35 and 3.70 $\mu \mathrm{V}$ in phase 3 . There was no statistical difference in latency and amplitude between phases. The means of correct answers in the sentence recognition test in silence (F1 = $79 \%, F 2=85.4 \%$ and $F 3=86.6 \%)$ show statistical difference $(\mathrm{p}=0.0003)$ with the use of hearing aids when compared to phases 1 and 2 and phases 1 and 3. The application of the HHIE or HHIA questionnaire showed favorable results for the use of hearing aids, showing a reduction in the individual's participation restriction. Conclusion: There were no differences in the measures of latency and amplitude of the P3 component in the three phases of the study, there was an improvement in the responses of individuals to the speech perception tests in the three phases of the study. There was a correlation between the variable degree of hearing loss and the results of the speech perception test. The scores of the self-assessment questionnaire showed a reduction in the perception of participation restriction, after using the hearing aid, both emotionally and socially.

Keywords: Hearing; P300 Evoked Potential; Hearing Loss; Hearing Aid. 


\section{LISTA DE TABELAS}

TABELA 1 - Caracterização sociodemográfica ............................................ 34

TABELA 2 - Dados audiológicos dos pacientes estudados $(\mathrm{n}=24) \ldots \ldots \ldots \ldots \ldots . . . . . .35$

TABELA 3 - Médias de latência e amplitude entre as derivações CzA1 e CzA2, nas três fases do estudo, para o estímulo tone burst e estímulo de fala ......................................................................... 36

TABELA 4 - Comparação da latência (ms) entre as derivações CzA1 e CzA2, nas três fases do estudo, para o estímulo tone burst e estímulo de fala

TABELA 5 - Comparação da amplitude $(\mu \mathrm{V})$ entre as derivações CzA1 e CzA2, nas três fases do estudo, para o estímulo tone burst e estímulo de fala

TABELA 6 - Média, desvio padrão, valores mínimos e máximos do teste Listas de Sentenças em Português para os indivíduos, nas três fases do estudo 


\section{LISTA DE FIGURAS}

FIGURA 1 - Representação do posicionamento dos eletrodos, segundo “10-20 International System” (JASPER, 1958) ..................... 30

FIGURA 2 - Análise das médias dos limiares auditivos em campo sonoro nas 3 fases do estudo (F1 = sem AASI, F2 = com AASI há 6 meses, F3 = com AASI há 12 meses)

FIGURA 3 - Médias dos valores de latência (ms) de tone burst (P300) nas três fases do estudo ............................................................. 38

FIGURA 4 - Média dos valores de latência (ms) de estímulo de fala (P300) nas três fases do estudo

FIGURA 5 - $\quad$ Médias dos valores de amplitude $(\mu \mathrm{V})$ de tone burst (P300) nas três fases do estudo

FIGURA 6 - Média dos valores de amplitude $(\mu \mathrm{V})$ de estímulo de fala (P300) nas três fases do estudo

FIGURA 7 - Distribuição dos resultados dos valores de latência (ms) em relação ao grau da perda auditiva para os estímulos tone burst (a) e fala (b), nas três fases do estudo.

FIGURA 8 - Distribuição dos resultados dos valores de amplitude $(\mu \mathrm{V})$ em relação ao grau da perda auditiva para os estímulos tone burst (a) e fala (b), nas três fases do estudo

FIGURA 9 - Distribuição dos resultados dos valores de latência (ms) em relação a configuração da perda auditiva para os estímulos tone burst (a) e fala (b), nas três fases do estudo.

FIGURA 10 - Distribuição dos resultados dos valores de amplitude $(\mu \mathrm{V})$ em relação a configuração da perda auditiva para os estímulos tone burst (a) e fala (b), nas três fases do estudo

FIGURA $11-\quad$ Média dos valores de IPRSS nas três fases do estudo

FIGURA 12 - Valores médios dos resultados do desempenho para o Índice Percentual de Reconhecimento de Sentenças no Silêncio (IPRSS) em relação ao grau da perda auditiva, nas três fases do estudo

FIGURA 13 - Valores médios dos resultados do desempenho para o Índice Percentual de Reconhecimento de Sentenças no Ruído 
(IPRSR) em relação ao grau da perda auditiva, na fase três do estudo

FIGURA 14 - Valores médios dos resultados do desempenho para o Índice Percentual de Reconhecimento de Sentenças no Silêncio (IPRSS) em relação à configuração da perda auditiva, nas três fases do estudo

FIGURA 15 - Valores médios dos resultados do desempenho para o Índice Percentual de Reconhecimento de Sentenças no Ruído (IPRSR) em relação à configuração da perda auditiva, na fase três do estudo

FIGURA 16 - Questionário HHIE ou HHIA nas fases 2 e 3 46 
LISTA DE FLUXOGRAMA

FLUXOGRAMA 1 - Constituição amostral .............................................. 26 


\section{LISTA DE QUADROS}

QUADRO 1 - $\quad$ Parâmetros gerais para a aquisição do exame P300............... 30 


\section{LISTA DE ABREVIATURAS, SIGLAS E SÍMBOLOS}

AASI

CD

dBNA

dBNS

DP

HCRP-FMRP-

USP

HCRP

HHIA

HHIE

HHIE-S

$\mathrm{Hz}$

IC

IPRSR

IPRSS

K

$\mathrm{K} \Omega$

LA

LRSR

LRSS

LSP
Aparelho de Amplificação Sonora Individual

Compact Disc

Decibel Nível de Audição

Decibel Nível de Sensação

Desvio Padrão

Hospital das Clínicas de Ribeirão Preto - Faculdade de Medicina de Ribeirão Preto - Universidade de São Paulo

Hospital das Clínicas de Ribeirão Preto

Hearing Handicap for Inventory for Adults

Hearing Handicap for Inventory for Elderly

Hearing Handicap Inventory for the Elderly - Screening

Hertz

Implante Coclear

Índice Percentual de Reconhecimento de Sentenças no Ruído

Índice Percentual de Reconhecimento de Sentenças no Silêncio

Kilo

Kilo ohm

Limiar Auditivo

Limiar de Reconhecimento de Sentenças no Ruído

Limiar de Reconhecimento de Sentenças no Silêncio

Lista de Sentenças Para o Português 


$\begin{array}{ll}\text { MAE } & \text { Meato Acústico Externo } \\ \text { Máx. } & \text { Máximo } \\ \text { Mín. } & \text { Mínimo } \\ \text { ms } & \text { Milissegundo } \\ \text { n } & \text { Número } \\ \text { OD } & \text { Orelha Direita } \\ \text { OE } & \text { Orelha Esquerda } \\ \text { OMS } & \text { Organização Mundial da Saúde } \\ \text { p. } & \text { Página } \\ \text { PA } & \text { Por centro } \\ \text { PEA } & \text { Perda Auditiva } \\ & \text { Potencial Evocado Auditivo } \\ & \end{array}$




\section{SUMÁRIO}

1. INTRODUÇÃO

1.1. Perda auditiva e Reabilitação

1.2. Potenciais Evocados Auditivos de longa Latência - PEALL ........................ 20

1.3. Teste de reconhecimento de sentenças ...................................................... 21

1.4. Aplicação de questionários em indivíduos com perda auditiva..................... 22

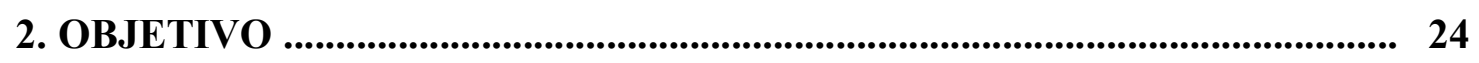

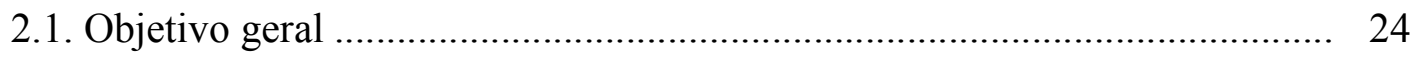

2.2. Objetivos específicos .......................................................................... 24

3. MATERIAL E MÉTODOS........................................................................... 25

3.1. Análise estatística ………….............................................................. 33

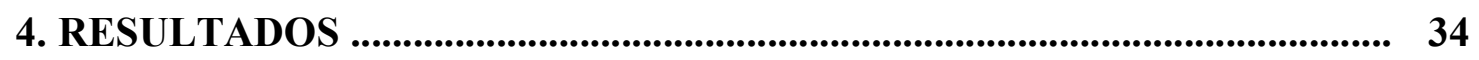

4.1. Caracterização sociodemográfica e audiológica.......................................... 34

4.2. Avaliação eletrofisiológica da audição - PEALL P300............................... 36

4.3. Teste Listas de Sentenças em Português ...................................................... 42

4.4. Questionários - HHIE/HHIA .................................................................... 46

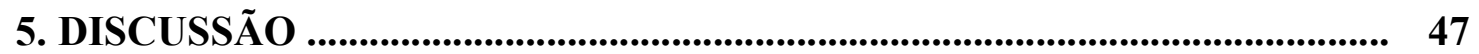

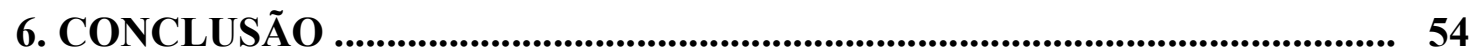

7. REFERÊNCIAS BIBLIOGRÁFICAS .................................................... 55

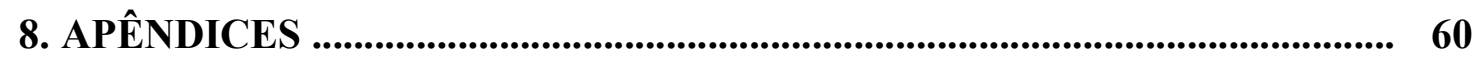

Apêndice A - Termo de Consentimento Livre e Esclarecido ............................. 60

Apêndice B - Roteiro de orientação para o Exame P300 ................................. 62

Apêndice C - Dados específicos das medidas de latência e amplitude do P300, nas derivações CzA1 e CzA2, nas 3 fases da pesquisa para os estímulos tone burst e fala ......

Apêndice D - Comparação da dispersão das medidas de latência (a e b) e amplitude (c e d) do componente $\mathrm{P} 3$, em relação à escolaridade, nas 3 fases do estudo

Apêndice E - Comparação da dispersão das medidas de latência (a e b) e amplitude (c e d) do componente $\mathrm{P}$, em relação ao tempo de privação auditiva (anos), nas 3 fases do estudo 
Apêndice F - Comparação da dispersão dos resultados do Índice Percentual de Reconhecimento de Sentenças no Silêncio (IPRSS) em relação à escolaridade dos participantes, nas 3 fases do estudo

Apêndice G - Comparação da dispersão dos resultados do Índice Percentual de Reconhecimento de Sentenças no Silêncio (IPRSS) em relação ao tempo de privação auditiva, nas 3 fases do estudo

Apêndice H - Exemplo dos registros do P300 nas três fases do estudo, com os diferentes estímulos utilizados (tone burst $\mathrm{e}$ fala)

9. ANEXOS

Anexo A - Parecer do Comitê de Ética em Pesquisa HCRP

Anexo B - Questionário (Apontador Cognitivo) de 10 Pontos (10-CS) (APOLINARIO et al., 2015) - traduzido para o português brasileiro

Anexo C - Listas de sentenças em Português (COSTA, 2015)

Anexo D - Questionário Hearing Handicap Inventory for Adults (HHIA)

(NEWMAN et al., 1990)

Anexo E - Hearing Handicap Inventory for the Elderly (HHIE) (VENTRY; WEINSTEIN, 1982) 


\section{INTRODUÇÃO}

\subsection{Perda auditiva e reabilitação}

A audição é um dos sentidos fundamentais para que o ser humano possa se comunicar. Sendo ela deficiente, a conduta apropriada para minimizá-la, quando não é possível tratamento médico ou cirúrgico, é o uso de aparelhos de amplificação sonora, tais como Aparelho de Amplificação Sonora Individual (AASI), Próteses Auditivas Ósteo Ancoradas (PAOA) e Implantes Cocleares (IC).

Uma maneira efetiva de verificar se o uso de AASI está trazendo benefícios para o paciente é investigar o funcionamento do sistema nervoso auditivo central por meio de testes objetivos da audição, visto que os testes comportamentais da audição, quando aplicados isoladamente, não fornecem dados abrangentes sobre a contribuição dos dispositivos de amplificação sonora (SHARMA, 2005).

Segundo Boéchat (2003), o desenvolvimento e funcionamento do sistema auditivo em pessoas com perda auditiva estão relacionados à quantidade e à qualidade da entrada auditiva (input), o que tem efeito na plasticidade auditiva.

A plasticidade auditiva é a capacidade de mudanças anatômicas e/ou funcionais no sistema responsável pelas informações auditivas (PASCUAL-LEONE, 2005) e tem sido discutida em estudos com indivíduos que apresentam perda auditiva e utilizam AASI (BOÉCHAT, 2003; AMORIM; ALMEIDA, 2007). Estes estudos mostram que a reintrodução do estímulo auditivo pelo uso de AASI é capaz de promover uma plasticidade secundária devido a estimulação auditiva, o que contribui para os efeitos da aclimatização.

Mesmo que haja a tendência de se encontrar estudos como estes na literatura, referindo melhora do indivíduo após uso de AASI, apenas recentemente começou-se a utilizar, tanto em pesquisas, como na prática clínica, testes objetivos como meio de auxílio na avaliação e reabilitação de usuários de AASI.

Dessa, forma, mesmo que não haja um único procedimento que responda à pergunta sobre a integridade funcional da via auditiva central (AAA, 2010), a junção de avaliações objetivas da audição e de testes comportamentais, por meio de exames eletrofisiológicos e testes de pesquisa de limiares e percepção de fala, podem mensurar e trazer informações sobre os processos neurais envolvidos na decodificação dos estímulos acústicos, bem como trazer subsídios para entender o processo de plasticidade auditiva proporcionado pela amplificação sonora. 


\subsection{Potenciais Evocados Auditivos de Longa Latência - PEALL}

Como relatado anteriormente, atualmente há o grande interesse em incluir na prática clínica os exames eletrofisiológicos da audição, principalmente em indivíduos com perda auditiva e usuários de AASI. Estes avaliam o sistema auditivo central, da porção sub-cortical à cortical (McPHERSON, 1996).

A avaliação do Potencial Evocado Auditivo (PEA) é usada como instrumento objetivo nos diagnósticos funcionais, na investigação da plasticidade da função auditiva, no monitoramento das modificações no sistema nervoso auditivo central e na avaliação da atividade neuroelétrica, desde o nervo auditivo até o córtex cerebral. As modificações destes potenciais, em situações de estimulação ou privação auditiva, mostram variações funcionais da via auditiva (WIESELBERG; IÓRIO, 2012).

Dentre os potenciais evocados auditivos, que são divididos em três grupos, sendo curta, média e longa latência, o avanço de estudos utilizando como foco o potencial de longa latência, é observado na literatura. Os Potenciais Evocados Auditivos de Longa Latência se referem a uma série de mudanças elétricas, ocorridas no sistema nervoso auditivo central e que se formam há aproximadamente entre 80 e 700 milissegundos (ms) após a apresentação de um estímulo (McPHERSON, 1996).

As componentes tardias do PEA, obtidas por meio do PEALL são divididas em componentes exógenas, as quais incluem P1, N1 e P2, e são assim consideradas pois são influenciadas por eventos extrínsecos relacionados às características físicas do estímulo acústico e em componentes endógenas, as quais incluem N2 e P3 (P300), que por sua vez, revelam a ação ou contribuição dos processos top-down sobre o processamento auditivo, por isso são consideradas relacionadas a eventos e designadas em conjunto na literatura como "Potencial Evocado Auditivo Relacionado a Eventos" ou Potencial Evocado Auditivo Cognitivo (McPHERSON, 1996; PATEL; AZZAM, 2005; MARTIN; TREMBLAY; STAPELLS, 2007).

O PEALL - P300, a ser estudado nesta pesquisa, reflete a atividade neuroelétrica da via auditiva nas regiões do tálamo e córtex auditivo, estruturas estas que envolvem as funções de discriminação, integração e atenção auditiva, fornecendo informações sobre o funcionamento do sistema nervoso auditivo central, bem como aspectos fundamentais da função mental, como percepção, cognição, atenção e memória recente, como respostas a uma atividade cognitiva (KRAUS; McGEE, 2002; HALL, 2006).

Para que o P300 seja morfologicamente gerado, é necessário que o indivíduo consiga discriminar um estímulo raro apresentado diante de outro estímulo frequente de 
mesma modalidade, seguindo o paradigma de Oddball. O paradigma auditivo Oddball consiste na apresentação de estímulos acústicos frequentes e intercalada a estímulos acústicos raros, diferentes, na qual o indivíduo deverá discriminá-los (SQUIRES; SQUIRES; HILLYARD, 1975). O P300 não é eliciado se a diferença de frequência para estímulos raros e frequentes for menor que o limiar de discriminação (HALL,1992) e pode ser obtido usando diferentes estímulos acústicos (tons puros ou fala).

O P300, onda positiva com latência aproximada de $300 \mathrm{~ms}$, pode variar de $250 \mathrm{a}$ 350 ms (KRAUS; McGEE, 1994) ou de 220 a 380 ms (McPHERSON, 1996). A idade é um fator que pode influenciar as medidas de latência, entre outros fatores. Valores próximos a 350 ms são considerados para a latência de P300 como normal para adultos até 45 anos de idade e após esta idade, foi proposto adicionar $10 \mathrm{~ms}$ a cada década de vida (POLICH; MCISAAK, 1994; COLAFÊMINA, 2000; STENKLEV E LAUKLI, 2004).

O registro dos potenciais, na prática clínica, é realizado por meio de eletrodos posicionados na superfície do crânio, de acordo com o International System 10-20 (JASPER, 1958) de colocação de eletrodo, adotado com sistema internacional pela Sociedade Americana de Eletroencefalografia. Apesar disso, não há um consenso em relação ao número e ao posicionamento dos eletrodos ativos (DUARTE; ALVARENGA; BANHARA, 2009; SIMÕES et al., 2016).

Estudo recente mostrou que a componente P300 pode ser registrada normalmente em sujeitos com perda auditiva desde que estes possam perceber a presença dos estímulos raros e frequentes (REIS; IÓRIO, 2007). Outros estudos mostraram que indivíduos com perda auditiva sensorioneural bilateral e simétrica, que fazem uso de AASI unilateral, apresentam maior latência do potencial P300 na orelha privada auditivamente quando comparada à orelha que faz uso do AASI (WIESELBERG; IÓRIO, 2012).

\subsection{Teste de reconhecimento de sentenças}

A inteligibilidade de fala de usuários de AASI é favorecida quando estes estão em ambientes silenciosos, visto que é relação sinal/ruído encontra-se baixa. A situação tornase desafiadora em situações em que há a presença de ruído competitivo, sendo relatada pelos usuários de AASI como a condição mais desfavorável para o entendimento de fala. Por este motivo, testes de reconhecimento de sentenças, tanto no silêncio, como no ruído, são considerados como uma ferramenta importante na avaliação audiológica, por avaliarem as habilidades auditivas em condições que se aproximam das experiências auditivas do dia-a-dia (THEUNISSEN; SWANEPOEL; HANEKON, 2009). 
O teste Listas de Sentenças em Português - LSP (COSTA, 1998) tem sido empregado em pesquisas no Brasil com normo-ouvintes e indivíduos com perda auditiva para mensurar habilidades de reconhecimento de fala. Recentemente, a autora do teste apresentou e descreveu uma nova estratégia e um novo protocolo (COSTA, 2015) para obtenção do índice percentual de reconhecimento de sentenças para ser aplicado em indivíduos com distúrbios de audição. Essa nova proposta de aplicação do teste LSP, permitiu que todas as palavras passem a ser consideradas para análise e assim avalie com melhor precisão a capacidade de reconhecimento de fala dos indivíduos.

Henriques e Costa (2011) estudaram 62 indivíduos adultos com idade entre 18 e 64 anos, sendo 30 com perda auditiva neurossensorial de grau leve a moderadamente severo e 32 com audição normal, para determinar as relações $S / R$ nas quais são obtidos os Limiares de Reconhecimento de Sentença no ruído (LRSR), em campo livre e comparar os resultados. Os pesquisadores realizaram um treinamento prévio com a lista 1A, inicialmente sem ruído para familiarizar o indivíduo com o teste e posteriormente com ruído a $65 \mathrm{~dB}$ NPS. Para garantir a melhor compreensão a $1^{\mathrm{a}}$ sentença foi apresentada com intensidade de $20 \mathrm{~dB}$ acima do limiar de reconhecimento de fala da melhor orelha. Após o treino, foi aplicada a lista 1B para pesquisa do LRSR. As relações sinal-ruído nas quais foram obtidos os LRSR foram -7,57 dB para indivíduos com audição normal e 2,10 dB para indivíduos com perda auditiva, havendo diferença estatisticamente significante entre os resultados destes grupos. Sabe-se que a diferença de $1 \mathrm{~dB}$ na relação $\mathrm{S} / \mathrm{R}$ equivale a uma perda de $11,20 \%$ no reconhecimento de sentenças, assim, em uma variação ampla na relação $S / R$ a variação de acerto pode variar de 0 a $100 \%$. Verificaram que os indivíduos com perda auditiva necessitaram de 5,47 dB mais favoráveis na relação $\mathrm{S} / \mathrm{R}$ para obter o mesmo desempenho dos indivíduos normo-ouvintes.

\subsection{Aplicação de questionários em indivíduos com perda auditiva}

Juntamente dos testes eletrofisiológicos e comportamentais da audição, faz-se importante avaliar como o indivíduo que está em processo de reabilitação com AASI percebe o benefício da amplificação. Assim, a aplicação conjunta de questionários que avaliam a percepção do próprio indivíduo acerca das restrições de participação em situações do cotidiano, como o Hearing Handicap Inventory for the Elderly - HHIE (VENTRY; WEINSTEIN, 1982) e o Hearing Handicap Inventory for Adults - HHIA (NEWMAN et al., 1990), podem trazer maior detalhamento dos efeitos da perda auditiva, nos aspectos comunicativo, social e emocional (WIESELBERG, 1997). 
Souza e Lemos (2015) concluíram que os questionários mais utilizados para avaliar a restrição à participação auditiva foram o HHIE, HHIA e o Hearing Handicap Inventory for the Elderly - Screening (HHIE-S). A aplicação de questionários de restrição à participação auditiva pode auxiliar na validação de decisões na pratica clínica audiológica e ser útil na prática de adaptação dos aparelhos de amplificação sonora individual e resultados da reabilitação auditiva.

O handicap auditivo, ou a "restrição de participação", está relacionada aos efeitos sociais e emocionais impostos pela deficiência auditiva a partir da limitação ou impedimento de desempenhar adequadamente suas atividades (FARIAS; BUCHALLA, 2005) Sabendo-se que essas limitações e restrições irão impactar a qualidade de vida desses indivíduos, a avaliação dessas, por meio dos questionários padronizados, é fundamental, possibilitando estabelecer as necessidades e expectativas específicas de cada paciente e quantificar a melhora após a intervenção (ROSIS et al., 2009; MENEGOTTO et al., 2011).

A partir do exposto, verifica-se na literatura que são poucos os estudos relacionando o potencial P300 em novos usuários de AASI bilateral. Por outro lado, há uma tendência cada vez maior à associação de procedimentos comportamentais e objetivos para o monitoramento do processo de adaptação de AASI.

Associar os testes eletrofisiológicos, como medidas objetivas da resposta auditiva, à avaliação comportamental, tem sido um desafio. Este estudo contribui para o entendimento dos resultados dos testes comportamentais e eletrofisiológicos associados à percepção do próprio sujeito, por meio dos questionários de autoavaliação. Consequentemente, melhora o entendimento das dificuldades do processo de adaptação destes dispositivos a fim de promover, se necessário, uma reavaliação e replanejamento do processo, adequando os ajustes necessários para melhoria do benefício e satisfação dos usuários de AASI. 


\section{OBJETIVOS}

\subsection{Objetivo Geral}

Verificar as possíveis adaptações a nível funcional após a estimulação auditiva com uso de AASI em adultos com perda auditiva sensorioneural de grau moderado e severo.

\subsection{Objetivos Específicos}

- Comparar as medidas de latência e amplitude do componente P3 anteriormente à adaptação do AASI, após seis ( \pm um mês) e 12 meses ( \pm um mês) de uso.

- Comparar os resultados da avaliação comportamental - teste de percepção de fala anteriormente à adaptação do AASI, após seis ( \pm um mês) e 12 meses ( \pm um mês) de uso.

- Analisar e comparar os resultados dos questionários de autoavaliação do impacto social e emocional da deficiência auditiva dos indivíduos com perda auditiva.

- Associar os resultados da avaliação comportamental (teste de percepção de fala) e das medidas de latência e amplitude do componente P3 com as variáveis: grau e configuração da perda auditiva, tempo de privação auditiva e escolaridade dos indivíduos. 


\section{MATERIAL E MÉTODOS}

Esse projeto de pesquisa foi submetido e aprovado pelo Comitê de Ética e Pesquisa - HC-FMRP-USP, processo HCRP no 8774/2017 de acordo com resolução 466/2012 CNS/MS (CAAE 70664817.7.0000.5440) (Anexo A). Os voluntários foram informados sobre os objetivos e procedimentos da pesquisa. Também foram orientados quanto aos seus direitos durante a realização da pesquisa, incluindo a garantia de total anonimato, liberdade de participação e possível desistência em qualquer período da pesquisa, sem qualquer punição. Assim, assinaram o Termo de Consentimento Livre e Esclarecido (Apêndice A).

Trata-se de um estudo observacional, descritivo, longitudinal, comparativo, com enfoque de pesquisa em diagnóstico.

A amostra foi constituída por 24 indivíduos com perda auditiva sensorioneural de grau moderado ou severo, bilateral, simétrica, de ambos os sexos, com média de idade de 58,9 anos $(\mathrm{DP}+-15,0)$.

Como critérios de inclusão, foram considerados indivíduos com faixa etária entre 18 e 79 anos de idade e 11 meses, de ambos os sexos, limiares indicativos de perda auditiva sensorioneural moderada ou severa, bilateral, simétrica, sem uso prévio de qualquer tipo de recurso eletrônico aplicado à surdez (AASI, PAOA, IC).

Como critérios de exclusão, foram considerados indivíduos com distúrbios neurológicos e/ou psiquiátricos diagnosticados; perdas auditivas com componente condutivo e/ou misto e indivíduos que já fizeram uso de recursos tecnológicos aplicados à surdez (AASI, PAOA, IC).

Para auxílio no controle do critério de exclusão, nos indivíduos com idade superior a 60 anos, foi utilizado o teste Apontador Cognitivo de 10 pontos (10-CS) (APOLINARIO et al., 2015) (Anexo B). Este teste funciona como uma triagem e tem sido cada vez mais utilizado para a detecção de comprometimento cognitivo em adultos a partir dos 60 anos. Ele é baseado em três formas de rastreio, sendo orientação temporal, em que o indivíduo deve dizer a data, o mês e o ano atual; a fluência, em que o indivíduo deve nomear animais o mais rápido possível no tempo de 60 segundos e, por último, a lembrança de palavras, em que deverá recordar o nome de três objetos ditos logo no início do teste. Cada forma de rastreio possui pontuações específicas, sendo três pontos atribuídos a orientação temporal (ano:1 / mês:1 / data:1), quatro pontos a nomeação de 
animais (0-5:0 / 6-8:1 / 9-11:2 / 12-14:3 / 15 ou mais:4) e três pontos a lembrança de palavras (Carro:1 / Vaso:1 / Tijolo:1), totalizando 10 pontos. Há um ajustamento quanto ao nível educacional de cada indivíduo, portanto, se não há educação formal é acrescentado dois pontos na somatória e se há de um a três anos de educação é acrescentado um ponto. $\mathrm{O}$ indivíduo que soma de oito pontos para cima é classificado como normal, aquele que obtém pontuação seis e sete é classificado com um possível comprometimento cognitivo e os que pontuam entre zero e cinco são classificados com provável comprometimento cognitivo.

Anteriormente ao início da coleta, foram selecionados pela análise do prontuário eletrônico do Programa de Saúde Auditiva do HCRP-FMRP-USP 60 indivíduos, sendo que foram triados 53, que atenderam aos critérios de elegibilidade (idade, tipo e grau da perda auditiva). Desses 53 selecionados, foram excluídos 13 indivíduos no dia agendado para ocorrer a primeira fase da coleta e no decorrer da pesquisa, outros indivíduos também foram excluídos, por motivos diversos, como mostra a figura 1, abaixo.

Ao final, foram coletados dados completos de 24 indivíduos, os quais compareceram para todas as fases do estudo.

Fluxograma 1 - Constituição amostral

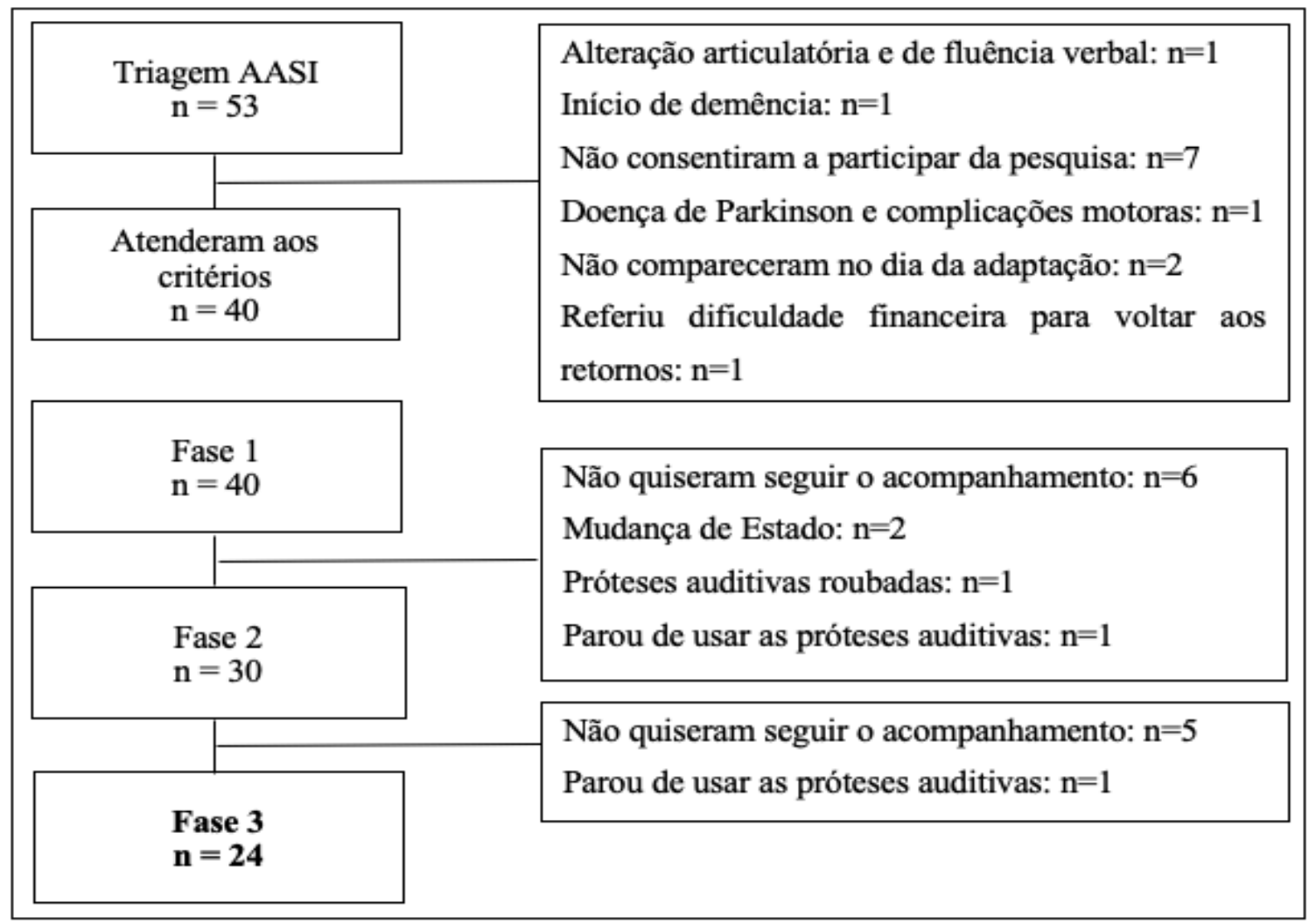

Fonte: Própria (2019) 
Para a realização da coleta de dados propriamente dita, foram utilizados os seguintes materiais:

- Termo de Consentimento Livre e Esclarecido;

- Prontuários de dados (Dados pessoais e Avaliação Audiológica Básica);

- Lista de Sentenças em Português - LSP (COSTA, 2015) (Anexo C);

- HHIA (Hearing Handicap Inventory for Adults) (Anexo D) ou HHIE (Hearing Handicap Inventory for the Elderly) (Anexo E);

Os equipamentos utilizados foram:

- Otoscópio HEINE mini 2000;

- Audiômetro (Madsen Astera 2 - Otoflex), caixas acústicas e cabina;

- Navigator ${ }^{\circledR}$ Pro da Bio-logic ${ }^{\circledR}$ Systems Corp. Auditory Evoked Potential AEPSystem, 1.3.0 version/ Natus Medical, USA, de dois canais, acoplado a um computador convencional.

Após o convite e aceite da participação na pesquisa, foi realizado o levantamento de dados demográficos de cada indivíduo através do prontuário eletrônico.

A coleta de dados foi realizada em três momentos distintos, denominados neste estudo como fases. A primeira fase foi realizada no dia da entrega dos aparelhos auditivos, antes da adaptação dos mesmos; a segunda fase seis meses ( \pm um mês) após a adaptação e a terceira fase após 12 meses ( \pm um mês) do dia da adaptação, sendo estas últimas no retorno de acompanhamento agendado pelo serviço.

O grupo de estudo foi selecionado da triagem de AASI do Serviço de Saúde Auditiva do HCRP-FMRP-USP, sendo que os indivíduos que apresentaram média (500, 1k, 2k e 4k Hz) (OMS, 2014) dos limiares auditivos de 41 a 80 dB NA, sem alterações psiquiátricas ou neurológicas diagnosticadas e que estavam aguardando o recebimento de aparelho de amplificação sonora bilateral, foram incluídos no estudo e passaram em atendimento nas três fases de coleta, detalhadas a seguir:

$\mathbf{1}^{\mathrm{a}}$ fase - indivíduo avaliado sem AASI:

- Inspeção dos meatos acústicos externos (OD e OE);

- Pesquisa dos limiares auditivos em campo livre das frequências de 500,1k, $2 \mathrm{k}$ e 4k Hz sem AASI; 
- Realização do teste LSP (COSTA, 2015);

- Realização do exame eletrofísiológico P300 em campo livre com estímulo tone burst e estímulo de fala;

- Teste Apontador Cognitivo de 10 pontos (10-CS) - para indivíduos com idade superior a 60 anos.

$2^{\mathbf{a}}$ fase - seis meses ( \pm um mês) - indivíduo avaliado com AASI:

- Pesquisa dos limiares auditivos em campo livre das frequências de $500,1 \mathrm{k}, 2 \mathrm{k}$ e 4k Hz com e sem AASI;

- Realização do teste LSP (COSTA, 2015);

- Realização do exame eletrofísiológico P300 em campo livre com estímulo tone burst e estímulo de fala;

- Aplicação do questionário HHIE/HHIA.

$\mathbf{3}^{\mathbf{a}}$ fase - doze meses ( \pm um mês $)$ - indivíduo avaliado com AASI:

- Pesquisa dos limiares auditivos em campo livre das frequências de 500, 1k, $2 \mathrm{k}$ e 4k Hz com e sem AASI;

- Realização do teste LSP (COSTA, 2015), com e sem ruído;

- Realização do exame eletrofísiológico P300 em campo livre com estímulo tone burst e estímulo de fala;

- Aplicação do questionário HHIE/HHIA.

Continuaram na pesquisa os indivíduos que relataram uso diário de AASI bilateral, sendo o mínimo de seis horas, a fim de garantir a efetividade do uso. Tal informação foi obtida por questionamento ao paciente e anotado na folha de registro do questionário HHIA ou HHIE.

Os procedimentos citados acima estão detalhados a seguir.

\section{Inspeção dos meatos acústicos externos (OD e OE)}

Consiste na inspeção visual do meato acústico externo (MAE) realizada por orelha, para verificação de corpos estranhos ou cera que poderiam obstruir o MAE, impedindo a visualização da membrana timpânica e condução sonora até a mesma, podendo inviabilizar a realização dos demais procedimentos. $\mathrm{O}$ procedimento foi realizado com Otoscópio.

\section{Audiometria Tonal Limiar}


Foi realizada a avaliação individual de cada uma das orelhas. Determinou-se os limiares tonais por via aérea com fone supra aural, nas frequências de 250, 500, 1, 2, 3, 4, 6, 8k Hz. O procedimento de pesquisa dos limiares foi pelo método descendente/ascendente, iniciando na frequência de $1 \mathrm{k} \mathrm{Hz}$, passando para as oitavas superiores, retomada do limiar de $1 \mathrm{k} \mathrm{Hz}$, para verificar a reprodutibilidade, este se confirmando foram testadas as oitavas inferiores (ASHA, 2005). Uma vez identificado limiares de via aérea superiores a 25 dBNA em qualquer uma das frequências de $500,1 \mathrm{k}$, $2 \mathrm{k}, 3 \mathrm{k}$ e $4 \mathrm{k} \mathrm{Hz}$, foram realizados os limiares de via óssea, com objetivo de determinar o topodiagnóstico da perda auditiva.

\section{Pesquisa dos limiares auditivos em campo livre}

Foi realizada a pesquisa dos limiares auditivos em campo sonoro das frequências de $500,1 \mathrm{k}, 2 \mathrm{k}$ e $4 \mathrm{k} \mathrm{Hz}$. O procedimento foi realizado com o indivíduo posicionado a 80 $\mathrm{cm}$ da caixa de som, a $0^{\circ}$ azimute, com a caixa de som à altura do pavilhão auricular do indivíduo. A pesquisa dos limiares foi realizada pelo método descendente/ascendente com estímulos tone burst e o paciente foi orientado a levantar a mão toda vez que ouvisse o estímulo.

\section{Exame Eletrofisiológico da audição - PEALL P300}

Para garantir controle sobre variáveis individuais, inicialmente foram realizadas orientações aos participantes sobre as condições para a realização de exame eletrofisiológico P300 (Apêndice B).

Para obtenção do exame eletrofisiológico da audição P300, o eletrodo ativo foi posicionado em $\mathrm{Cz}$ e conectado na entrada 1 do pré-amplificador, canal 1 e canal 2 (jumper). Os eletrodos de referência foram colocados nos lóbulos da orelha esquerda (A1) e da direita (A2), e conectados na entrada 2 dos canais 1 e 2, respectivamente, do préamplificador. O eletrodo terra foi posicionado em Fpz. A representação do posicionamento dos eletrodos está disposta na figura 1, a seguir. Para a realização do exame foi necessário que os eletrodos apresentassem impedância individual menor que 5 $\mathrm{K} \Omega$ e impedância entre eles menor que $2 \mathrm{~K} \Omega$. 
Figura 1 - Representação do posicionamento dos eletrodos, segundo "10-20 International System" (JASPER, 1958).

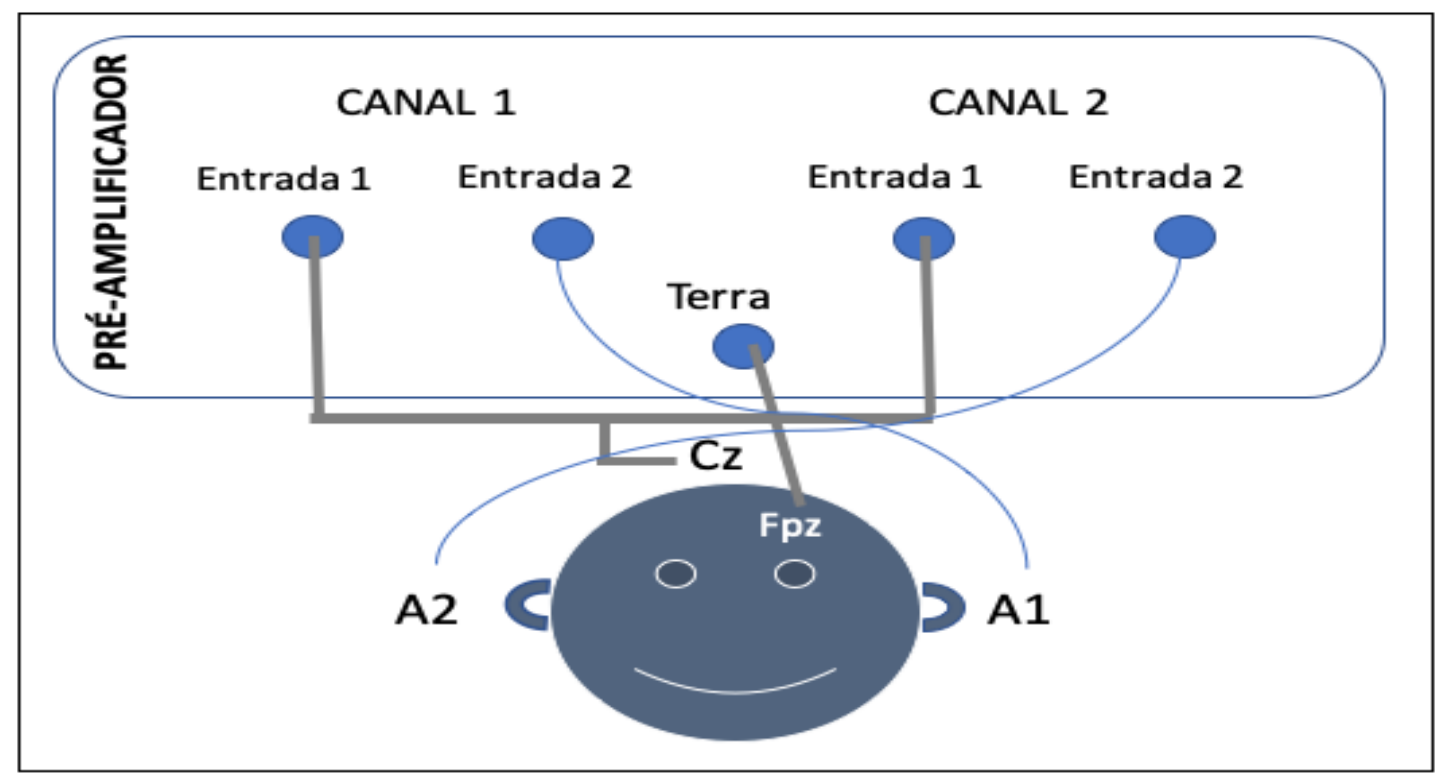

Fonte: Própria (2019)

O exame foi realizado em campo sonoro, $0^{\circ}$ azimute, com o indivíduo em posição semi-sentada, orientado a permanecer com os olhos abertos e fixos a um ponto determinado a frente do mesmo, a fim de evitar artefatos biológicos referentes às atividades musculares/oculares, em sala acusticamente tratada. Foi solicitado ao indivíduo para identificar o estímulo infrequente levantando o dedo indicador.

Como estímulo auditivo foram utilizados tone burst e fala (/ba/ e /da/). O estímulo tone burst foi realizado em tons de $1000 \mathrm{~Hz}$ para o estímulo frequente e de $2000 \mathrm{~Hz}$ para o estímulo raro, na probabilidade de $20 \%$ de estímulos raros, de forma imprevisível e aleatória, com intensidade de $30 \mathrm{~dB}$ NS. Para o estímulo de fala utilizou-se a sílaba /ba/ para os estímulos frequentes e a sílaba /da/ para os estímulos infrequentes. A intensidade de fala foi calculada pela média tritonal $(500,1 \mathrm{k}$ e $2 \mathrm{k} \mathrm{Hz})$ encontrada na pesquisa dos limiares auditivos em campo sonoro, adicionada $30 \mathrm{~dB}$. A ordem de apresentação dos estímulos foi randomizada de indivíduo para indivíduo.

O Quadro 1 descreve os parâmetros gerais utilizados para aquisição dos registros de latência e amplitude do P300.

Quadro 1 - Parâmetros gerais para a aquisição do exame P300.

\begin{tabular}{|l|l|l|}
\hline \multicolumn{3}{|c|}{ ESTÍMULO } \\
\hline Tipo & Tone burst & Sons de fala \\
& $1000 \mathrm{~Hz}-$ frequente & $/ \mathrm{ba} /-$ frequente \\
& $2000 \mathrm{~Hz}-$ infrequente & $/ \mathrm{da} /-$ infrequente \\
\hline
\end{tabular}




\begin{tabular}{|l|l|}
\hline Ganho & $50.000 \mu \mathrm{V}$ \\
\hline Intensidade & $\begin{array}{l}30 \mathrm{~dB} \text { NS }- \text { frequente } \\
30 \mathrm{~dB} \text { NS }- \text { infrequente }\end{array}$ \\
\hline Filtro & $\begin{array}{l}30.0 \text { (altas frequências) } \\
1.0 \text { (baixas frequências) }\end{array}$ \\
\hline Tempo de análise & $512 \mathrm{~ms}$ \\
\hline Estimulador & Campo livre - $0^{\circ}$ azimute a 1 metro da caixa \\
\hline Polaridade & Rarefação \\
\hline Amostra & $\begin{array}{l}80 \% \text { - Estímulos frequentes (aproximadamente 160 estímulos) } \\
20 \% \text { - Estímulos raros (40 estímulos) }\end{array}$ \\
\hline \multicolumn{2}{|c|}{ TAREFA } \\
\hline Atenção / Cognitiva & Levantar o dedo indicador \\
\hline \multicolumn{2}{|c|}{ AQUISIÇÃO } \\
\hline Canais & 2 canais \\
\hline Eletrodos & CzA1 e CzA2 e Fpz (terra)
\end{tabular}

Legenda: $\mathrm{Hz}=$ Hertz; $\mu \mathrm{V}=$ microvolt; $\mathrm{dB} \mathrm{NS}$ = decibel nível de sensação; $\mathrm{ms}=$ milissegundo.

O exame aconteceu com duas passagens sucessivas para permitir boa definição e replicação. A fim de evitar influências das variáveis circunstâncias no registro do P300, fatores como hora do dia em que o exame foi realizado, temperatura, ingestão de alimentos, ciclo hormonal e atividades físicas foram fatores controlados. Foi utilizado o equipamento Navigator ${ }^{\circledR}$ Pro da Bio-logic ${ }^{\circledR}$ Systems Corp. Auditory Evoked Potential AEPSystem, 1.3.0 version.

\section{Teste Listas de Sentenças em Português - LSP (COSTA, 2015)}

O teste Listas de Sentenças em Português foi realizado de acordo com a nova proposta de aplicação (COSTA, 2015), que avalia o reconhecimento de sentenças do paciente considerando cada palavra apresentada.

Antes da aplicação do teste foi realizada a calibração dos canais com um estímulo tom puro presente na primeira faixa do $\mathrm{CD}$ e também realizada uma explicação prévia dos procedimentos ao paciente.

A primeira medida obtida foi o Limiar de Reconhecimento de Sentenças no Silêncio (LRSS), intensidade necessária para que o indivíduo reconhecesse em torno de $50 \%$ dos estímulos apresentados. Nesse momento foi utilizada a lista $1 \mathrm{~A}$, em todas as fases, constituída por 25 sentenças. Para garantir que o indivíduo fosse capaz de reconhecer corretamente a primeira sentença da lista, a intensidade inicial de apresentação 
das sentenças no silêncio foi de $30 \mathrm{~dB}$ acima da média tritonal $(500,1 \mathrm{k}$ e $2 \mathrm{k} \mathrm{Hz})$ encontrada na pesquisa dos limiares auditivos em campo sonoro anteriormente.

A técnica para apresentação das sentenças na pesquisa do LRSS foi baseada na estratégia denominada sequencial adaptativa, ou ainda ascendente-sequencial (LEVITT; RABINER, 1967). Dessa forma, quando o indivíduo respondeu corretamente a frase inteira, diminuiu-se a intensidade de apresentação do estímulo seguinte. A partir do momento que a resposta foi incorreta, aumentou-se a intensidade de apresentação do estímulo. Os intervalos utilizados até a primeira mudança do tipo de resposta, ou seja, quando o paciente não respondeu corretamente uma sentença, foram de $10 \mathrm{~dB}$ e, posteriormente, os intervalos de apresentação foram de $5 \mathrm{~dB}$ até encontrar o LRSS. Foi considerado como o LRSS quando o indivíduo conseguiu reconhecer a frase inteira.

Assim, após obter a intensidade do LRSS para cada indivíduo, ela foi mantida fixa e foi obtido o Índice Percentual de Reconhecimento de Sentenças no Silêncio (IPRSS).

Para obter o IPRSS, a aplicação do teste foi realizada em ambiente acusticamente controlado, em campo sonoro e com o indivíduo posicionado a frente da fonte sonora, a altura do pavilhão auricular, a $0^{\circ}$ azimute. Foi orientado a repetir a sentença inteira ou as palavras que entender. Foram utilizadas as listas $1 \mathrm{~B}\left(1^{\mathrm{a}}\right.$ fase $)$, lista $3 \mathrm{~B}\left(2^{\mathrm{a}}\right.$ fase $)$ e lista $5 \mathrm{~B}$ ( $3^{\mathrm{a}}$ fase), tendo cada lista 10 sentenças, que somam $100 \%$ de acerto.

$\mathrm{Na} 3^{\mathrm{a}}$ fase, além do LRSS e do IPRSS, foi realizada a pesquisa do Índice Percentual de Reconhecimento de Sentenças no Ruído (IPRSR), utilizando a lista 6B, contendo 10 sentenças, que somam $100 \%$ de acerto. A relação sinal/ruído utilizada foi de $-5 \mathrm{~dB}$, com apresentação da fala a $0^{\circ}$ e do ruído a $180^{\circ}$. A intensidade de fala foi a mesma encontrada na pesquisa do LRSS.

O motivo de se utilizar diferentes listas para cada repetição do teste é para evitar que o indivíduo memorize as listas e tenha um resultado melhor. Mesmo que o teste foi realizado novamente após um longo período, optou-se por manter esse método para evitar qualquer influência. Durante a aplicação do teste, as respostas foram anotadas no protocolo elaborado pela própria autora e, ao final, realizado o cálculo do escore obtido.

\section{Questionários}

\section{O Hearing Handicap Inventory for Elderly (HHIE) ou Hearing Handicap} Inventory for Adult (HHIA) foram desenvolvidos em 1982 por Ventry e Weinstein e em 1990 por Newman e colaboradores, respectivamente. O que os diferencia são apenas três 
questões e a idade do indivíduo avaliado, sendo que os que possuíam idade igual ou maior que 60 anos, responderam ao HHIE e menor que 60 anos ao HHIA. Ambos são questionários que identificam as situações em que o indivíduo apresenta dificuldades e determina se o problema auditivo afeta o comportamento do indivíduo, além de avaliar a atitude e resposta emocional do indivíduo ao déficit auditivo.

Esse questionário foi aplicado na $2^{\mathrm{a}}$ e $3^{\mathrm{a}}$ fase, em sala reservada, pelo pesquisador. Sua composição é feita por 25 perguntas, divididas em duas escalas, sendo escala social/situacional (12) e escala emocional (13). Para responder ao questionário, aplicado como roteiro dirigido de entrevista, foram lidas oralmente as perguntas ao participante, que deveria optar por apenas uma resposta para cada questão: sim (4 pontos), às vezes ( 2 pontos) ou não (0 ponto). O escore total foi calculado pela somatória dos pontos obtidos, sendo o mínimo de 0 e o máximo de 100. Quanto maior o escore, pior é o resultado, sendo que menos de 16 pontos não há restrição de participação, de 18 a 42 pontos há percepção leve a moderada da restrição de participação e acima de 42 pontos há percepção severa ou significativa da restrição de participação. Também foi realizada a pontuação em cada sub-escala (social e emocional).

\subsection{Análise estatística}

Os resultados das variáveis qualitativas foram apresentados como frequência e proporções. As variáveis quantitativas foram apresentadas por média e desvio padrão (média $\pm \mathrm{DP}$ ) quando avaliadas por métodos paramétricos e mediana (intervalo interquartil, IIQ) quando avaliadas por métodos não-paramétricos. Empregou-se a Análise de Variância com medidas repetidas (ANOVA-RM) para testar as diferenças de latência (ms) e amplitude $(\mu \mathrm{V})$ entre as fases $(\mathrm{F} 1=$ sem AASI, F2 = com AASI há 6 meses, F3 = com AASI há 12 meses). As comparações entre medidas dependentes foram realizadas por meio dos testes $\mathrm{t}$ de Student pareado e soma de postos de Wilcoxon. Para as medidas independentes foram aplicados os testes de Mann-Whitney e Kruskall-Wallis. Correlações entre variáveis foram obtidas por meio do teste de correlação de Spearman. Múltiplas comparações foram avaliadas pelo teste de Tukey-HSD ou tiveram o valor de p corrigido pelo método FDR (False Discovery Rate). Todos os procedimentos de análise foram realizados usando o software $\mathrm{R}$ versão 3.5.2 ( $\mathrm{R}$ Foundation for Statistical Computing, Vienna, Austria. URL $=$ https://www.R-project.org/). Adotou-se significância para $\mathrm{p}<0,05$. 


\section{RESULTADOS}

Os resultados serão apresentados na seguinte ordem: características sociodemográficas e audiológicas; avaliação eletrofisiológica da audição, por meio do PEALL P300; teste de percepção de fala, por meio do teste Listas de Sentenças em Português (COSTA, 2015) e os resultados dos questionários aplicados - HHIE ou HHIA.

\subsection{Caraterização sociodemográfica e audiológica}

Os indivíduos avaliados $(n=24)$ encontraram-se com a idade entre 30 e 78 anos, com média de 58,9 anos (DP+-15,0). A Tabela 1 apresenta a descrição das características sociodemográficas, por meio de caracterização do sexo, estado civil e nível de escolaridade.

Tabela 1 - Caracterização sociodemográfica.

\begin{tabular}{llrr}
\hline Variáveis & Categorias & N & \% \\
Sexo & Masculino & 11 & 45,8 \\
& Feminino & 13 & 54,2 \\
Estado civil & Casado & 11 & 45,8 \\
& Divorciado & 3 & 12,5 \\
& Solteiro & 5 & 20,8 \\
Nível de & Viúvo & 5 & 20,8 \\
escolaridade & Analfabeto & 1 & 4,2 \\
& Ensino Fundamental Incompleto & 7 & 29,2 \\
& Ensino Fundamental Completo & 12 & 50 \\
& Ensino Médio Incompleto & 1 & 4,2 \\
& Ensino Médio Completo & 2 & 8,3 \\
& Superior Incompleto & 0 & 0 \\
& Superior Completo & 1 & 4,2 \\
\hline
\end{tabular}

Legenda: $\mathrm{N}=$ número; $\%=$ por cento.

Com relação a perda auditiva, pôde-se observar que dos 24 indivíduos, 18 foram diagnosticados audiologicamente com perda auditiva sensorioneural de grau moderado bilateral (OMS, 2014) e seis com perda auditiva sensorioneural de grau severo bilateral (OMS, 2014). O tipo de etiologia encontrada nesses indivíduos mostra 21 ainda em processo de investigação, um diagnosticado com perda auditiva induzida por ruído e dois diagnosticados com presbiacusia.

Os dados audiológicos dos indivíduos, incluindo a idade do indivíduo quando começou a apresentar a perda auditiva, o tempo de privação auditiva até o momento em que recebeu AASI bilateral, os limiares auditivos da fase pré-adaptação, realizados com 
fones supra-aurais e as médias dos limiares auditivos das frequências de $500,1 \mathrm{~K}, 2 \mathrm{~K}$ e $4 \mathrm{~K} \mathrm{~Hz}$ da OD e OE, pesquisados em campo sonoro, com o paciente sem uso ( $1^{\mathrm{a}}$ fase) e com uso de AASI ( $2^{\mathrm{a}}$ e $3^{\mathrm{a}}$ fase), estão apresentados na Tabela 2.

Tabela 2 - Dados audiológicos dos pacientes estudados $(\mathrm{n}=24)$.

\begin{tabular}{|c|c|c|c|c|c|c|c|}
\hline Indivíduo & $\begin{array}{l}\text { Idade } \\
\text { na PA }\end{array}$ & TPA & $\begin{array}{l}\text { Média } \\
\text { LA OD } \\
\text { (dBNA) }\end{array}$ & $\begin{array}{c}\text { Média } \\
\text { LA OE } \\
\text { (dBNA) }\end{array}$ & $\begin{array}{c}\text { FASE } 1 \\
\text { Média LA } \\
\text { sem AASI } \\
\text { (dBNPS) }\end{array}$ & $\begin{array}{c}\text { FASE } 2 \\
\text { Média LA } \\
\text { com AASI } \\
\text { (dBNPS) }\end{array}$ & $\begin{array}{c}\text { FASE } 3 \\
\text { Média LA } \\
\text { com AASI } \\
\text { (dBNPS) }\end{array}$ \\
\hline 1 & 26 & 4 & 47 & 45 & 44 & 33 & 30 \\
\hline 2 & 50 & 18 & 55 & 50 & 49 & 29 & 34 \\
\hline 3 & 50 & 11 & 51 & 52 & 48 & 34 & 35 \\
\hline 4 & 9 & 31 & 67 & 61 & 59 & 42 & 41 \\
\hline 5 & 40 & 8 & 76 & 76 & 76 & 37 & 35 \\
\hline 6 & 48 & 20 & 52 & 57 & 55 & 37 & 35 \\
\hline 7 & 50 & 14 & 50 & 46 & 49 & 35 & 32 \\
\hline 8 & 64 & 6 & 46 & 45 & 49 & 38 & 38 \\
\hline 9 & 20 & 20 & 42 & 46 & 46 & 32 & 35 \\
\hline 10 & 52 & 12 & 61 & 61 & 62 & 42 & 44 \\
\hline 11 & 32 & 6 & 45 & 41 & 52 & 33 & 32 \\
\hline 12 & 58 & 7 & 41 & 55 & 57 & 40 & 45 \\
\hline 13 & 62 & 10 & 58 & 60 & 63 & 48 & 46 \\
\hline 14 & 22 & 18 & 42 & 50 & 54 & 38 & 41 \\
\hline 15 & 32 & 7 & 53 & 53 & 54 & 33 & 32 \\
\hline 16 & 37 & 2 & 64 & 71 & 66 & 47 & 47 \\
\hline 17 & 65 & 10 & 55 & 49 & 52 & 31 & 39 \\
\hline 18 & 58 & 15 & 67 & 62 & 68 & 36 & 37 \\
\hline 19 & 55 & 20 & 53 & 50 & 53 & 35 & 38 \\
\hline 20 & 65 & 13 & 55 & 53 & 55 & 38 & 41 \\
\hline 21 & 52 & 13 & 60 & 56 & 60 & 34 & 34 \\
\hline 22 & 60 & 11 & 40 & 42 & 43 & 29 & 31 \\
\hline 23 & 60 & 3 & 47 & 41 & 48 & 32 & 32 \\
\hline 24 & 50 & 18 & 70 & 61 & 61 & 34 & 32 \\
\hline Média & 46,54 & 12,37 & 54,04 & 53,45 & 55,12 & 36,12 & 36,91 \\
\hline DP & 15,77 & 6,80 & 9,80 & 9,03 & $\mathbf{8 , 0 7}$ & 4,94 & 5,07 \\
\hline
\end{tabular}

Legenda: LA= Limiares Auditivos; dBNA= decibel nível de audição; dBNPS= decibel nível de pressão sonoro; $\mathrm{AASI}=$ Aparelho de Amplificação Individual; $\mathrm{OD}=$ Orelha Direita; $\mathrm{OE}=$ Orelha Esquerda; $\mathrm{CL}=$ Campo Livre; $\mathrm{PA}=$ Perda auditiva; $\mathrm{TPA}=$ Tempo de privação auditiva; $\mathrm{DP}=$ Desvio Padrão.

A figura 2, abaixo, apresenta os resultados das médias dos limiares auditivos em campo sonoro nas 3 fases do estudo $(\mathrm{F} 1=55,1$ dBNPS; F2 $=36,1$ dBNPS e F3 = 36,9 dBNPS), sendo que o ponto representa a média e as barras verticais o intervalo de 
confiança 95\%. Verifica-se diferença estatística $(\mathrm{p}=<0,001)$ com o uso de AASI quando comparamos as fases 1 e 2 e as fases 1 e 3 , já na comparação das fases 2 e 3 as respostas se mantém semelhantes e não há diferença estatística.

Figura 2 - Análise das médias dos limiares auditivos em campo sonoro nas 3 fases do estudo (F1 = sem AASI, F2 = com AASI há 6 meses, F3 = com AASI há 12 meses).

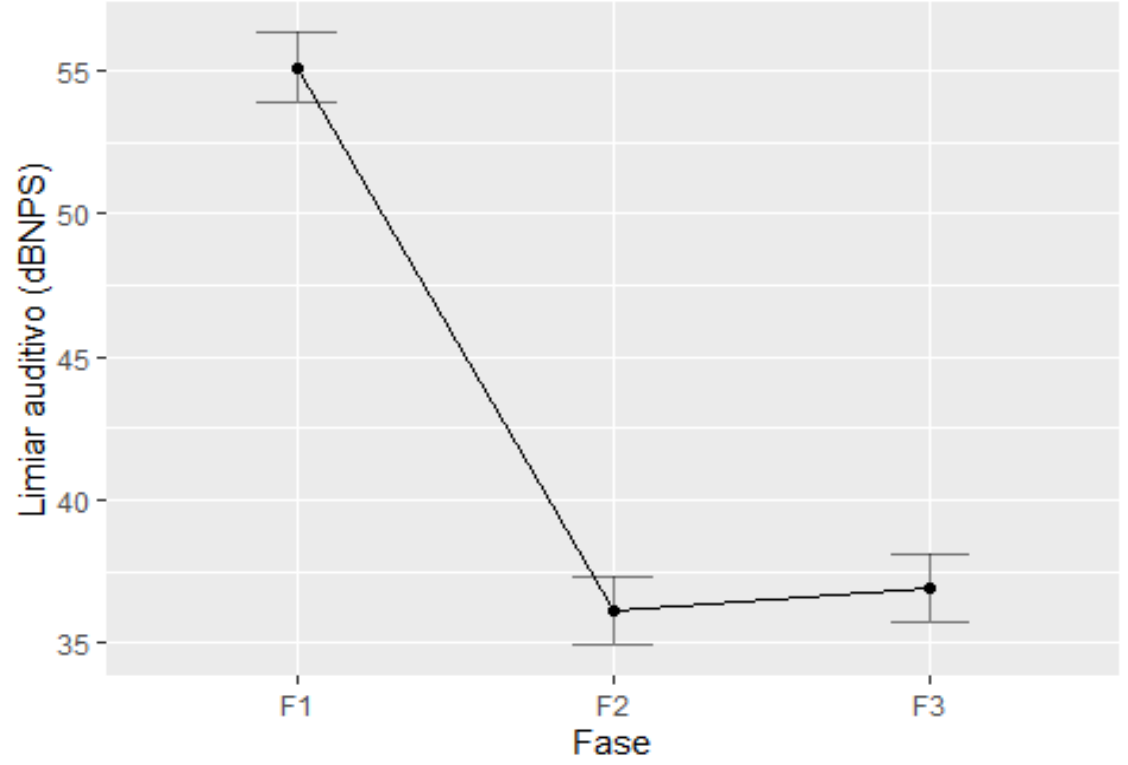

Legenda: $\mathrm{F} 1=$ Fase $1 ; \mathrm{F} 2=$ Fase $2 ; \mathrm{F} 3=$ Fase 3 .

\subsection{Avaliação eletrofisiológica da audição - PEALL P300}

Os dados específicos (média, desvio padrão, valores mínimo e máximo) relativos às medidas de latência e amplitude da componente $\mathrm{P} 3$, de cada indivíduo estão apresentados no Apêndice C. A tabela 3, a seguir, mostra as médias de latência e amplitude referentes a todas as fases do estudo e para ambos os estímulos utilizados.

Tabela 3 - Médias de latência e amplitude entre as derivações CzA1 e CzA2, nas três fases do estudo, para o estímulo tone burst e estímulo de fala.

\begin{tabular}{|c|c|c|c|c|c|}
\hline \multirow{3}{*}{ Estímulo } & \multirow{3}{*}{ Fases } & \multicolumn{2}{|c|}{ Latência (ms) } & \multicolumn{2}{|c|}{ Amplitude $(\mu \mathrm{V})$} \\
\hline & & CzA1 & $\mathrm{CzA} 2$ & CzA1 & $\mathrm{CzA} 2$ \\
\hline & & Média (DP) & Média (DP) & Média (DP) & Média (DP) \\
\hline \multirow{3}{*}{ 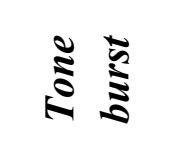 } & 1 & $345,9(52,3)$ & $351,8(50,8)$ & $3,3(2.3)$ & $3,4(3,0)$ \\
\hline & 2 & $330,9(37,0)$ & $338,7(37,3)$ & $3,9(2.8)$ & $4,3(2,9)$ \\
\hline & 3 & $337,0(39,9)$ & $337,0(41,4)$ & $4,2(2.3)$ & $4,5(2,2)$ \\
\hline \multirow{3}{*}{$\frac{\pi}{\pi}$} & 1 & $325,7(27,1)$ & $326,4(28,2)$ & $4,1(2,1)$ & $4,4(1,9)$ \\
\hline & 2 & $333,2(27,5)$ & $328,2(26,7)$ & $4,3(1,8)$ & $4,2(1,9)$ \\
\hline & 3 & $317,0(28,3)$ & $320,2(30,9)$ & $3,6(2,1)$ & $3.9(2,1)$ \\
\hline
\end{tabular}

Legenda: $\mathrm{ms}=$ milissegundos, $\mu \mathrm{V}=$ microvolts, $\mathrm{DP}=$ Desvio Padrão. 
Nas Tabelas 4 e 5, a seguir, pode-se notar que não houve diferença estatisticamente significante entre as derivações CzA1 e CzA2, no que se refere à latência e a amplitude da componente P3 com estimulo tone burst e estímulo de fala. Sendo assim, as orelhas foram agrupadas para as análises posteriores.

Tabela 4 - Comparação da latência (ms) entre as derivações CzA1 e CzA2, nas três fases do estudo, para o estímulo tone burst e estímulo de fala.

\begin{tabular}{ccccc}
\hline Estímulo & Fases & $\begin{array}{c}\text { CzA1 } \\
\text { Média (DP) }\end{array}$ & $\begin{array}{c}\text { CzA2 } \\
\text { Média (DP) }\end{array}$ & P-valor * \\
& 1 & $345,9(52,3)$ & $351,8(50,8)$ & 0,73 \\
& 2 & $330,9(37,0)$ & $338,7(37,3)$ & 0,39 \\
& 3 & $337,0(39,9)$ & $337,0(41,4)$ & 1,00 \\
& 1 & $325,7(27,1)$ & $326,4(28,2)$ & 0,81 \\
& 2 & $333,2(27,5)$ & $328,2(26,7)$ & 0,60 \\
& 3 & $317,0(28,3)$ & $320,2(30,9)$ & 0,67 \\
\hline
\end{tabular}

* Teste t-pareado. Valor de p corrigido pelo método FDR (False Discovery Rate) Legenda: $\mathrm{DP}=$ Desvio Padrão.

Tabela 5 - Comparação da amplitude $(\mu \mathrm{V})$ entre as derivações CzA1 e CzA2, nas três fases do estudo, para o estímulo tone burst e estímulo de fala.

\begin{tabular}{ccccc}
\hline Estímulo & Fases & $\begin{array}{c}\text { CzA1 } \\
\text { Média (DP) }\end{array}$ & $\begin{array}{c}\text { CzA2 } \\
\text { Média (DP) }\end{array}$ & P-valor * \\
& 1 & $3,3(2.3)$ & $3,4(3,0)$ & 0,60 \\
& 2 & $3,9(2.8)$ & $4,3(2,9)$ & 0,31 \\
& 3 & $4,2(2.3)$ & $4,5(2,2)$ & 0,28 \\
& 1 & $4,1(2,1)$ & $4,4(1,9)$ & 0,45 \\
& 2 & $4,3(1,8)$ & $4,2(1,9)$ & 0,75 \\
& 3 & $3,6(2,1)$ & $3.9(2,1)$ & 0,45 \\
\hline
\end{tabular}

* Teste t-pareado. Valor de p corrigido pelo método FDR (False Discovery Rate)

Legenda: DP= Desvio Padrão

A seguir, estão apresentadas as figuras 3 e 4 com as médias de latência da componente P3 nas 3 fases do estudo, para o estímulo tone burst $(\mathrm{F} 1=348,85 \mathrm{~ms}, \mathrm{~F} 2=$ $334,84 \mathrm{~ms}$ e F3 $=337,01 \mathrm{~ms})$ e estímulo de fala $(\mathrm{F} 1=326,08 \mathrm{~ms}, \mathrm{~F} 2=330,72 \mathrm{~ms}$ e F3 = $318,62 \mathrm{~ms}$ ). Observa-se que não houve diferença estatística entre as fases ( $\mathrm{p}=0,35$ e $\mathrm{p}=$ 0,20 , respectivamente). 
Figura 3 - Médias dos valores de latência (ms) de tone burst (P300) nas três fases do estudo.

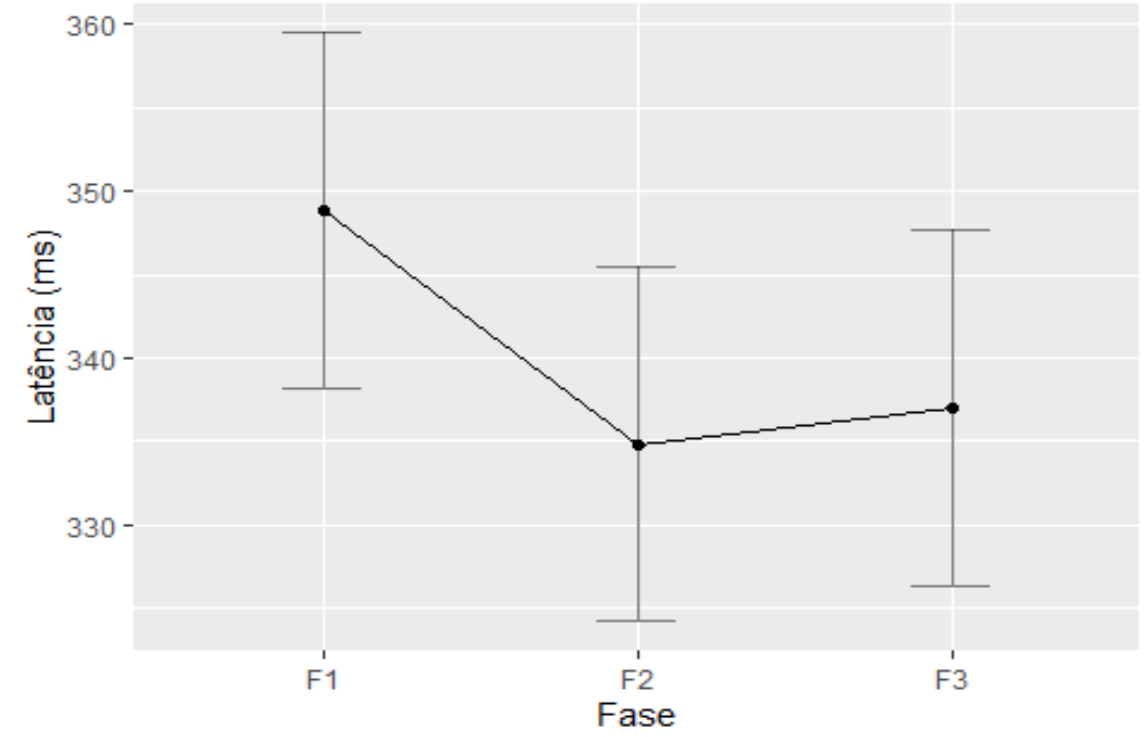

Legenda: $\mathrm{F} 1=$ Fase $1 ; \mathrm{F} 2=$ Fase $2 ; \mathrm{F} 3=$ Fase $3 ; \mathrm{ms}=$ milissegundos.

Figura 4 - Média dos valores de latência (ms) de estímulo de fala (P300) nas três fases do estudo.

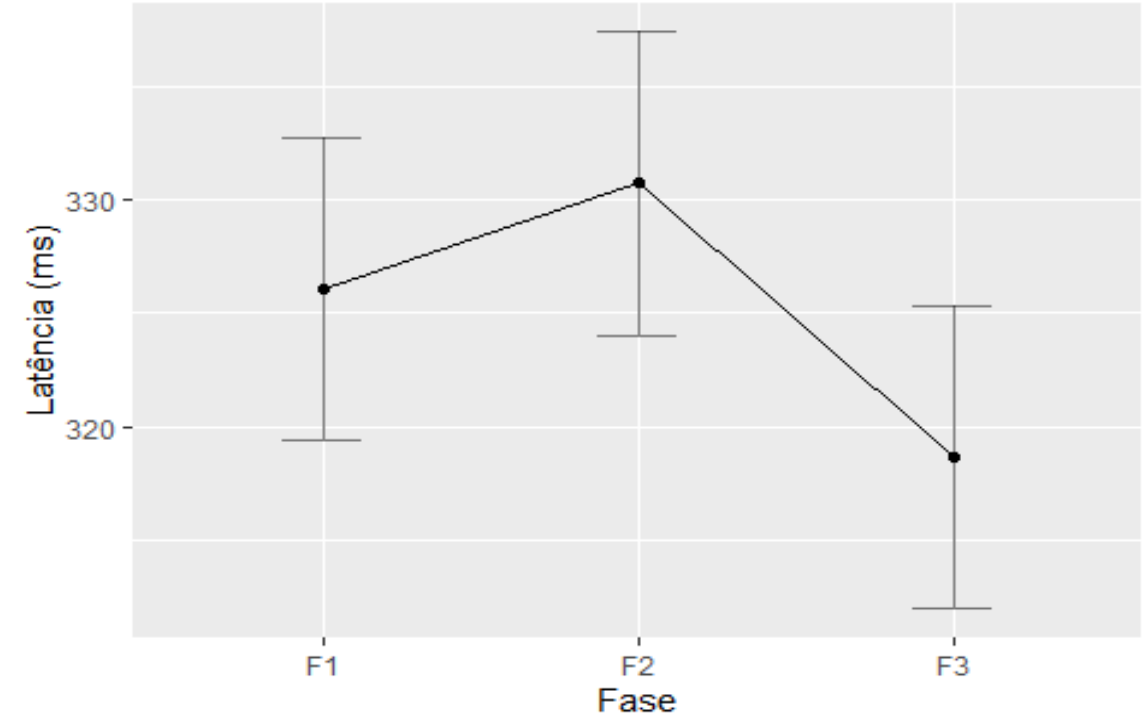

Legenda: $\mathrm{F} 1=$ Fase $1 ; \mathrm{F} 2=$ Fase $2 ; \mathrm{F} 3=$ Fase $3 ; \mathrm{ms}=$ milissegundos.

Da mesma forma, as médias de amplitude da componente P3 nas 3 fases do estudo, para o estímulo tone burst $(\mathrm{F} 1=3,38 \mu \mathrm{V}, \mathrm{F} 2=4,12 \mu \mathrm{V}$ e $\mathrm{F} 3=4,35 \mu \mathrm{V})$ e estímulo de fala $(\mathrm{F} 1=4,25 \mu \mathrm{V}, \mathrm{F} 2=4,26 \mu \mathrm{V}$ e $\mathrm{F} 3=3,70 \mu \mathrm{V})$ não mostraram diferença estatística entre as fases $(\mathrm{p}=0,057 \mathrm{e} \mathrm{p}=0,12$, respectivamente), como apresentado nas figuras $5 \mathrm{e}$ 6. 
Figura 5 - Médias dos valores de amplitude $(\mu \mathrm{V})$ de tone burst (P300) nas três fases do estudo.

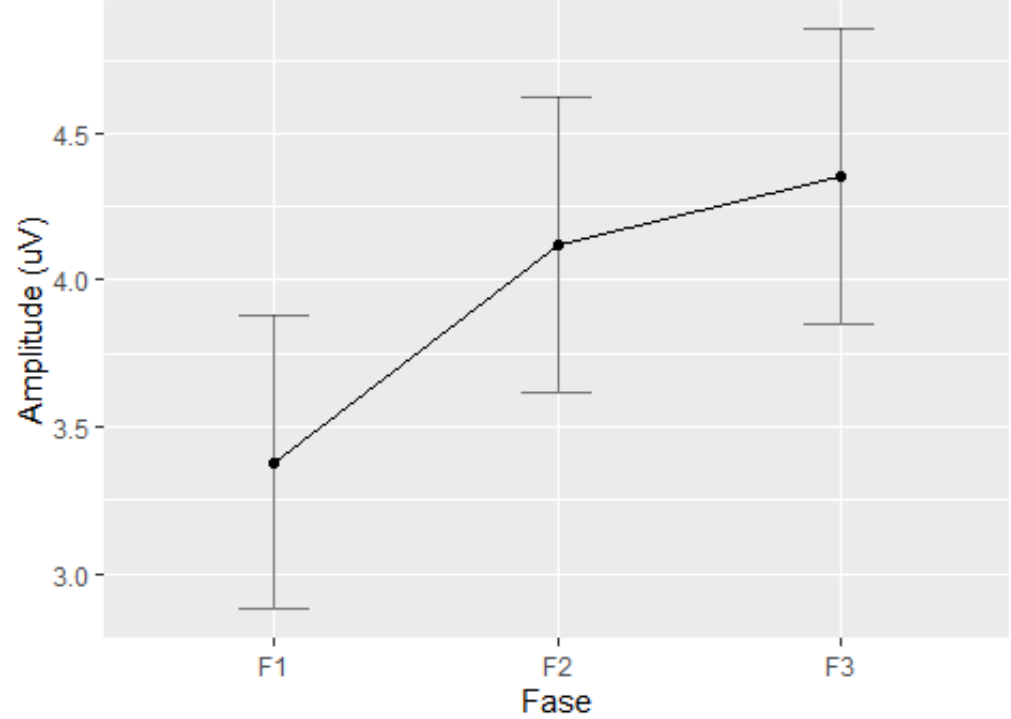

Legenda: $\mathrm{F} 1=$ Fase $1 ; \mathrm{F} 2=$ Fase $2 ; \mathrm{F} 3=$ Fase $3 ; \mu \mathrm{V}=$ microvolt.

Figura 6 - Média dos valores de amplitude $(\mu \mathrm{V})$ de estímulo de fala (P300) nas três fases do estudo.

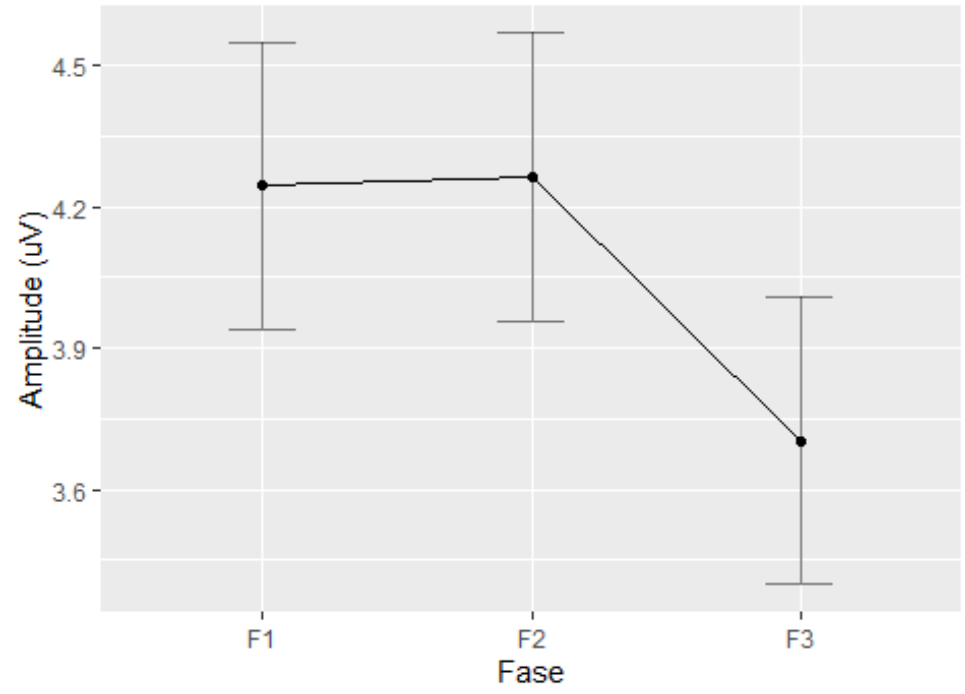

Legenda: $\mathrm{F} 1=$ Fase $1 ; \mathrm{F} 2=$ Fase $2 ; \mathrm{F} 3=$ Fase $3 ; \mu \mathrm{V}=$ microvolt.

Em estudo estatístico realizado, foi observado que não houve correlação da escolaridade do indivíduo com os resultados encontrados de latência e amplitude do P300 (Apêndice D). Assim como, não houve associação das medidas de latência e amplitude com o tempo de privação auditiva dos indivíduos, nas três fases do estudo (Apêndice E).

Como mostrado nas figuras 7 e 8 , abaixo, mesmo havendo uma diferença de amostragem, devido ao baixo número de indivíduos com perda de grau severo $(n=6), o$ 
estudo estatístico realizado indicou que o grau da perda auditiva também não influenciou nos resultados do P300, tanto em latência quanto em amplitude.

Figura 7 - Distribuição dos resultados dos valores de latência (ms) em relação ao grau da perda auditiva para os estímulos tone burst (a) e fala (b), nas três fases do estudo.

a

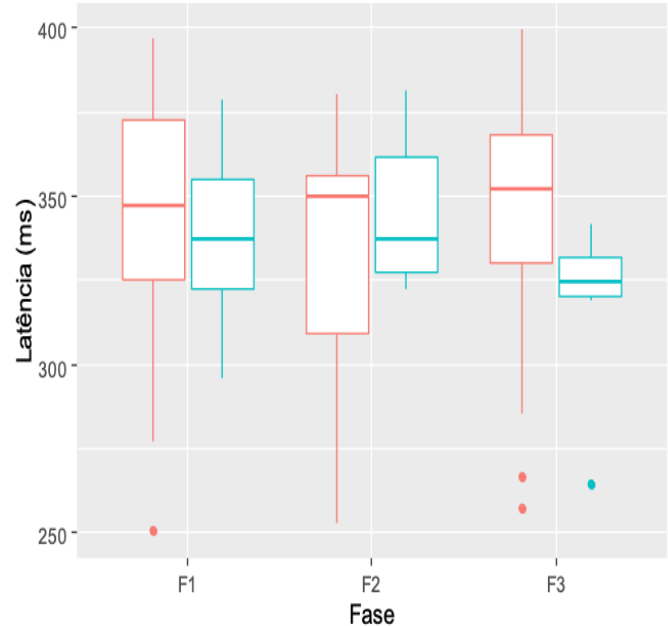

$\mathrm{b}$

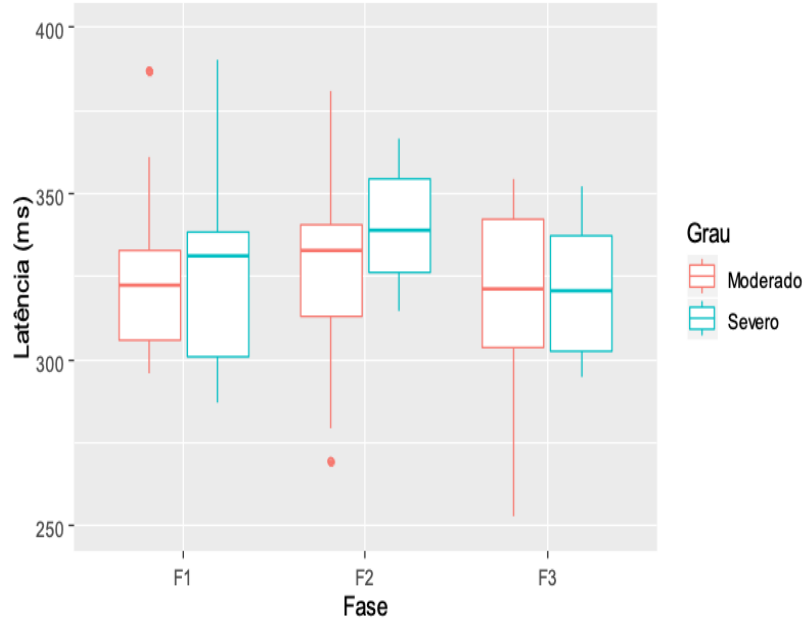

Legenda: $\mathrm{F} 1=$ Fase $1 ; \mathrm{F} 2=$ Fase $2 ; \mathrm{F} 3=$ Fase $3 ; \mathrm{ms}=$ milissegundos.

Figura 8 - Distribuição dos resultados dos valores de amplitude $(\mu \mathrm{V})$ em relação ao grau da perda auditiva para os estímulos tone burst (a) e fala (b), nas três fases do estudo.

a

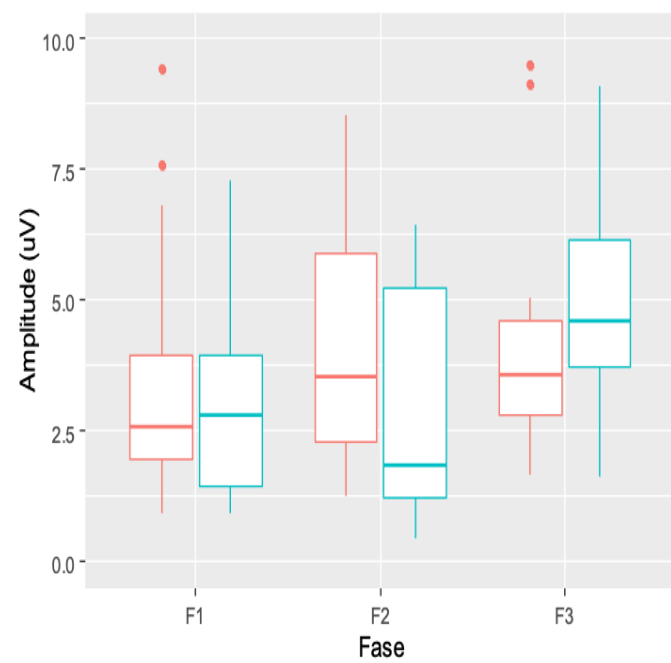

$\mathrm{b}$

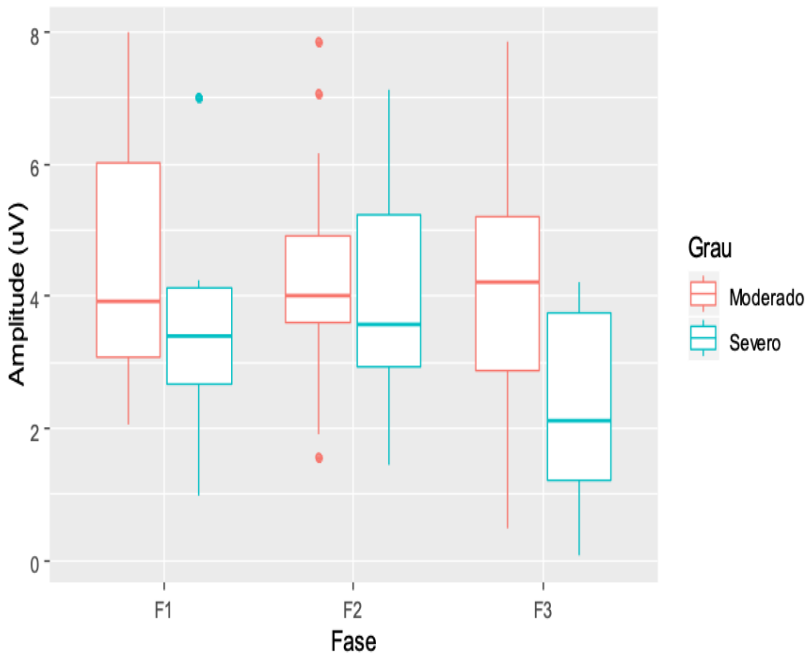

Legenda: $\mathrm{F} 1=$ Fase $1 ; \mathrm{F} 2=$ Fase $2 ; \mathrm{F} 3=$ Fase $3 ; \mu \mathrm{V}=$ microvolt.

Assim como o grau da perda auditiva, a configuração da perda auditiva não interferiu nos resultados encontrados de latência e amplitude do P300, como mostrado nas figuras 9 e 10, a seguir. 
Figura 9 - Distribuição dos resultados dos valores de latência (ms) em relação a configuração da perda auditiva para os estímulos tone burst (a) e fala (b), nas três fases do estudo.

a

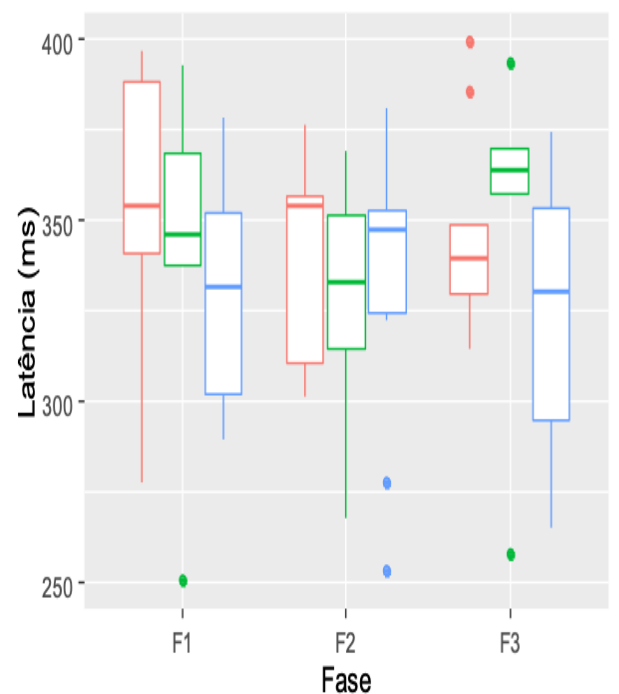

b

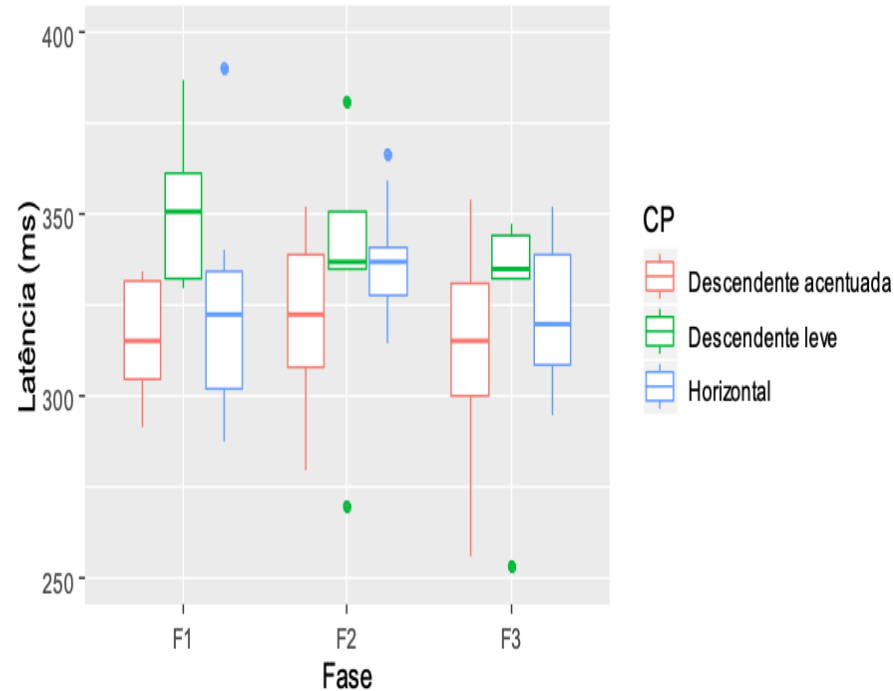

Legenda: $\mathrm{CP}=$ Configuração da perda; $\mathrm{F} 1=$ Fase $1 ; \mathrm{F} 2=$ Fase $2 ; \mathrm{F} 3=$ Fase $3 ; \mathrm{ms}=$ milissegundo.

Figura 10 - Distribuição dos resultados dos valores de amplitude $(\mu \mathrm{V})$ em relação a configuração da perda auditiva para os estímulos tone burst (a) e fala (b), nas três fases do estudo.

a

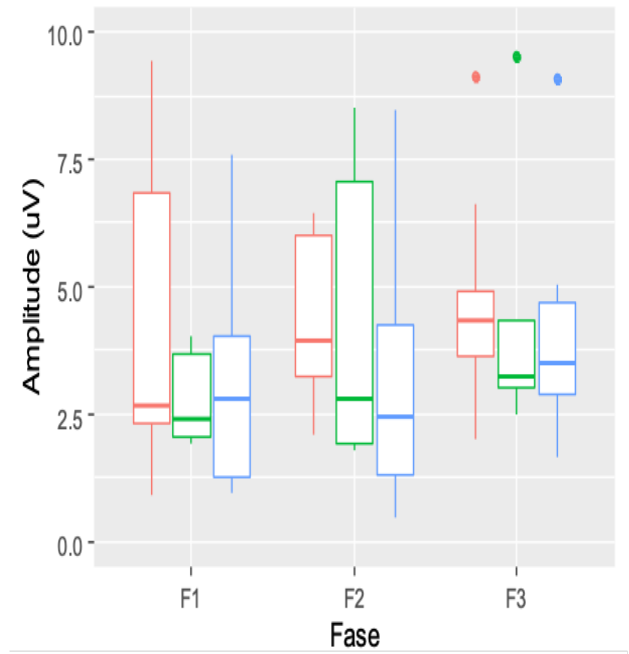

b

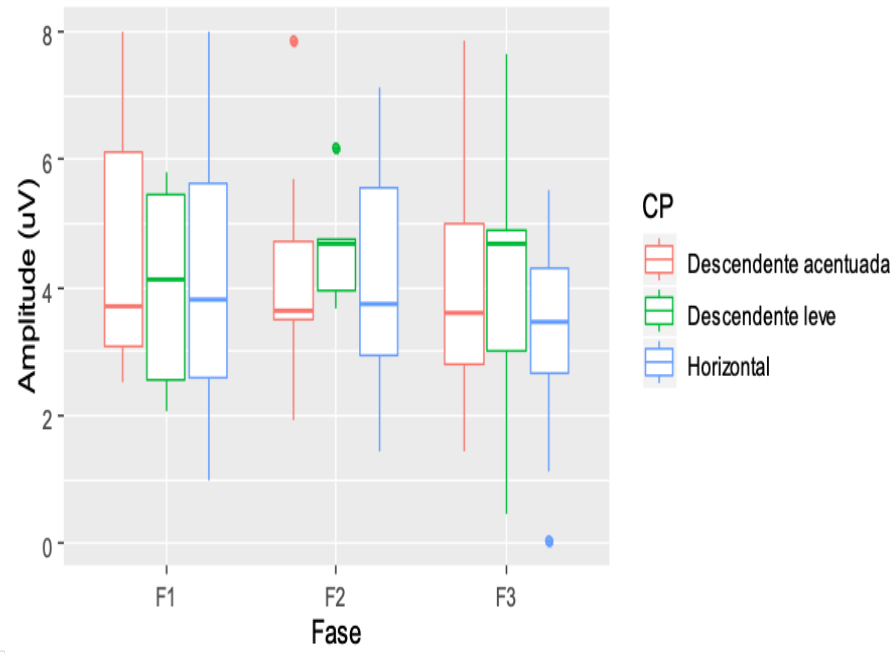

Legenda: $\mathrm{CP}=$ Configuração da perda; $\mathrm{F} 1=$ Fase $1 ; \mathrm{F} 2=$ Fase $2 ; \mathrm{F} 3=$ Fase $3 ; \mu \mathrm{V}=$ microvolt. 


\subsection{Teste Listas de Sentenças em Português (COSTA, 2015)}

A Tabela 6 apresenta as médias aritméticas, desvios padrão e valores mínimo e máximo dos Limiares de Reconhecimento de Sentenças no Silêncio, Índices Percentual de Reconhecimento de Sentenças no Silêncio e Índices Percentual de Reconhecimento de Sentenças no Ruído para o grupo do estudo.

Tabela 6 - Média, desvio padrão, valores mínimos e máximos do teste Listas de Sentenças em Português para os indivíduos, nas três fases do estudo.

\begin{tabular}{|c|c|c|c|c|c|c|c|}
\hline \multirow{2}{*}{ Medidas } & \multicolumn{2}{|c|}{ FASE $1(n=24)$} & \multicolumn{2}{|c|}{ FASE $2(n=24)$} & \multicolumn{3}{|c|}{ FASE $3(n=24)$} \\
\hline & $\begin{array}{l}\text { LRSS } \\
\text { (dB) }\end{array}$ & $\begin{array}{l}\text { IPRSS } \\
(\%)\end{array}$ & $\begin{array}{l}\text { LRSS } \\
\text { (dB) }\end{array}$ & $\begin{array}{l}\text { IPRSS } \\
(\%)\end{array}$ & $\begin{array}{l}\text { LRSS } \\
\text { (dB) }\end{array}$ & $\begin{array}{l}\text { IPRSS } \\
(\%)\end{array}$ & $\begin{array}{l}\text { IPRSR } \\
(\%)\end{array}$ \\
\hline Média & 49,58 & 78,95 & 37,08 & 85,43 & 35,41 & 86,58 & 70,12 \\
\hline D.P. & 9,88 & 13,83 & 5,69 & 10,47 & 5,08 & 8,97 & 12,13 \\
\hline Mín. & 35 & 45,78 & 30 & 59,67 & 25 & 68,40 & 47,96 \\
\hline Máx. & 70 & 100 & 50 & 100 & 45 & 100 & 89.38 \\
\hline
\end{tabular}

Legenda: LRSS $=$ Limiares de Reconhecimento de Sentenças no Silêncio; IPRSS = Índice Percentual de Reconhecimento de Sentenças no Silêncio; IPRSR = Índice Percentual de Reconhecimento de Sentenças no Ruído; D.P. = Desvio Padrão; Mín. = mínimo; Máx. = máximo; $\mathrm{dB}=$ Decibel.

A figura 11, abaixo, apresenta os resultados das médias do IPRSS nas três fases do estudo $(\mathrm{F} 1=79 \%, \mathrm{~F} 2=85,4 \%$ e F3 $=86,6 \%)$ e mostra diferença estatística $(\mathrm{p}=$ 0,0003) com o uso de AASI quando comparamos as fases 1 e 2 e as fases 1 e 3. Já a análise entre as fases 2 e 3 mostra que as médias foram semelhantes e, portanto, não houve diferença. 
Figura 11 - Média dos valores de IPRSS nas três fases do estudo.

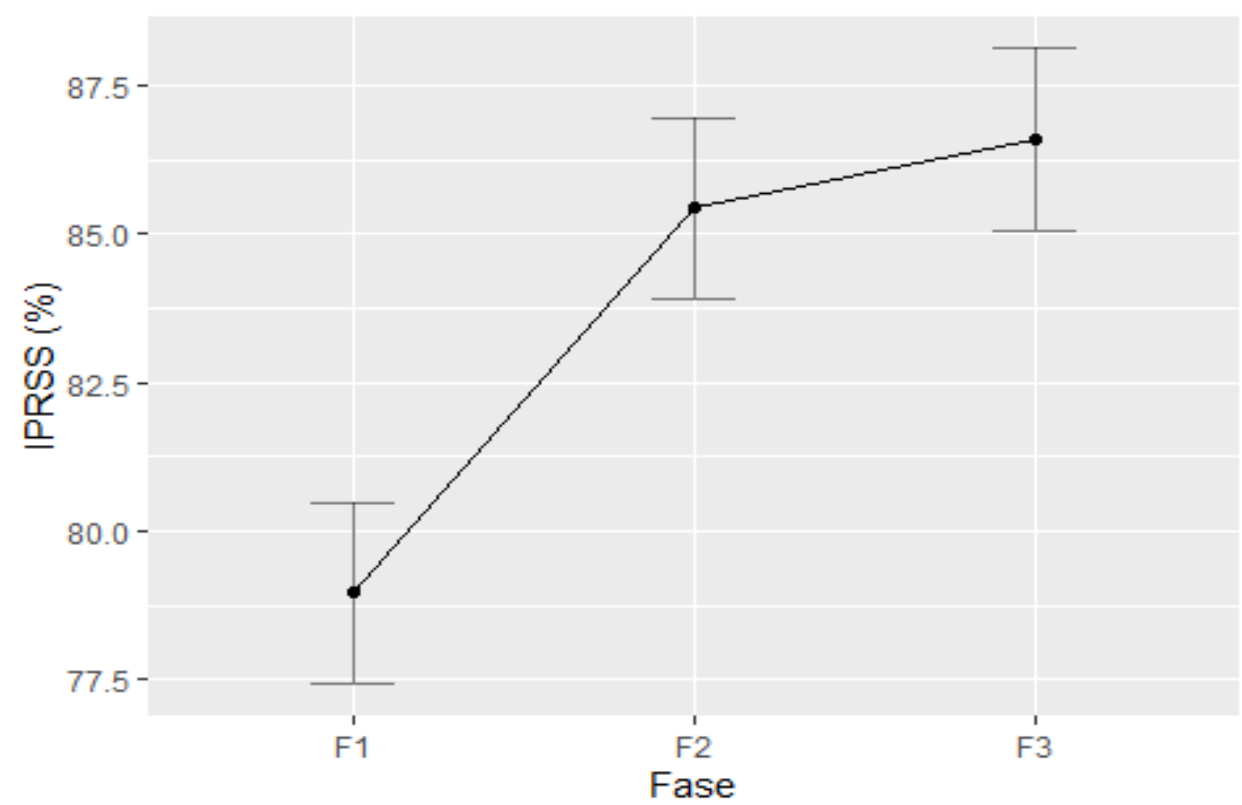

Legenda: F1 = Fase 1; F2 = Fase 2; F3 = Fase 3; IPRSS = Índice Percentual de Reconhecimento de Sentenças no Silêncio; $\%=$ por cento.

Em estudo estatístico realizado, foi observado que não houve correlação da escolaridade dos indivíduos com os resultados do teste de percepção de fala (Apêndice F). Assim como, não houve relação do tempo de privação auditiva com os resultados do teste de percepção de fala com sentenças (Apêndice G).

Já a análise de comparação do grau de perda auditiva com o desempenho no teste de percepção de fala, identificou-se diferença significativa dos indivíduos com perda auditiva de grau moderado e severo. Como observado na figura 12, abaixo, os indivíduos com grau moderado obtiveram melhor desempenho nas fases 1 e 2 . Apenas na fase 3 não houve diferença. Ainda na fase 3, quando o teste foi realizado com presença de ruído competitivo, os indivíduos com grau moderado obtiveram melhor desempenho, como mostrado na figura 13. 
Figura 12 - Valores médios dos resultados do desempenho para o Índice Percentual de Reconhecimento de Sentenças no Silêncio (IPRSS) em relação ao grau da perda auditiva, nas três fases do estudo.

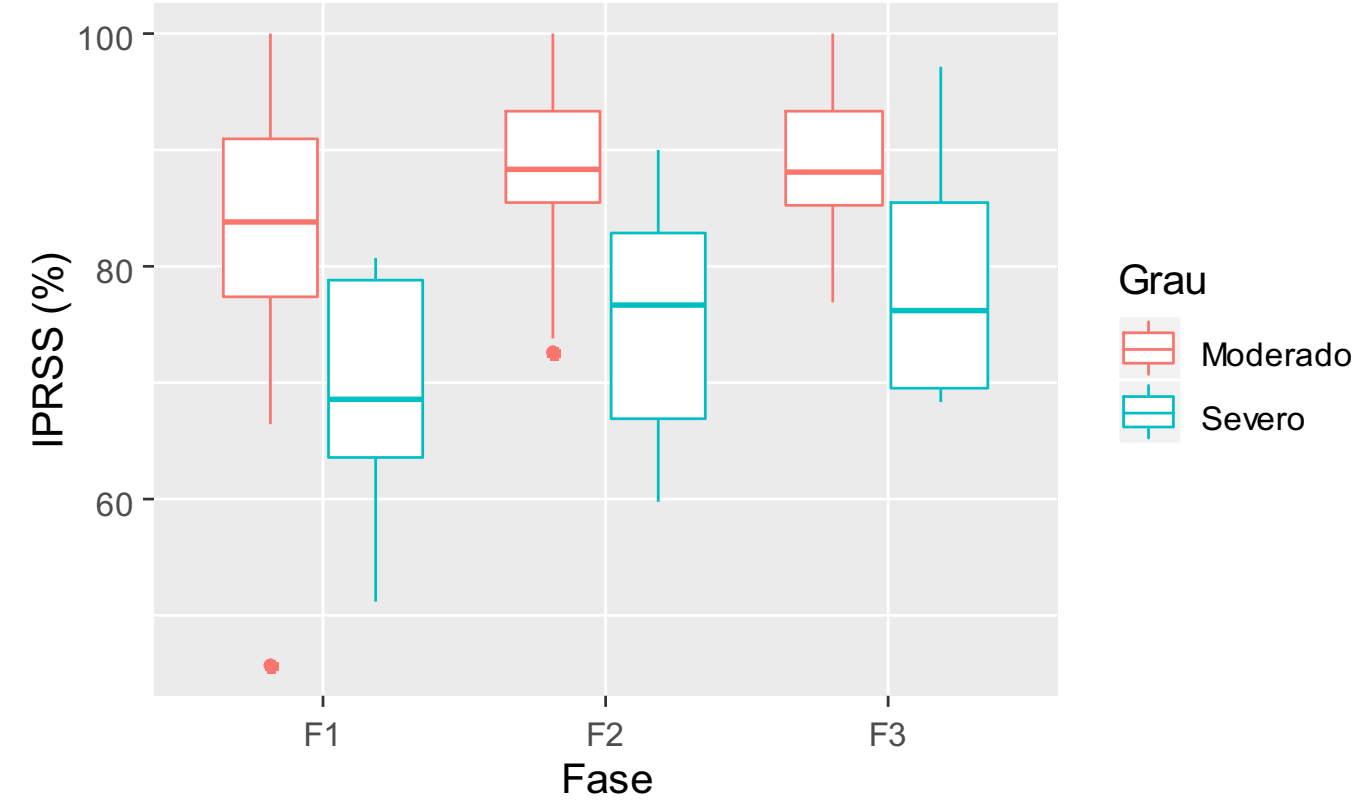

Legenda: F1 = Fase 1; F2 = Fase 2; F3 = Fase 3; IPRSS = Índice Percentual de Reconhecimento de Sentenças no Silêncio; $\%=$ por cento.

Figura 13 - Valores médios dos resultados do desempenho para o Índice Percentual de Reconhecimento de Sentenças no Ruído (IPRSR) em relação ao grau da perda auditiva, na fase três do estudo.

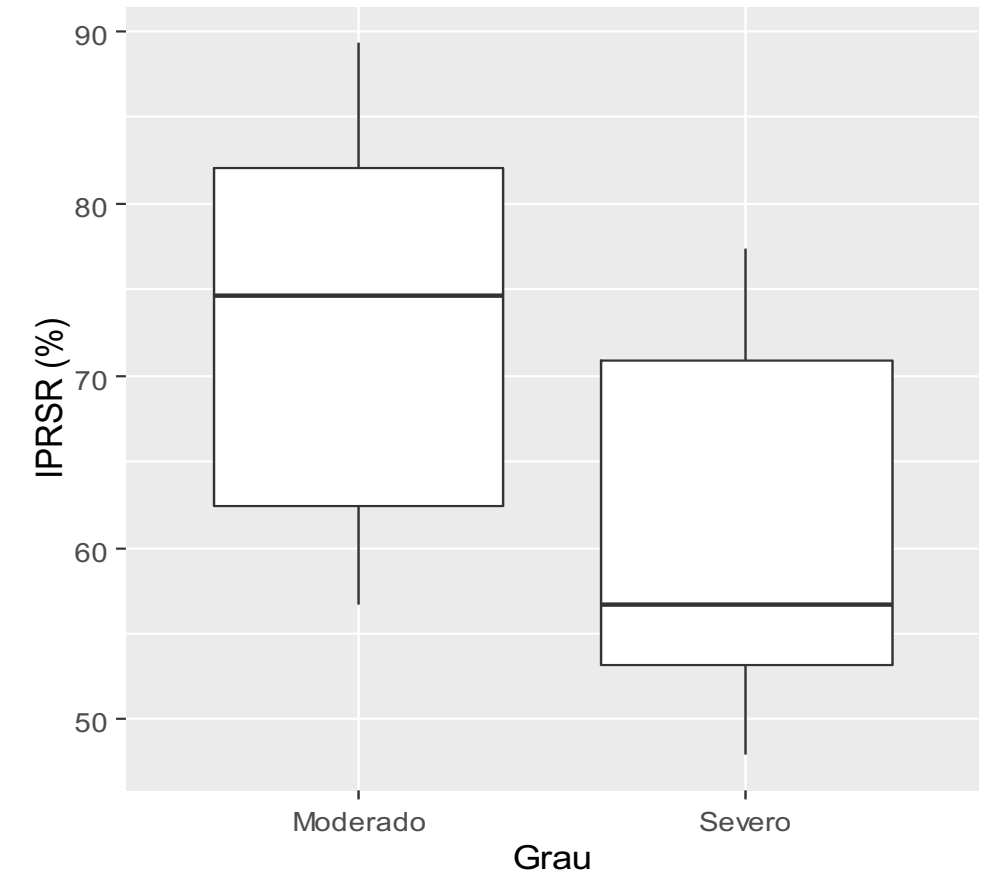

Legenda: IPRSR = Índice Percentual de Reconhecimento de Sentenças no Ruído; \% = por cento. 
Já a configuração da perda auditiva não interferiu nos resultados do teste de percepção de fala (sentenças), como indicado abaixo pelas figuras 14 e 15 .

Figura 14 - Valores médios dos resultados do desempenho para o Índice Percentual de Reconhecimento de Sentenças no Silêncio (IPRSS) em relação à configuração da perda auditiva, nas três fases do estudo.

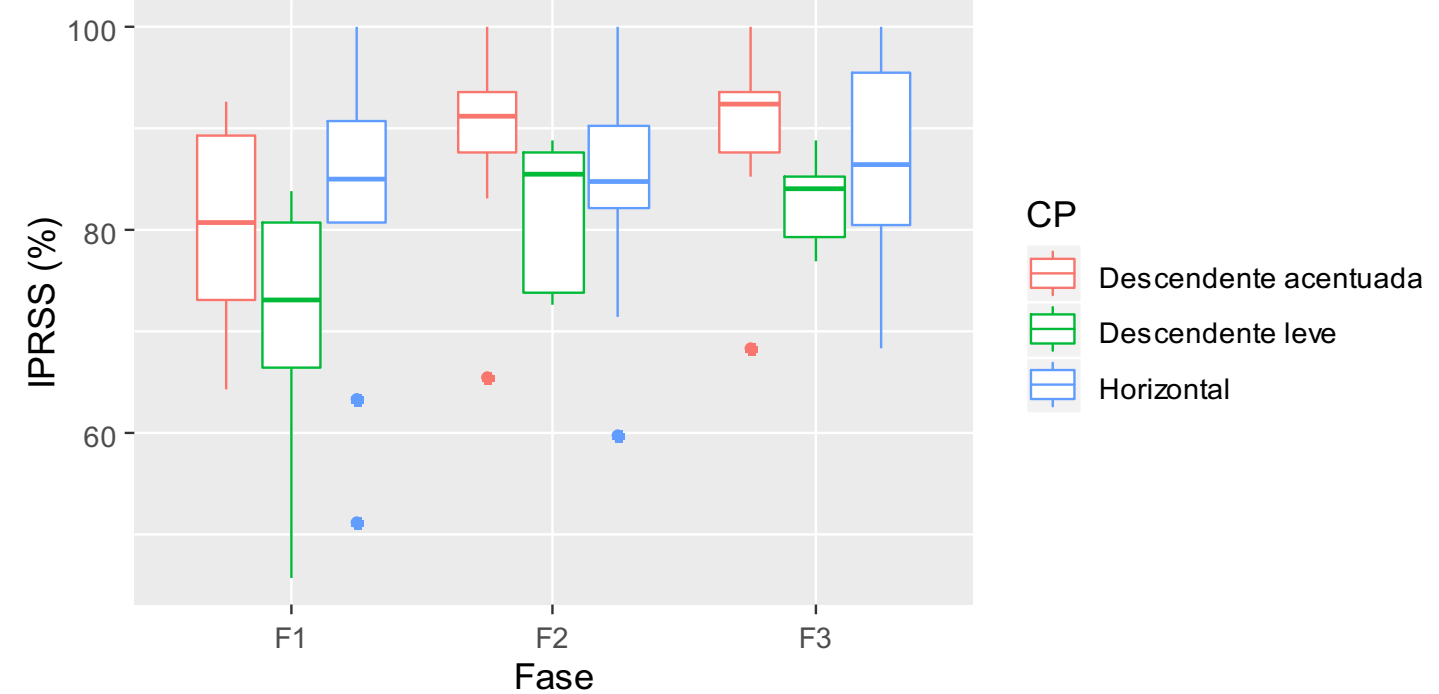

Legenda: $\mathrm{CP}=$ Configuração da perda; $\mathrm{F} 1=$ Fase $1 ; \mathrm{F} 2=$ Fase $2 ; \mathrm{F} 3=$ Fase $3 ;$ IPRSS $=$ Índice Percentual de Reconhecimento de Sentenças no Silêncio; \% = por cento.

Figura 15 - Valores médios dos resultados do desempenho para o Índice Percentual de Reconhecimento de Sentenças no Ruído (IPRSR) em relação à configuração da perda auditiva, na fase três do estudo.

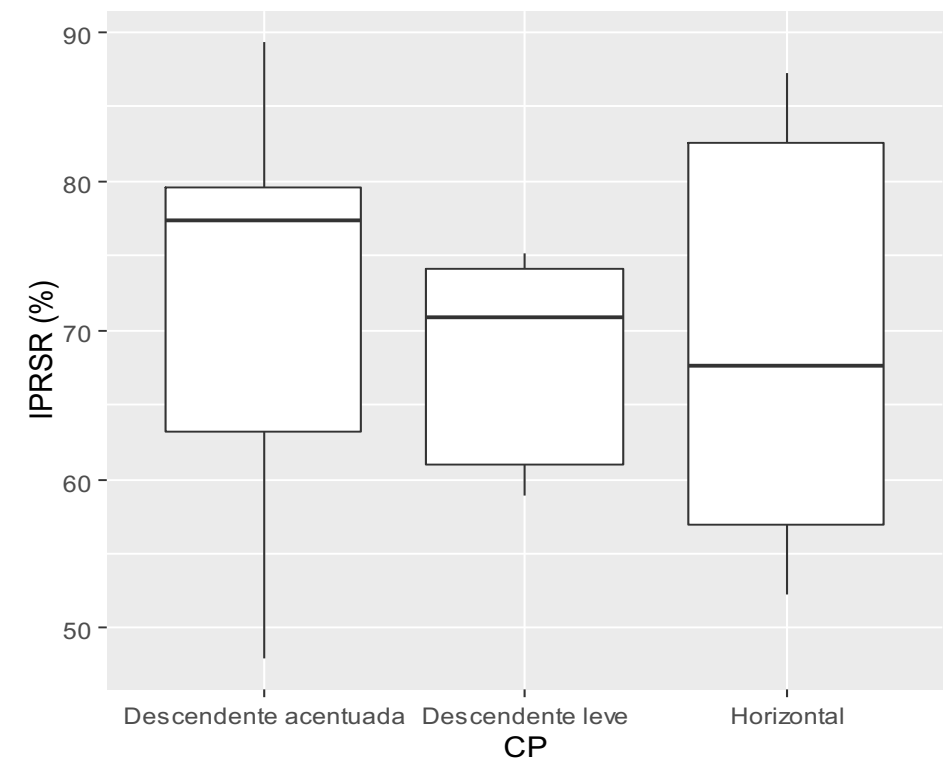

Legenda: $\mathrm{CP}=$ Configuração da perda; IPRSR = Índice Percentual de Reconhecimento de Sentenças no Ruído; \% = por cento. 


\subsection{Questionários - HHIE ou HHIA}

O questionário HHIE/HHIA foi aplicado nos 24 indivíduos, na $2^{\mathrm{a}}$ e $3^{\mathrm{a}}$ fase. No total, 16 responderam ao HHIE e oito responderam ao HHIA.

Quanto a pontuação total na $2^{\mathrm{a}}$ fase $(\mathrm{n}=24)$, foi possível identificar que quatro indivíduos não têm percepção da restrição de participação, 12 apresentam uma percepção leve a moderada da percepção da restrição de participação e oito sujeitos apresentam uma percepção severa ou significante da percepção da restrição de participação, segundo classificação do questionário.

$\mathrm{Na} 3^{\mathrm{a}}$ fase, em que os indivíduos $(\mathrm{n}=24)$ responderam novamente ao questionário, dois deles passaram de uma percepção severa ou significante da percepção de restrição de participação, devido ao déficit auditivo, para a não percepção da restrição de participação, dois passaram de uma percepção severa para uma percepção leve a moderada, quatro continuaram com uma percepção severa ou significante, 10 permaneceram com uma percepção leve a moderada, dois passaram de uma percepção leve a moderada para a não percepção e quatro continuaram sem percepção da restrição de participação.

$\mathrm{Na}$ figura 16, abaixo, estão distribuídos os resultados do questionário HHIE/HHIA, em relação aos domínios investigados, sendo o emocional, o social e o escore total, investigados nas fases 2 e 3. Observa-se melhora dos escores em todos os domínios na fase 3 .

Figura 16 - Questionário HHIE ou HHIA nas fases 2 e 3.

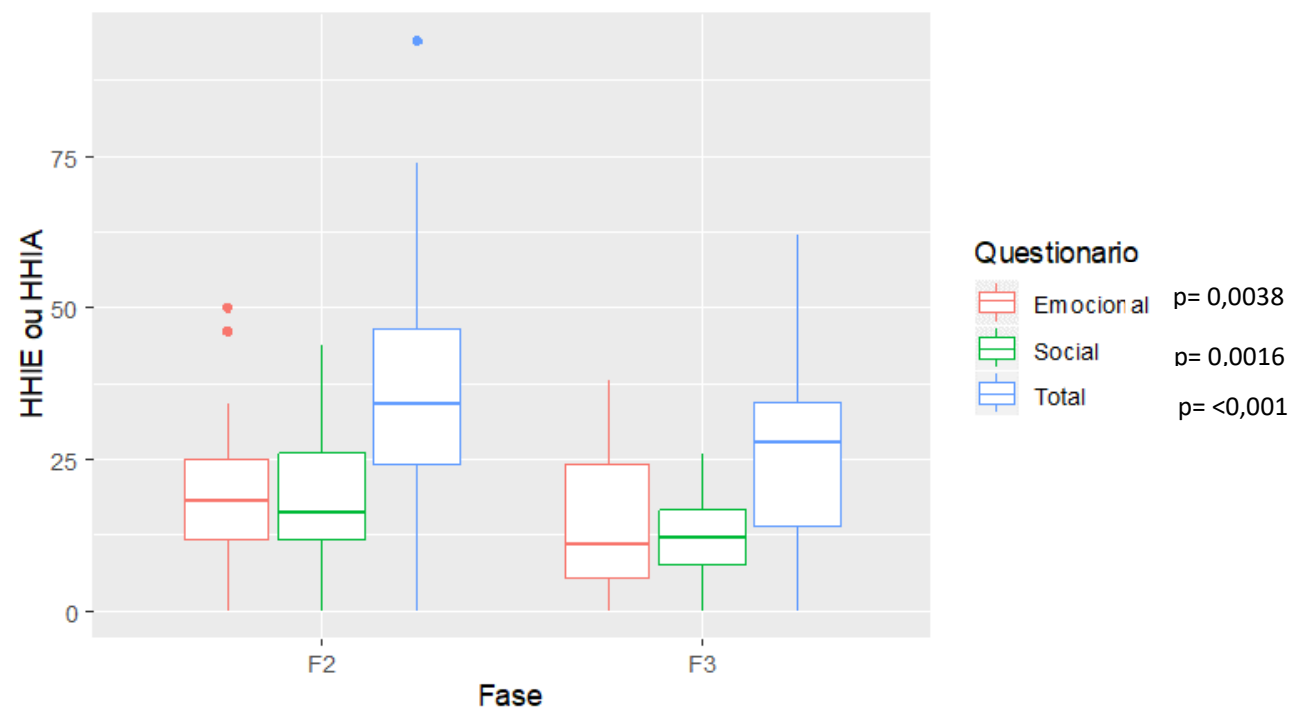

Legenda: F2 = Fase 2; F3 = Fase 3; HHIA = Hearing Handicap for Inventory for Adult HHIE = Hearing Handicap for Inventory for Elderly. 


\section{DISCUSSÃO}

A amostra do estudo foi equilibrada em relação ao sexo (45,8\% - masculino e $54,2 \%$ - feminino). Em relação à idade, a média foi de 58,9 anos (DP+-15,0), com ampla variação de idade, entre 30 e 78 anos, incluindo na amostra indivíduos com idades em que há variações das medidas de latência constatadas na literatura (CÓSER et al., 2010; POLICH, 1992), demonstrando aumento da medida de latência da componente P3 após os 45 anos. Apesar desta variação dos potenciais corticais com a idade, considerou-se uma variável controlada neste estudo uma vez que a coleta dos potenciais de P300 permitiu a comparação de sujeito único, ou seja, sendo o indivíduo o controle dele mesmo, para as diferentes fases do estudo.

O tipo de etiologia da surdez encontrada nesses indivíduos mostrou 21 ainda em processo de investigação, um diagnosticado com perda auditiva induzida por ruído e dois diagnosticados com presbiacusia. Essa incidência para a etiologia idiopática (em investigação) também foi encontrada em outros estudos (BRITO et al., 2012; LIMA JUNIOR et al., 2010).

Segundo estudo nacional (PINHEIRO et al., 2012), o nível educacional deve ser sempre analisado, uma vez que indivíduos com melhor escolaridade apresentam melhor desempenho em situações de comunicação. Em sua maioria, os instrumentos de triagem cognitiva incluem o ajuste de escolaridade, o que também ocorre com o instrumento utilizado no presente estudo, o 10-CS. Neste estudo, observou-se que a escolaridade predominante foi o ensino fundamental completo e ao correlacionar os resultados dos testes de percepção de fala com o nível de escolaridade dos indivíduos, não foi evidenciada diferenças estatísticas (Apêndice F). Também não foi evidenciada diferença estatística entre o tempo de privação auditiva e os resultados nos testes de percepção de fala (Apêndice G), sugerindo, nestas duas correlações, que a variabilidade do tempo de perda auditiva e nível de escolaridade dos indivíduos da pesquisa possam ter contribuído para os resultados encontrados e, principalmente, que as interações entre as habilidades auditivas periféricas, o processamento auditivo centrais e cognitivos não são totalmente compreendidos.

No presente estudo, foi utilizado o potencial cognitivo P300 em indivíduos com perda auditiva e novos usuários de dispositivo eletrônico para surdez, AASI, a fím de estudar o comportamento auditivo desses pacientes. Foram selecionados do Serviço de Saúde Auditiva da instituição os modelos de AASI melhores indicados para cada caso de paciente, sendo ajustados em regulagem habitual, que é considerada a melhor para o 
paciente. O indivíduo quando em uso de AASI, dispositivo que basicamente tem a função de amplificar o som, torna possível a estimulação das células ciliadas remanescentes e gera o impulso nervoso pela própria cóclea, que são transmitidos para o sistema nervoso central, produzindo dessa forma, a sensação auditiva. Vale ressaltar que os indivíduos também comparecerem ao menos uma vez na empresa que fez a entrega dos aparelhos auditivos, para melhoria dos ajustes e orientações.

A pesquisa do P300 é um procedimento de fácil aplicabilidade e de grande valor diagnóstico. Henkin et al. (2009) reforçaram em seus estudos a contribuição do componente P3 como um índice neural sensível do processamento cortical do estímulo auditivo. No presente estudo optou-se em analisar apenas o componente P300 por ele ser um potencial endógeno, que reflete a contribuição dos processos top-down sobre o processamento auditivo.

Não houve indivíduo que não foi capaz de discriminar os dois tipos de estímulos utilizados no estudo (tone burst e fala), mas notou-se a necessidade de maior tempo de treino para perceberem com nitidez e discriminar o estímulo raro de fala (/da/).

No estudo, comparou-se as derivações CzA1 e CzA2 e não foram observadas diferenças estatisticamente significantes, tanto quando utilizado o estímulo tone burst quanto o estímulo de fala (latência e amplitude). Não há estudo relacionando esses achados em indivíduos com perda auditiva usuários de AASI, porém, estão de acordo com o estudo de Frizzo et al. (2001) e Massa et al. (2011), que não encontraram diferenças estatisticamente significantes entre as derivações para as medidas de latência e amplitude do P300 com os estímulos em adultos com audição normal, como também com o estudo de Amaral e Hypolitto (2019) com indivíduos usuários de implante coclear.

Quanto à condição de teste e reteste, estudos com indivíduos audiologicamente normais indicam que a latência do P300 apresenta confiabilidade nessa condição. (POLICH et al., 1983; SKLARE \& LYNN, 1984; SANDMAN \& PETTERSON, 2000). Polich et al. (1983) ainda observaram confiabilidade das componentes do P300 intrasessões e entre sessões, sugerindo que tais padrões, observados em longo termo, podem refletir habituação ou desabituação de determinados processos no sistema nervoso central. Estudos em relação à estabilidade dos resultados referentes as medidas de latência do componente P3 têm demonstrado que não há diferença significativa desta medida para os intervalos de teste e reteste, quando os exames são realizados no mesmo paciente em curto intervalo de tempo (LEW; GRAY; POOLE, 2007; JUNQUEIRA; COLAFÊMINA, 2002; REIS et al., 2014;). Mesmo que o tempo de teste e reteste no presente estudo foi 
realizado após um longo período de tempo (6 meses / 12 meses) e em indivíduos que passaram por um período de reorganização da via auditiva central pela entrada do estimulo auditivo proporcionado pelo uso de AASI, os resultados de teste e reteste do P300 seguem os mesmos padrões citados na literatura em comparação a indivíduos normais.

Sabe-se que o P300 fornece ao pesquisador uma possibilidade de observar o substrato neurofisiológico de processos que ocorrem no córtex cerebral e que são relacionados com a cognição, o que envolve memória e atenção auditiva, necessárias ao processamento auditivo central (HALL, 2006). Neste estudo, a memória não foi uma habilidade analisada, uma vez que a tarefa solicitada ao paciente durante o registro do potencial P300 não foi contar mentalmente os estímulos raros, mas levantar levemente o dedo indicador na presença do estímulo raro. Dessa forma, trabalhamos com a função executiva, relacionada à tarefa envolvida no teste P300 e que necessita de ações de função executiva, como planejar e executar ações.

Esperava-se neste estudo que as médias de latência do P300, para o estímulo tone burst e estímulo de fala, ocorressem de forma progressivamente melhor, ou seja, latências mais curtas com o passar das fases, devido ao maior tempo de estímulo acústico promovido pelos aparelhos auditivos, porém não ocorreu dessa forma. Observou-se que após seis meses de uso de AASI, houve variação do P300 tanto para um valor maior, quanto para um valor menor, mas após 1 ano, todos os valores foram melhores (menores) em comparação a primeira fase, em que os indivíduos não utilizavam AASI. Ainda observou-se que a média das latências mantêm-se com valores dentro da normalidade para o teste em todas as fases, de acordo com McPHERSON (1996), que estabelece normalidade do P300 entre 220 a 380 ms. Groenen et al. (1996) relatam que aqueles pacientes que sempre apresentam melhor discriminação auditiva também apresentam melhores latências, ou seja, latências mais curtas.

É válido ressaltar que as médias de latência do P300 para o estímulo de fala foram sempre menores nas três fases, em comparação com as médias de latência do P300 para o estímulo tone burst. Um estudo realizado com indivíduos audiologicamente normais (MASSA et al., 2011) encontrou resultados contrários quando comparou os estímulos tone burst e fala. Observaram que a latência para tone burst foi menor em comparação a latência de fala. Sabe-se que os estímulos de fala constituem uma tarefa de dificuldade de escuta mais complexa, quando comparada com a discriminação de estímulos não verbais (MARTIN; TREMBLAY; KORCZAK, 2008) e dessa forma o habitual seja encontrar a 
latência do P300 com resultado maior para um estímulo mais complexo, como o estímulo de fala. No presente estudo ocorreu o oposto, ou seja, os indivíduos apresentaram valores de latência menores quando o teste foi aplicado com o estímulo de fala. Nos apoiamos na ideia de que os indivíduos encontraram maior dificuldade quando o estímulo apresentado era o de fala. Uma das hipóteses levantada para justificar este achado é a de que o treinamento prévio para discriminação das sílabas envolvidas levou o indivíduo a realizar o teste nesta condição com maior nível de atenção, mantido durante o teste também, o que provavelmente demandou maior atividade cognitiva e fez com que os indivíduos apresentassem respostas "mais rápidas", ou seja, menor valor de latência quando o estímulo era de fala, quando comparado ao teste realizado com tone burst.

Outro fator a se considerar para os resultados obtidos de latência para os estímulos de fala e tone burst, seria o fato de que os indivíduos desta amostra apresentarem perda auditiva pós-lingual, portanto, esta via auditiva já havia sido estabelecida em alguma fase da vida, reforçado pelo fato da variável escolhida neste estudo em relação ao grau da perda auditiva, moderado a severo, ou seja, a grande maioria manteve algum grau, mesmo que pequeno, de acesso do input auditivo ao córtex. Reforça-se a hipótese verificada na correlação do desempenho para os testes de percepção de fala e grau da perda auditiva, ou seja, que as medidas comportamentais e eletrofisiológicas de percepção de sons da fala estão relacionadas ao grau da perda auditiva sensorioneural, da intensidade dos estímulos e do nível de processamento auditivo cortical que se avalia.

A avaliação eletrofisiológica, em especial os PEALL, talvez não seja um teste com sensibilidade para observarmos a plasticidade funcional auditiva em pacientes com perda auditiva pós-lingual, após 12 meses de uso dos dispositivos, uma vez que não observamos evidências estatísticas nas três fases do estudo. Ao se comparar com as avaliações comportamentais, estas mostraram resultados mais significativos que a eletrofisiológica, possivelmente devido as habilidades auditivas envolvidas (detecção/discriminação) e cognitiva (atenção). Possivelmente, os participantes não necessitaram de alterações funcionais relevantes e passíveis de registros a ponto de serem identificadas no PEALL.

Com o objetivo de verificar se havia influência do tipo de estímulo utilizado na obtenção dos registros de latência do P300 foi realizado o teste ANOVA para as variáveis estímulo de fala e tone burst nas diferentes fases do estudo. Não foram encontradas evidências estatísticas nessas associações para as medidas de latência. A influência do tipo de estímulo é pouco mencionada na literatura, principalmente em usuários de AASI. Kaga et al. (1991) compararam estímulos de fala e tom puro em usuários de IC unilateral 
pelo período de seis meses. Com três meses de uso do dispositivo, os autores relataram o aparecimento do componente P3 para ambos os estímulos e após seis meses do uso do IC, o P3 se tornou mais robusto, indicando que esses achados seriam devido ao restabelecimento do processo da informação após a reabilitação auditiva, podendo o exame do P300 ser útil para elucidar as alterações das percepções auditivas que ocorrem em usuários de IC. Oppitz et al. (2015), em um estudo com normo-ouvintes, não encontraram diferenças significativas quando comparados os registros do teste P300 com estímulos tone burst e fala para as medidas de latência e amplitude dos componentes exógenos do P300. Em outro estudo, que utilizou diferentes estímulos associados a teste de percepção de fala, os autores não citaram a análise em relação às medidas de latência, mas verificaram valores maiores de amplitude com tone burst (GROENEN et al., 2001).

Quanto à amplitude, observou-se que os valores de amplitude encontrados foram relativamente baixos em todas as fases, próximos a $4 \mu \mathrm{V}$. Mesmo com valores de amplitudes relativamente baixos, observou-se para o estímulo tone burst, que ao passar das fases, ou seja, quanto maior o tempo de estimulação auditiva pelo uso de AASI, melhor foram os valores de amplitude. Em relação aos estímulos de fala, a amplitude diminuiu com o tempo de estimulação. Segundo Martin, Tremblay \& Korczak, (2008), a amplitude do P300 é maior para tarefas mais fáceis e vai diminuindo conforme a tarefa torna-se mais difícil.

Apesar dos resultados de latência e amplitude não mostrarem diferença significativa da fase 1 para a fase 2 , da fase 2 para a fase 3 e da fase 1 para a fase 3 , foi possível notar durante a realização do teste eletrofisiológico que a morfologia da onda do registro frequente e raro mostrou-se mais favorável para a marcação do complexo N1-P2N2 e, principalmente, do P300, no registro raro, com o passar das fases (Apêndice H).

Pode-se notar que o registro do P300 apresenta melhora de latência e amplitude após um período de estimulação auditiva com uso de AASI, o que enfatiza a importância do uso desse exame para monitorar a neuroplasticidade funcional do sistema nervoso auditivo central em usuários de AASI.

No estudo estatístico realizado não houve relação do potencial P300 com as variáveis estudadas: escolaridade, tempo de privação auditiva, grau da perda auditiva e configuração da perda auditiva. Portanto, mesmo havendo seis indivíduos com grau severo, verificou-se que não houve influência do grau da perda auditiva na latência do P300 e isso indica que a perda auditiva periférica não impede a utilização deste procedimento. Musiek \& Geurkink (1981), Hall (1992) e Reis \& Iorio (2007) referiram 
que o P300 não é afetado pela perda auditiva, desde que o indivíduo possa perceber o estímulo. No presente estudo, não era esperada diferença estatística em relação ao grau da perda auditiva com a latência e amplitude do P300, pois, além dos indivíduos serem pós linguais, garantiu-se o acesso ao estímulo auditivo (frequência e intensidade), uma vez que todos os participantes apresentaram resíduos auditivos para as frequências utilizadas nos parâmetros para elicitar o P3 e a intensidade foi de $30 \mathrm{dBNS}$, o que também garantiu que percebessem os estímulos independente do grau da perda auditiva.

Durante realização do teste Listas de Sentenças em Português observou-se que a média do IPRSS apresentou melhor porcentagem de acertos quando o indivíduo foi avaliado com AASI, ou seja, fases 2 e 3 . A diferença estatística encontrada da fase 1 para a fase 2 e da fase 1 para a fase 3 já era esperada, visto que o indivíduo estava em uso de amplificação nas fases 2 e 3 .

Durante pesquisa do IPRSR na fase 3, observou-se a dificuldade dos indivíduos em responder ao teste devido ao ruído presente. Os indivíduos referiram que o ruído tornou a compreensão das sentenças ininteligível. Eles eram capazes de detectar o som de fala, porém não eram capazes de reconhecer as sentenças inteiras ou parte delas. Mesmo observando dificuldades em todos os indivíduos, aqueles com perda auditiva de grau moderado apresentaram melhores resultados.

Notou-se que o método utilizado colocou os indivíduos em uma situação de escuta desafiadora quando apresentadas as sentenças com a presença do ruído, visto que o ruído foi calculado a partir do LRSS, limiar este em que o indivíduo é capaz de reconhecer em torno de $50 \%$ dos estímulos de fala e que já é preciso atenção e concentração para repetir a sentença no silêncio. Assim, já era esperado que a média de acertos para esse tipo de situação, em que há presença de ruído com intensidade maior que a intensidade de fala, mantivesse uma porcentagem baixa de acertos. Ressalta-se também que o método de pesquisa utilizado, com intervalos de $10 \mathrm{~dB}$ e $5 \mathrm{~dB}$, possa ter limitado as respostas dos pacientes, visto que são intervalos relativamente amplos. Acredita-se que utilizar intervalos menores, como $4 \mathrm{~dB}$ e $2 \mathrm{~dB}$, faz-se importante.

No estudo estatístico realizado não houve relação do teste de sentenças com as variáveis estudadas: escolaridade, tempo de privação auditiva e configuração da perda auditiva, porém, diferente do teste eletrofisiológico, o grau da perda auditiva influenciou os resultados do teste de sentenças, ou seja, pacientes com perda auditiva de grau moderado apresentaram melhor desempenho nas fases 1 e 2 em comparação aos 
indivíduos com perda auditiva de grau severo. Na fase 3 não houve diferença, possivelmente devido ao tempo de estimulação auditiva pelo uso dos AASIS (12 meses).

Os dados apresentados pela aplicação dos questionários sugerem que o uso de aparelhos auditivos, quando adaptados adequadamente, tendem a melhorar a qualidade de vida das pessoas com perda auditiva, pois diminui os efeitos da perda auditiva sobre a comunicação e as relações sociais dessas pessoas. Sendo assim, este estudo demonstrou que o uso dos aparelhos auditivos teve impacto positivo sobre a qualidade de vida dos pacientes, pois reduziu a restrição de participação, tanto no âmbito emocional quanto no social.

Pode-se observar que mesmo poucos indivíduos, apenas seis, terem mudado de classificação no questionário, estes mudaram para classificações melhores, ou seja, apresentaram diminuição da restrição de participação. Já a grande maioria, 18 indivíduos, mesmo não tendo mudado de categoria, apresentaram somatória dos escores melhores na fase 3, ou seja, escores menores, mas que não foram suficientes para que estes mudassem de categoria. Assim, a aplicação do questionário HHIE/HHIA apontou resultados favoráveis ao uso de AASI após 6 meses de uso e principalmente após 12 meses, concordando com resultados de Teixeira et al. (2008) e Mantello et al. (2016).

Vale ressaltar a importância observada com este estudo que a associação da avaliação eletrofisiológica com a avaliação comportamental e aplicação de questionário contribui para melhor compreensão do desempenho auditivo dos indivíduos usuários de AASI durante o processo de reabilitação. 


\section{CONCLUSÃO}

O presente estudo permitiu concluir que:

- Não houve diferenças nas medidas de latência e amplitude da componente P3 nas três fases do estudo.

- Evidenciou-se melhora das respostas dos indivíduos para os testes de fala nas três fases do estudo.

- Houve correlação da variável grau da perda auditiva com os resultados do teste de percepção de fala.

- Os escores do questionário de autoavaliação demonstraram redução da percepção de restrição de participação, após uso do AASI, tanto no âmbito emocional quanto no social. 


\section{REFERÊNCIAS BIBLIOGRÁFICAS ${ }^{1}$}

AMERICAN ACADEMY OF AUDIOLOGY (AAA). Clinical Practice Guidelines: Diagnosis, Treatment and Management of Children and Adults with Central Auditory Processing Disorder [Guideline]. 2010. Disponível em: $<$ http://audiology.org/resources/documentlibrary/Pages/CentralAuditoryProcessingDiso rder.aspx $>$. Acesso em 18 fev., 2014.

AMORIM, R.M.C.; ALMEIDA, K. Estudo do benefício e da aclimatização em novos usuários de próteses auditivas. Pro Fono, v.19, n.1, p. 39-48, 2007.

APOLINARIO, D.; LICHTENTHALER, D. G.; MAGALDI, R. M.; SOARES, A. T.; BUSSE, A. L.; DAS GRACAS AMARAL, J. R.; JACOB-FILHO, W.; BRUCKI, S. M. D. Using temporal orientation, category fluency, and word recall for detecting cognitive impairment: the 10-point cognitive screener (10-CS). Int J Geriatr Psychiatry, v. 31, p. 4-12, 2015.

AMERICAN SPEECH-LANGUAGE-HEARING ASSOCIATION. (2005). Guidelines for Manual Pure-Tone Threshold Audiometry [Guidelines]. Disponível em: $<$ http://www.asha.org/policy>. Acesso em 06 fev. 2014.

BARBOSA REIS, A.C.M.B.; FRIZZO, A.C.F.; LOZANO, A.C.; SANTOS, F.R.; ANASTASIO, A.R.T.; HYPPOLITO, M.A. Variabilidade do registro de latência e amplitude do potencial evocado auditivo de Longa Latência (P3) na condição teste e reteste. Audiol Commun Res., v. 19, n.3, p. 293-8, 2014.

BOÉCHAT EM. Plasticidade do sistema auditivo quanto à sensibilidade auditiva para tons puros e respostas para fala na deficiência auditiva neurossensorial [tese]. São Paulo: Faculdade de Medicina da Universidade de São Paulo; 2003.

BRITO, R. et al. Complicações em 550 cirurgias consecutivas de implante coclear. Braz J Otorhinolaryngol. v. 78, n. 3, p. 80-5, 2012.

COLAFÊMIMA, J.F.; FELLIPE, A.C.N.; JUNQUEIRA, C.A.O.; FRIZZO, A.C.F. Potenciais evocados auditivos de longa latência (P300) em adultos jovens saudáveis: um estudo normativo. Rev. Bras. Otorrinolaringol., São Paulo, v. 66, n. 2, p.144-148, 2000.

CÓSER, M. J. S. et al. Latência do potencial evocado auditivo P300 em idosos. Braz J Otorhinolaryngol. v. 76. n. 3, p. 287-93, 2010.

COSTA, M.J. Listas de sentenças em português: apresentação e estratégias de aplicação na audiologia. Santa Maria: Pallotti; 1998.

COSTA, M.J.; SANTOS, S.N.; LESSA, A.H.; MEZZOMO, C.L. Proposta de aplicação do Índice Percentual de Reconhecimento de Sentenças em indivíduos com distúrbio de audição. CoDAS, v. 27, n. 2, p. 148-54, 2015.

\footnotetext{
${ }^{1}$ Elaboradas de acordo com as Diretrizes para Apresentação de Dissertações e Teses da USP: Documento Eletrônico e Impresso - Parte I (ABNT) 3 $3^{a}$ ed. São Paulo: SIBi/USP, 2016.
} 
DUARTE, J.L.; ALVARENGA, K.F.; BANHARA, M. R. Potencial evocado auditivo de longa latência-P300 em indivíduos normais: valor do registro simultâneo em Fz e Cz. Braz. J. Otorhinolaryngol., v. 75, n. 2, p. 231-6, 2009.

DO AMARAL, M.S. A.; HYPPOLITO, M.A. Comportamento do P300 em pacientes usuários de implante coclear com eletroestimulação unilateral. Tese (Doutorado em Ciências) - Faculdade de Medicina de Ribeirão Preto, Universidade de São Paulo. Ribeirão Preto, p. 105. 2019.

FARIAS, N.; BUCHALLA, C.M. A classificação internacional de funcionalidade, incapacidade e saúde da Organização Mundial da Saúde: conceitos, usos e perspectivas. Rev Bras Epidemiol., v. 8, p. 187-93, 2005.

FRIZZO, A.C.; ALVES, R.P.C.; COLAFÊMINA, J.F. Potenciais Evocados Auditivos de Longa Latência: um estudo entre hemisférios cerebrais. Rev Bras Otorrinolaringol., v. 67, n. 5, p. 618-25, 2001.

GROENEN, P. A. et al. The relation between electric auditory brain stem and cognitive responses and speech perception in cochlear implant users. Acta Otolaryngol. v. 116, n. 6, p. 785-90, 1996.

GROENEN, P. A. et al. Speech-evoked cortical potentials and speech recognition in cochlear implant users. Scand Audiol. v. 30. n. 1, p. 31-40, 2001.

HALL, J. Handbook of auditory evoked responses. Boston: Allyn \& Bacon, 1992.

HALL, J. New Handbook of auditory evoked responses. Boston: Allyn \& Bacon, 2006.

HENKIN, Y. et al. Cortical neural activity underlying speech perception in postlingual adult cochlear implant recipients. Audiol Neurootol. v. 14, n. 1, p. 39-53, 2009.

HENRIQUES, M.O.; COSTA, M.J. Reconhecimento de sentenças no ruído, em campo livre, em indivíduos com e sem perda auditiva. Rev. CEFAC., v. 13, n. 6, p. 1040-47, 2011.

JASPER, H.H. The ten-twenty electrode system of the International Federation. Electroencephalogr. Clin. Neurophysiol. v. 10, n. 2, p. 371-375, 1958.

JUNQUEIRA, C.A.O.; COLAFÊMINA, J.F. Investigação da estabilidade inter e intraexaminador na identificação do P300 auditivo: análise de erros. Rev Bras Otorrinolaringol., v. 68, n. 4, p. 468-78, 2002.

KAGA, K. et al. P300 response to tones and speech sounds after cochlear implant: a case report. Laryngoscope. v. 101, n. 8, p. 905-7, 1991.

KRAUS, N.; McGEE, T. - Auditory Event-related Potentials. In: KATZ, J. Handbook of Clinical Auditory. 4 ed. Baltimore: Williams \& Wilkins; 1994. cap. 27, p. 406-426.

KRAUS, N.; McGEE, T. Potenciais Evocados Auditivos de longa latência. In: KATZ, J. Tratado de Audiologia Clínica. 4. ed. São Paulo: Manole, 2002, p. 403-420. 
LEVITT, H.; RABINER, L.R. Use of a sequencial strategy in intelligibility testing. $\mathbf{J}$ Acoust Soc Am., v. 42, n. 3, p. 609-12, 1967.

LEW, H.L.; GRAY, M.; POOLE, J.H. Temporal stability of auditory event-related potentials in healthy individuals and patients with traumatic brain injury. J Clin Neurophysiol., v.24, n 5, p. 392-7, 2007.

LIMA JUNIOR, L. R. P. et al. Postoperative complications in implanted patients in the Cochlear Implant Program of Rio Grande do Norte. Braz J Otorhinolaryngol. v. 76, n. 4, p. 517-21, 2010.

MANTELlO, E.B.; MARINO, M.V.; ALVES, A.C.; HYPPOLITO, M.A.; REIS, A.C.M.B.; ISAAC, M.L. Avaliação da restrição de participação em atividades de vida diária de idosos usuários de aparelhos de amplificação sonora individual. Medicina (Ribeirão Preto. Online), v. 49, n. 5, p. 403-10, 2016.

MARTIN, B. A.; TREMBLAY, K. L.; KORCZAK, P. Speech evoked potentials: from the laboratory to the clinic. Ear Hear. v. 29, n. 3, p. 285-313, 2008. Review. Erratum in: Ear Hear. v. 29, n. 6, p. 979, 2008.

MARTIN, B.A.; TREMBLAY, K.L.; STAPELLS, D.R. Principles and aplications of cortical auditory evoked potentials. In: BURKARD, R.F.; DON, M.; EGGERMONT, J.J. (Orgs.). Auditory evoked potentials: basic principles and clinical application. Baltimore: Lippincott Williams \& Wilkins; p. 483-507, 2007.

MASSA, C. G. P. et al. P300 with verbal and nonverbal stimuli in normal hearing adults. Braz J Otorhinolaryngol. v. 77, n. 6, p. 686-90, 2011.

MCPHERSON, D. L. Late potential of the auditory system. San Diego: Singular Publishing Group, 1996.

MENEGOTTO, I.H.; SOLDERA, C.L.C.; ANDERLE, P.; ANHAIA, T.C. Correlação entre perda auditiva e resultados dos questionários Hearing Handicap Inventory for the Adults - Screening Version HHIA-S e Hearing Handicap Inventory for the Elderly Screening Version - HHIE-S. Arq Int Otorrinolaringol., v. 15, p. 319-26, 2011.

MUSIEK, F.E.; GEURKINK, N.A. Auditory brainstem and middle latency evoked response sensitivity near threshold. Ann Otol Rhinol Laryngol., v. 90, p. 236-40, 1981.

NEWMAN, C.W.; WEINSTEIN, B.E.; JACOBSON, G.P.; HUG, G.A. The hearing handicap inventory for adults: psychometric adequacy and audiometric correlates. Ear Hear, v. 11, n. 6, p. 430-3, 1990.

ORGANIZAÇÃO MUNDIAL DE SAÚDE - OMS, 2014. http://www.who.int/en/.

OPPITZ, S. J. et al . Potenciais evocados auditivos de longa latência com verbais e não verbais. Braz J Otorhinolaryngol. v. 81, n. 6, p. 647-652, 2015. 
PASCUAL-LEONE, A.; AMEDI, A.; FREGNI, F.; MERABET, L.B. The plastic human brain cortex. Annu Rev Neurosci., v. 28, p. 377-401, 2005.

PATEL, S.H.; AZZAM, P.N.; Characterization of N200 and P300: selected studies of the event-related potential. Int J. Med. Sci., v. 2, n. 4, p.147-154, 2005.

PINHEIRO, M.M.C.; IÓRIO, M.C.M.; MIRANDA, E.C.; DIAS, K.Z.; PEREIRA, L.D. A influência dos aspectos cognitivos e dos processos auditivos na aclimatização das próteses auditivas em idosos. J Soc Bras Fonoaudiol., v. 24, n. 4, p. 309-15, 2012.

POLICH, J.; MCISAAC, H.K. Comparison of auditory P300 habituation from active and passive conditions. Int J Psychophysiol., v. 17, p. 25-34, 1994.

POLICH, J.; HOWARD, L.; STARR, A. P300 latency correlates with digit span. Psychophysiol., v. 20, n. 6, p. 665-9, 1983.

POLICH, J. On the clinical application of P300. Biol Psychiatry. v. 31, n. 7, p. 647-9, 1992.

REIS, A. C. M. B.; IÓRIO, M. C. M. P300 em sujeitos com perda auditiva. Pró-Fono R. Atual. Cient., Barueri (SP), v. 19, n. 1, p. 113-122, jan.-abr, 2007.

REIS, A.M.B.R.; FRIZZO, A.C.F.; LOZANO, A.C.; SANTOS, F.R.; ANASTASIO, A.R.T.; HYPPOLITO, M.A. Variabilidade do registro de latência e amplitude do potencial evocado auditivo de Longa Latência (P3) na condição teste e reteste. Audiol., Commun. Res. vol.19 n.3, 2014.

ROSIS, A.C.A.; SOUZA, M.R.F.; IÓRIO, M.C.M. Questionário Hearing Handicap Inventory for the Elderly - Screening version (HHIE-S): estudo da sensibilidade e especificidade. Ver Soc Bras Fonoaudiol., v. 14, p. 339-45, 2009.

SANDMAN, C.A.; PETTERSON, J.V. The auditory event-related potential is a stable and reliable measure in elderly subjects over a 3-year period. Clin Neurophysiol., v. 111, n. 8, p. 1427-37, 2000. http://dx.doi.org/10.1016/S1388- 2457(00)00320-5 Comment in: Pratt H. Improving the clinical utility of event-related potentials [editorial]. Clin Neurophysiol. 2000;111(8):1425- 6. http://dx.doi.org/10.1016/S1388-2457(00)00344-8.

SHARMA, A.; DORMAN, M.F.; KRAL, A. The influence of a sensitive period on central auditory development in children with unilateral and bilateral cochlear implants. Hear Res., v. 203, n.1-2, p. 134-143, 2005.

SIMOES, H. O.; FRIZZO, A.C.F.; ZANCHETTA, S.; HYPPOLITO, M. A.; REIS, A. C. M. B. Variables in P300 recording: task type and electrode position. CoDAS, v. 28, p. 355-361, 2016.

SKLARE, D.A.; LYNN, G.E. Latency of the P3 event-related potential: normative aspects and within-subject variability. Electroencephalogr Clin Neurophysiol., v. 59, n.5, p. 420-4, 1984.

SOUZA, V.C.; LEMOS, S.M.A. Instrumentos para a avaliação da restrição à participação 
auditiva: revisão sistemática de literatura. CoDAS, v. 27, n. 4, p. 400-6, 2015.

SQUIRES, N. K.; SQUIRES, K. C.; HILLYARD, SA. Two varieties of long-latency positive waves evoked by unpredictable auditory stimuli in man. Electroencephalogr Clin Neurophysiol. v. 38, n. 4, p. 387-401, 1975.

STENKLEV, N.C.; LAUKLI, E. Cortical cognitive potentials in elderly persons. J Am Acad Audiol., v. 15, p. 401-13, 2004.

TEIXEIRA, A.R.; ALMEIDA, L.G.; JOTZ, G.P.; BARBA, M.C. Qualidade de vida de adultos e idosos pós adaptação de próteses auditivas. Rev Soc Bras Fonoaudiol., v. 13, p. $357-61,2008$.

THEUNISSEN, M.; SWANEPOEL, D.W.; HANEKON, J. Sentence recognition in noise: variables in compilation and interpretation of tests. Int J Audiol., v. 48, n. 11, p. 743-57, 2009.

VENTRY, I.M.; WEINSTEIN, B.E. The hearing handicap inventory for the elderly: a new tool. Ear Hear, v. 3, p. 128-34, 1982.

WIESELBERG, M. B.; IÓRIO, M. C. M. Adaptação de prótese auditiva e a privação da audição unilateral: avaliação comportamental e eletrofisiológica. Braz. J. Otorhinolaryngol., v. 78, n. 6, p. 69-76, 2012.

WIESELBERG MB. A autoavaliação do handicap em idosos portadores de deficiência auditiva: o uso do HHIE [dissertação]. São Paulo: Pontifícia Universidade Católica de São Paulo; 1997. 


\section{APÊNDICES}

APÊNDICE A - Termo De Consentimento Livre e Esclarecido

\section{TERMO DE CONSENTIMENTO LIVRE E ESCLARECIDO}

Prezado (a) Senhor (a), você está sendo convidado(a) como voluntário(a) a participar da pesquisa "Percepção de fala e P300: desempenho de indivíduos com perda auditiva sensorioneural moderada ou severa antes e após adaptação de AASI".

Objetivo da pesquisa: comparar as medidas de latência e amplitude do teste auditivo P300 e dos resultados da autoavaliação e da avaliação comportamental auditiva em indivíduos com perda auditiva sensorioneural moderada ou severa antes, seis meses e 12 meses após a adaptação do Aparelho de Amplificação Sonora Individual (AASI), visando identificar se há diferença das medidas após uso deste. Caso aceite participar, informamos que esta consistirá na realização do exame P300, levantando o dedo indicador para os estímulos infrequentes e da avaliação comportamental auditiva, que consiste da pesquisa dos limiares auditivos e de teste de percepção de fala, serão apresentadas palavras e sentenças para você repetir. Também serão aplicados questionários para avaliação do impacto da perda auditiva em suas atividades diárias. Será agendada a realização dos mesmos exames após 6 meses ( \pm 1 mês) e 12 meses ( \pm 1 mês).

Tendo recebido as informações sobre o projeto de pesquisa referido acima, por gentileza assinar duas vias deste documento e devolver uma delas ao pesquisador. A outra via ficará com o(a) senhor(a). Não há benefício direto para o participante. O sigilo será assegurado, na medida em que apenas os pesquisadores responsáveis terão acesso às informações fornecidas. Sua participação não terá nenhum custo para você e não causará nenhum prejuízo a você, entretanto, caso ocorra algum dano decorrente da sua colaboração, você tem direito à indenização conforme as leis vigentes no nosso país.

A qualquer momento, os participantes receberão respostas a eventuais perguntas ou esclarecimento sobre a pesquisa. Os pesquisadores estarão à sua disposição, Victor Goiris Calderaro (Fonoaudiólogo, Programa de Pós-graduação em Reabilitação e Desempenho Funcional, telefone (16) 99287-6771), Profa. Dra. Ana Cláudia Mirândola Barbosa Reis (Depto. Oftalmologia, Otorrinolaringologia e Cirurgia de Cabeça e Pescoço, Universidade de São Paulo de Ribeirão Preto, telefone (16) 3206-2527).

Os resultados obtidos neste estudo serão utilizados exclusivamente para esta pesquisa e seus resultados poderão ser publicados, mas será garantido o anonimato da sua participação. Agradecemos a princípio, por sua disponibilidade em ler este convite para a pesquisa.

Nome do pesquisador responsável pela coleta:

Data: Ribeirão Preto, de de 2017.

Assinatura:

Caso concorde em participar do estudo, por gentileza, assine abaixo. 
Recebi o esclarecimento sobre os objetivos, riscos, benefícios e condições de participação nesta pesquisa e concordo em participar.

Nome do participante:

Documento de identidade:

Data: Ribeirão Preto, de de 2017.

Assinatura:

Contato do Comitê de Ética em Pesquisa Hospital das Clínicas e da Faculdade de Medicina de Ribeirão Preto - (16) 3602-2228 
APÊNDICE B - Roteiro de orientação para o Exame P300

\section{Orientacões para a realizaç̃o do registro dos potenciais evocados auditivos - $\mathbf{P 3 0 0}$}

Após o convite e aceite, o indivíduo será orientado quanto aos cuidados e procedimentos para a realização do exame eletrofisiológico P300.

No dia do exame deverá:

- Lavar os cabelos e não usar condicionador, gel ou qualquer outro tipo de cosmético;

- Ter dormido o suficiente para evitar sonolência durante a realização do teste;

- Evitar ingestão de alimentos 60 minutos antes da realização do teste;

- Evitar exercícios físicos no dia do exame;

- Estar em abstinência de drogas e álcool por 24 horas antes do exame. 
APÊEDICE C - Dados específicos das medidas de latência e amplitude do P300, nas derivações CzA1 e CzA2, nas 3 fases da pesquisa para os estímulos tone burst e fala

Tabela 1. Medidas de latência do P300, nas derivações CzA1 e CzA2, nas 3 fases, para o estímulo tone burst $(\mathrm{n}=24)$.

\begin{tabular}{|c|c|c|c|c|c|c|}
\hline \multirow{4}{*}{ Indivíduos } & \multicolumn{6}{|c|}{ Resultados P300 - tone burst } \\
\hline & \multicolumn{2}{|c|}{ FASE 1} & \multicolumn{2}{|c|}{ FASE 2} & \multicolumn{2}{|c|}{ FASE 3} \\
\hline & $\begin{array}{c}\text { Latência } \\
\text { CzA1 }\end{array}$ & $\begin{array}{c}\text { Latência } \\
\mathrm{CzA2}\end{array}$ & $\begin{array}{c}\text { Latência } \\
\text { CzA1 }\end{array}$ & $\begin{array}{c}\text { Latência } \\
\mathrm{CzA} 2\end{array}$ & $\begin{array}{c}\text { Latência } \\
\text { CzA1 }\end{array}$ & $\begin{array}{c}\text { Latência } \\
\mathrm{CzA} 2\end{array}$ \\
\hline & (ms) & $(\mathrm{ms})$ & $(\mathrm{ms})$ & (ms) & $(\mathrm{ms})$ & $(\mathrm{ms})$ \\
\hline 1 & 253,21 & 248 & 262,58 & 271,95 & 257,37 & 257,37 \\
\hline 2 & 394,79 & 393,74 & 345,86 & 367,72 & 367,72 & 330,24 \\
\hline 3 & 354,19 & 320,87 & 340,65 & 362,51 & 367,72 & 371,88 \\
\hline 4 & 393,74 & 363,56 & 317,75 & 327,12 & 255,29 & 274,03 \\
\hline 5 & 339,61 & 378,13 & 330,24 & 324 & 318,79 & 319,83 \\
\hline 6 & 347,94 & 343,78 & 327,12 & 338,57 & 373,97 & 354,19 \\
\hline 7 & 353,15 & 351,06 & 275,07 & 279,23 & 386,46 & 327,12 \\
\hline 8 & 401,03 & 370,84 & 311,50 & 309,42 & 337,53 & 341,69 \\
\hline 9 & 315,67 & 287,56 & 379,17 & 327,12 & 380,21 & 368,76 \\
\hline 10 & 339,61 & 346,90 & 367,72 & 365,64 & 339,61 & 343,78 \\
\hline 11 & 324 & 373,97 & 272,99 & 329,20 & 332,33 & 330,24 \\
\hline 12 & 283,40 & 431,22 & 359,39 & 342,74 & 354,19 & 345,86 \\
\hline 13 & 389,58 & 404,16 & 376,05 & 377,09 & 409,36 & 389,58 \\
\hline 14 & 277,15 & 277,15 & 307,34 & 310,46 & 314,63 & 314,63 \\
\hline 15 & 356,27 & 310,46 & 354,19 & 353,15 & 332,33 & 327,12 \\
\hline 16 & 254,25 & 337,53 & 370,84 & 391,66 & 320,87 & 331,28 \\
\hline 17 & 373,97 & 362,51 & 322,96 & 306,30 & 343,78 & 370,84 \\
\hline 18 & 331,28 & 332,33 & 337,53 & 354,19 & 327,12 & 318,79 \\
\hline 19 & 408,32 & 406,24 & 358,35 & 355,23 & 371,88 & 399,99 \\
\hline 20 & 391,66 & 393,74 & 344,82 & 393,74 & 355,23 & 431,22 \\
\hline 21 & 468,70 & 465,58 & 257,37 & 249,04 & 267,78 & 265,70 \\
\hline 22 & 289,64 & 288,60 & 379,17 & 381,25 & 286,52 & 284,44 \\
\hline 23 & 339,61 & 337,53 & 346,90 & 352,10 & 355,23 & 354,19 \\
\hline 24 & 320,87 & 317,75 & 296,93 & 360,43 & 332,33 & 335,45 \\
\hline Média \pm DP & $\begin{array}{c}345,90 \pm \\
52,27\end{array}$ & $\begin{array}{c}351,80 \pm \\
50,83\end{array}$ & $\begin{array}{c}330,93 \pm \\
36,97\end{array}$ & $\begin{array}{c}338,74 \pm \\
37,27\end{array}$ & $\begin{array}{c}337,01 \pm \\
39,91\end{array}$ & $\begin{array}{c}337,00 \pm \\
41,34\end{array}$ \\
\hline Mínimo & 253,21 & 248 & 257,37 & 249,04 & 255,29 & 257,37 \\
\hline Máximo & 468,70 & 465,58 & 379,17 & 393,74 & 409,36 & 431,22 \\
\hline
\end{tabular}

Legenda: $\mathbf{m s}=$ milissegundos, $\mathbf{D P}=$ Desvio Padrão. 
Tabela 2. Medidas de latência do P300, nas derivações CzA1 e CzA2, nas 3 fases, para o estímulo de fala $(n=24)$.

\begin{tabular}{|c|c|c|c|c|c|c|}
\hline \multirow{4}{*}{ Indivíduos } & \multicolumn{6}{|c|}{ Resultados P300 - fala } \\
\hline & \multicolumn{2}{|c|}{ FASE 1} & \multicolumn{2}{|c|}{ FASE 2} & \multicolumn{2}{|c|}{ FASE 3} \\
\hline & $\begin{array}{c}\text { Latência } \\
\text { CzA1 }\end{array}$ & $\begin{array}{c}\text { Latência } \\
\text { CzA2 }\end{array}$ & $\begin{array}{c}\text { Latência } \\
\text { CzA1 }\end{array}$ & $\begin{array}{c}\text { Latência } \\
\text { CzA2 }\end{array}$ & $\begin{array}{c}\text { Latência } \\
\text { CzA1 }\end{array}$ & $\begin{array}{c}\text { Latência } \\
\text { CzA2 }\end{array}$ \\
\hline & (ms) & (ms) & (ms) & (ms) & (ms) & (ms) \\
\hline 1 & 351,06 & 350,02 & 336,49 & 336,49 & 332,33 & 332,33 \\
\hline 2 & 331,28 & 335,45 & 352,10 & 352,10 & 356,27 & 340,65 \\
\hline 3 & 368,76 & 353,15 & 378,13 & 383,33 & 339,61 & 348,98 \\
\hline 4 & 279,23 & 294,85 & 314,63 & 314,63 & 277,15 & 312,55 \\
\hline 5 & 297,97 & 284,40 & 337,53 & 339,61 & 301,09 & 299,01 \\
\hline 6 & 381,25 & 392,70 & 270,91 & 267,78 & 249,04 & 257,37 \\
\hline 7 & 287,56 & 312,55 & 344,82 & 335,45 & 353,15 & 320,87 \\
\hline 8 & 313,59 & 317,75 & 309,42 & 297,97 & 319,83 & 310,46 \\
\hline 9 & 306,30 & 295,89 & 350,02 & 331,28 & 285,48 & 305,26 \\
\hline 10 & 344,82 & 322,96 & 308,38 & 336,49 & 336,49 & 325,04 \\
\hline 11 & 344,82 & 318,79 & 310,46 & 314,63 & 271,95 & 239,67 \\
\hline 12 & 308,38 & 299,01 & 325,04 & 306,30 & 299,01 & 329,20 \\
\hline 13 & 284,44 & 307,34 & 308,38 & 307,34 & 317,75 & 315,67 \\
\hline 14 & 317,75 & 312,55 & 279,23 & 279,23 & 302,14 & 279,23 \\
\hline 15 & 314,63 & 309,42 & 372,92 & 329,20 & 328,16 & 380,21 \\
\hline 16 & 376,05 & 404,16 & 354,19 & 364,60 & 295,89 & 325,04 \\
\hline 17 & 332,33 & 332,33 & 350,02 & 351,06 & 340,65 & 354,19 \\
\hline 18 & 327,12 & 331,28 & 375,01 & 358,35 & 352,10 & 352,10 \\
\hline 19 & 303,18 & 305,26 & 361,47 & 296,93 & 303,18 & 301,09 \\
\hline 20 & 325,04 & 334,41 & 337,53 & 332,33 & 338,57 & 331,28 \\
\hline 21 & 316,71 & 317,75 & 336,49 & 330,24 & 303,18 & 311,50 \\
\hline 22 & 329,29 & 326,08 & 325,04 & 340,65 & 342,74 & 345,86 \\
\hline 23 & 336,49 & 335,45 & 324 & 327,12 & 322,96 & 328,16 \\
\hline 24 & 339,61 & 340,65 & 335,45 & 343,78 & 339,61 & 339,61 \\
\hline Média \pm DP & $\begin{array}{c}325,73 \pm \\
27,13\end{array}$ & $\begin{array}{c}326,42 \pm \\
28,24\end{array}$ & $\begin{array}{c}333,23 \pm \\
27,48\end{array}$ & $\begin{array}{c}328,20 \pm \\
26,65\end{array}$ & $\begin{array}{c}317,01 \pm \\
28,30\end{array}$ & $\begin{array}{c}320,22 \pm \\
30,86\end{array}$ \\
\hline Mínimo & 279,23 & 284,40 & 270,91 & 267,78 & 249,04 & 239,67 \\
\hline Máximo & 381,25 & 404,16 & 378,13 & 383,33 & 356,27 & 380,21 \\
\hline
\end{tabular}

Legenda: $\mathbf{m s}=$ milissegundos, $\mathbf{D P}=$ Desvio Padrão. 
Tabela 3. Medidas de amplitude do P300, nas derivações CzA1 e CzA2, nas 3 fases, para o estímulo tone burst $(\mathrm{n}=24)$.

\begin{tabular}{|c|c|c|c|c|c|c|}
\hline \multirow{4}{*}{ Indivíduos } & \multicolumn{6}{|c|}{ Resultados P300 - tone burst } \\
\hline & \multicolumn{2}{|c|}{ FASE 1} & \multicolumn{2}{|c|}{ FASE 2} & \multicolumn{2}{|c|}{ FASE 3} \\
\hline & $\begin{array}{c}\text { Amplitude } \\
\text { CzA1 }\end{array}$ & $\begin{array}{c}\text { Amplitude } \\
\mathrm{CzA2}\end{array}$ & $\begin{array}{c}\text { Amplitude } \\
\text { CzA1 }\end{array}$ & $\begin{array}{c}\text { Amplitude } \\
\text { CzA2 }\end{array}$ & $\begin{array}{c}\text { Amplitude } \\
\text { CzA1 }\end{array}$ & $\begin{array}{c}\text { Amplitude } \\
\text { CzA2 }\end{array}$ \\
\hline & $(\mu \mathrm{V})$ & $(\mu \mathrm{V})$ & $(\mu \mathrm{V})$ & $(\mu \mathrm{V})$ & $(\mu \mathrm{V})$ & $(\mu \mathrm{V})$ \\
\hline 1 & 3,55 & 3,83 & 5,21 & 8,90 & 10,05 & 8,96 \\
\hline 2 & 1,75 & 2,87 & 1,94 & 2,68 & 2,42 & 1,56 \\
\hline 3 & 2,32 & 1,52 & 9,17 & 7,89 & 3,01 & 3,02 \\
\hline 4 & 1,38 & 0,75 & 0,56 & 3,78 & 4,76 & 4,61 \\
\hline 5 & 3,10 & 2,20 & 6,79 & 6,14 & 3,95 & 5,06 \\
\hline 6 & 4,15 & 3,88 & 0,98 & 2,84 & 3,23 & 5,46 \\
\hline 7 & 1,41 & 2,32 & 3,93 & 2,49 & 3,62 & 3,44 \\
\hline 8 & 3,19 & 3,07 & 4,59 & 3,85 & 3,48 & 3,82 \\
\hline 9 & 6,52 & 8,65 & 2,58 & 2,84 & 4,60 & 5,47 \\
\hline 10 & 7,97 & 6,59 & 6,04 & 6,49 & 6,11 & 7,16 \\
\hline 11 & 1,09 & 0,75 & 3,15 & 4,21 & 4,01 & 4,01 \\
\hline 12 & 1,50 & 0,56 & 1,94 & 0,57 & 1,80 & 1,55 \\
\hline 13 & 6,39 & 7,27 & 5,70 & 6,14 & 5,14 & 4,70 \\
\hline 14 & 9,55 & 9,33 & 10,40 & 11,36 & 8,81 & 9,49 \\
\hline 15 & 1,48 & 3,64 & 3,85 & 3,27 & 4,08 & 4,63 \\
\hline 16 & 4,27 & 4,23 & 1,14 & 1,13 & 9,23 & 8,96 \\
\hline 17 & 1,81 & 2,33 & 2,95 & 2,63 & 2,58 & 3,88 \\
\hline 18 & 0,88 & 1,02 & 0,50 & 0,39 & 3,63 & 3,34 \\
\hline 19 & 2,23 & 1,32 & 2,10 & 2,09 & 2,13 & 3,31 \\
\hline 20 & 1,48 & 3,30 & 1,39 & 2,17 & 0,98 & 3,98 \\
\hline 21 & 3,63 & 3,57 & 5,31 & 3,87 & 3,20 & 2,26 \\
\hline 22 & 2,66 & 2,58 & 8,01 & 8,93 & 3,45 & 3,30 \\
\hline 23 & 3,71 & 4,59 & 5,77 & 6,04 & 4,75 & 4,62 \\
\hline 24 & 3,74 & 2,24 & 0,56 & 2,46 & 1,22 & 2,06 \\
\hline Média \pm DP & $3,32 \pm 2,26$ & $3,43 \pm 2,39$ & $3,94 \pm 2,80$ & $4,29 \pm 2,84$ & $4,17 \pm 2,34$ & $4,52 \pm 2,19$ \\
\hline Mínimo & 0,88 & 0,56 & 0,50 & 0,39 & 0,98 & 1,55 \\
\hline Máximo & 9,55 & 9,33 & 10,40 & 11,36 & 10,05 & 9,49 \\
\hline
\end{tabular}

Legenda: $\mu \mathrm{V}=$ microvolts, $\mathrm{DP}=$ Desvio Padrão. 
Tabela 4. Medidas de amplitude do P300, nas derivações CzA1 e CzA2, nas 3 fases, para o estímulo de fala $(\mathrm{n}=24)$.

\begin{tabular}{|c|c|c|c|c|c|c|}
\hline \multirow{4}{*}{ Indivíduos } & \multicolumn{6}{|c|}{ Resultados P300 - fala } \\
\hline & \multicolumn{2}{|c|}{ FASE 1} & \multicolumn{2}{|c|}{ FASE 2} & \multicolumn{2}{|c|}{ FASE 3} \\
\hline & $\begin{array}{c}\text { Amplitude } \\
\text { CzA1 }\end{array}$ & $\begin{array}{c}\text { Amplitude } \\
\text { CzA2 }\end{array}$ & $\begin{array}{c}\text { Amplitude } \\
\text { CzA1 }\end{array}$ & $\begin{array}{c}\text { Amplitude } \\
\text { CzA2 }\end{array}$ & $\begin{array}{c}\text { Amplitude } \\
\text { CzA1 }\end{array}$ & $\begin{array}{c}\text { Amplitude } \\
\text { CzA2 }\end{array}$ \\
\hline & $(\mu \mathrm{V})$ & $(\mu \mathrm{V})$ & $(\mu \mathrm{V})$ & $(\mu \mathrm{V})$ & $(\mu \mathrm{V})$ & $(\mu \mathrm{V})$ \\
\hline 1 & 2,03 & 2,09 & 4,77 & 4,74 & 2,38 & 3,62 \\
\hline 2 & 8,24 & 7,74 & 7,96 & 7,74 & 6,29 & 5,30 \\
\hline 3 & 4,24 & 3,99 & 4,03 & 3,32 & 4,61 & 4,74 \\
\hline 4 & 3,46 & 5,05 & 6,18 & 5,32 & 4,95 & 3,21 \\
\hline 5 & 3,09 & 4,31 & 3,47 & 3,50 & 2,91 & 2,69 \\
\hline 6 & 2,43 & 2,67 & 4,41 & 3,49 & 0,73 & 0,24 \\
\hline 7 & 2,02 & 5,39 & 4,93 & 5,02 & 3,45 & 5,18 \\
\hline 8 & 6,04 & 6,73 & 4,13 & 7,25 & 8,64 & 7,10 \\
\hline 9 & 3,58 & 4,20 & 3,85 & 3,31 & 3,55 & 1,99 \\
\hline 10 & 2,68 & 2,40 & 4,44 & 2,84 & 1,56 & 1,31 \\
\hline 11 & 6,07 & 6,16 & 4,60 & 4,84 & 3,22 & 3,98 \\
\hline 12 & 1,72 & 2,78 & 3,63 & 4,20 & 2,28 & 3,44 \\
\hline 13 & 3,15 & 3,01 & 4,08 & 4,08 & 4,91 & 5,08 \\
\hline 14 & 2,88 & 3,29 & 2,47 & 4,75 & 3,74 & 4,49 \\
\hline 15 & 3,49 & 3,24 & 2,54 & 1,31 & 2,52 & 1,11 \\
\hline 16 & 0,68 & 1,27 & 1,73 & 1,16 & 0,10 & 0,03 \\
\hline 17 & 5,89 & 5,71 & 4,39 & 5,01 & 4,71 & 5,05 \\
\hline 18 & 3,90 & 2,32 & 2,27 & 3,25 & 0,82 & 1,44 \\
\hline 19 & 3,23 & 4,67 & 2,85 & 1,97 & 1,85 & 3,98 \\
\hline 20 & 5,20 & 5,72 & 7,73 & 4,62 & 7,50 & 7,80 \\
\hline 21 & 8,15 & 7,82 & 2,95 & 3,99 & 4,77 & 5,75 \\
\hline 22 & 2,78 & 2,07 & 1,88 & 1,27 & 2,70 & 2,57 \\
\hline 23 & 6,10 & 6,05 & 6,76 & 7,39 & 5,13 & 5,89 \\
\hline 24 & 7,73 & 6,30 & 7,28 & 6,96 & 1,99 & 6,42 \\
\hline Média \pm DP & $4,11 \pm 2,09$ & $4,37 \pm 1,88$ & $4,30 \pm 1,77$ & $4,22 \pm 1,86$ & $3,55 \pm 2,09$ & $3,85 \pm 2,11$ \\
\hline Mínimo & 0,68 & 1,27 & 1,73 & 1,16 & 0,10 & 0,03 \\
\hline Máximo & 8,24 & 7,82 & 7,96 & 7,74 & 8,64 & 7,80 \\
\hline
\end{tabular}

Legenda: $\boldsymbol{\mu} \mathbf{V}=$ microvolts, $\mathbf{D P}=$ Desvio Padrão. 
APÊEDICE D - Comparação da dispersão das medidas de latência (a e b) e amplitude (c e d) do componente $\mathrm{P} 3$, em relação à escolaridade, nas 3 fases do estudo.

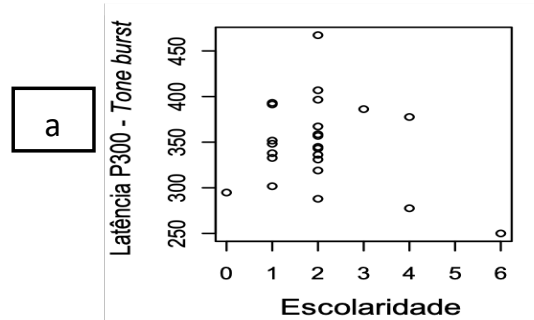

Fase 1: rho (p-valor)

$-0,02(0,91)$

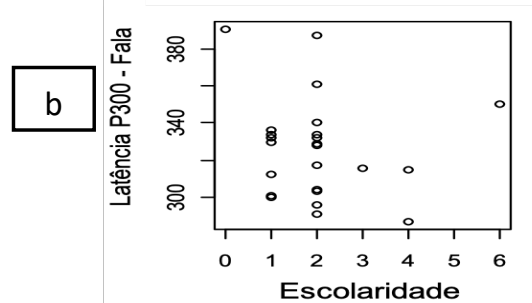

Fase 1: rho (p-valor)
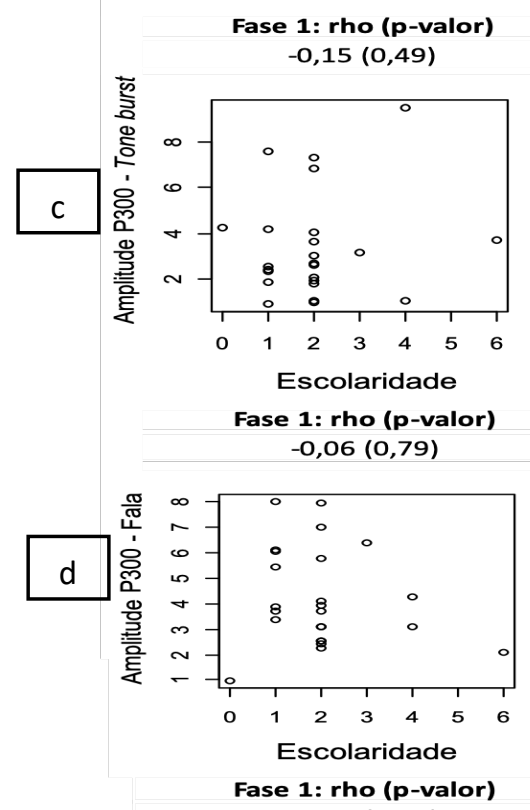

$-0,15(0,49)$

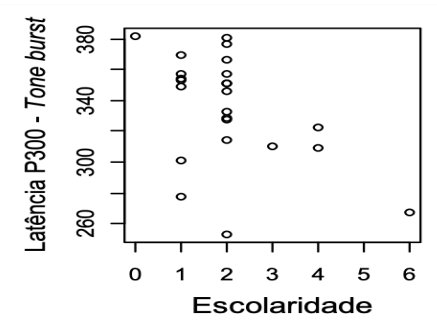

Fase 2: rho (p-valor)

$-0,42(0,0434)$
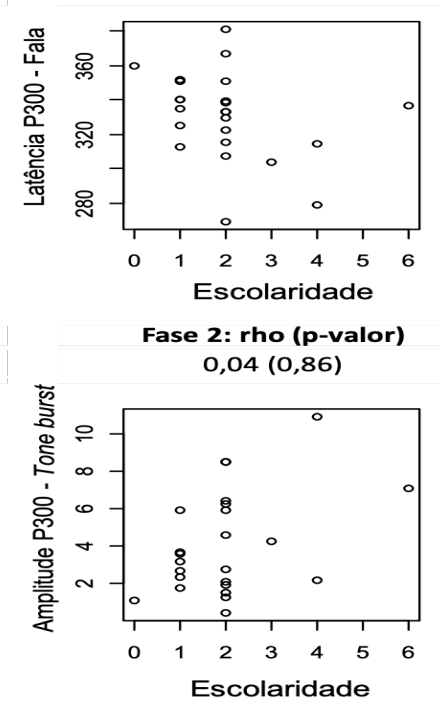

Fase 2: rho (p-valor) $0,35(0,10)$

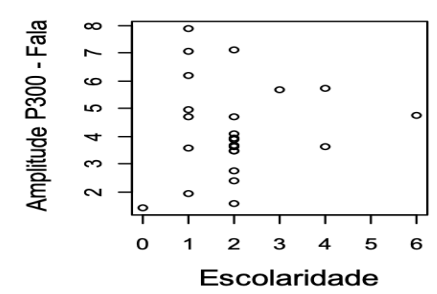

Fase 2: rho (p-valor) $0,04(0,86)$

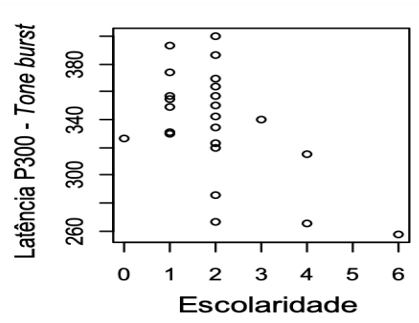

Fase 3: rho (p-valor)

$-0,39(0,06)$
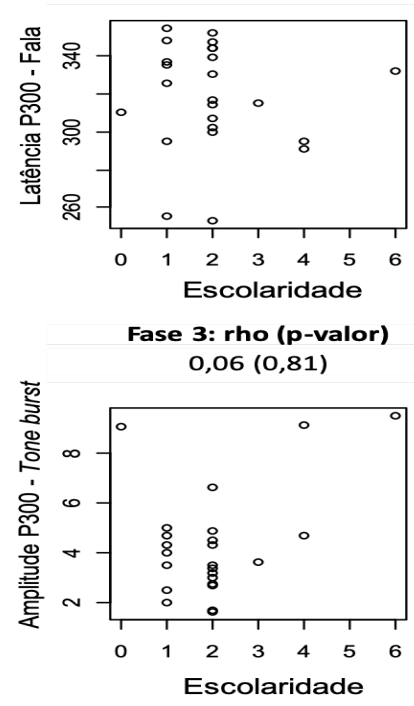

Fase 3: rho (p-valor) $0,13(0,54)$

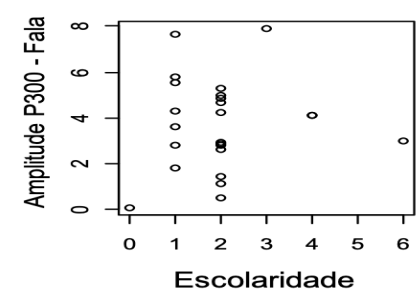

Fase 3: rho (p-valor) $0,06(0,81)$

Legenda: 0 = Analfabeto; 1 = Ensino Fundamental Incompleto; 2 = Ensino Fundamental Completo; 3 = Ensino Médio Incompleto; 4 = Ensino Médio Completo; 5 = Superior Incompleto; 6 = Superior Completo. 
APÊEDICE E - Comparação da dispersão das medidas de latência (a e b) e amplitude (c e d) do componente P3, em relação ao tempo de privação auditiva (anos), nas 3 fases do estudo.
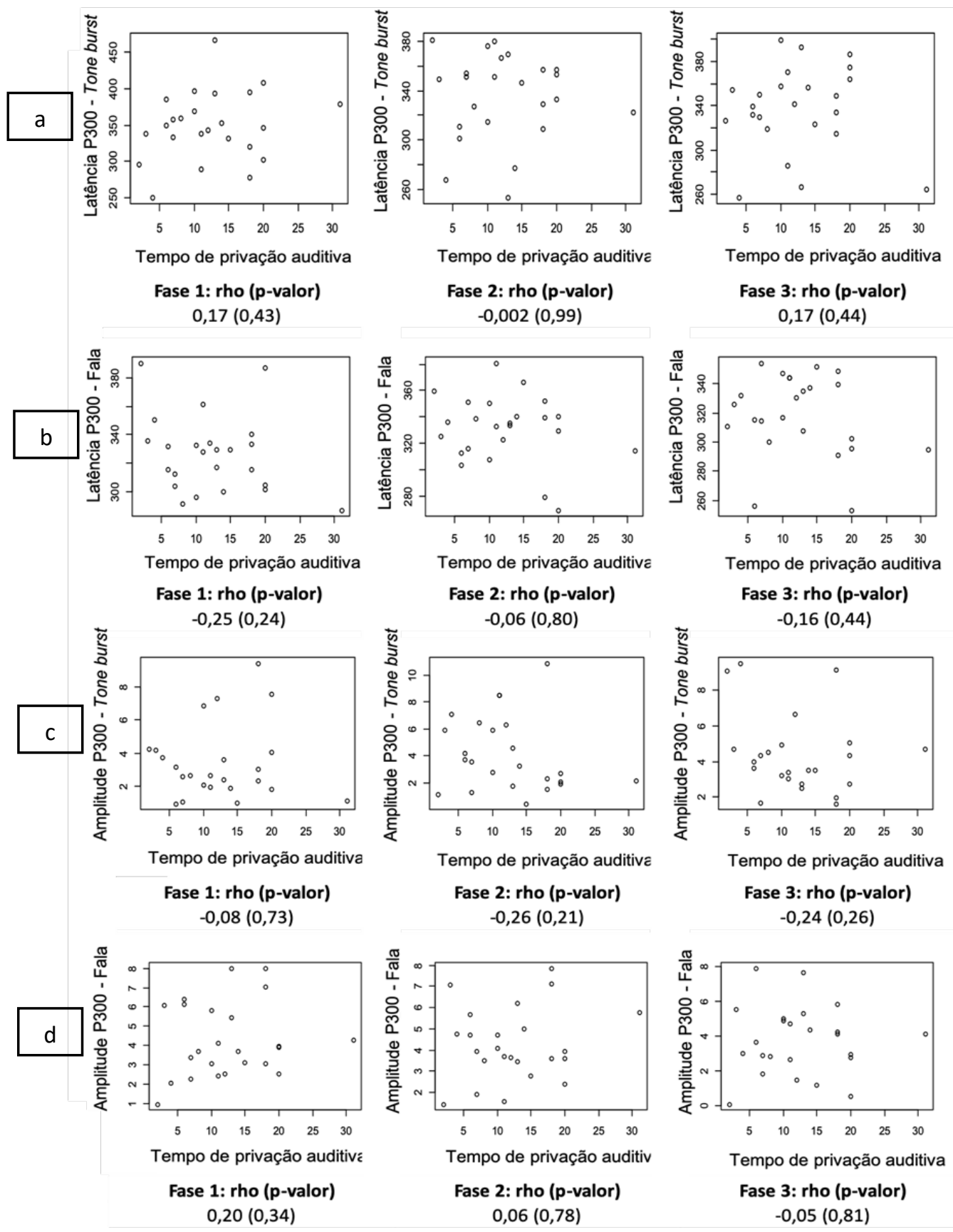
APÊNDICE F - Comparação da dispersão dos resultados do Índice Percentual de Reconhecimento de Sentenças no Silêncio (IPRSS) em relação à escolaridade dos participantes, nas 3 fases do estudo.

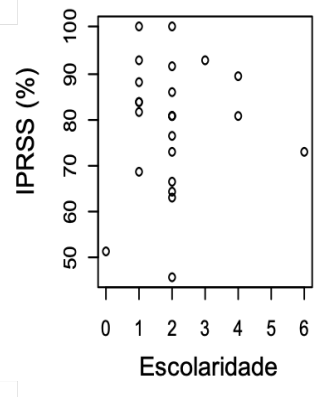

Fase 1: rho (p-valor) $-0,05(0,81)$

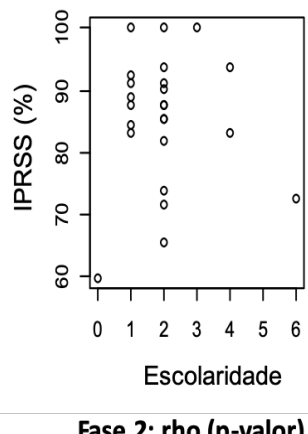

Fase 2: rho (p-valor) $0,01(0,97)$

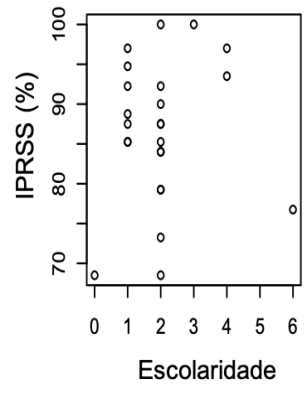

Fase 3: rho (p-valor) $0,08(0,73)$

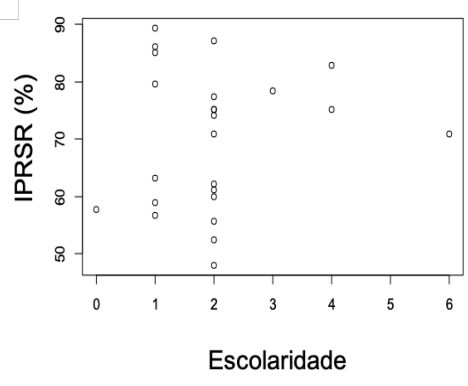

Fase 3 - Com ruído: rho (p-valor) $0,07(0,73)$

Legenda: $0=$ Analfabeto; $1=$ Ensino Fundamental Incompleto; $2=$ Ensino Fundamental Completo; 3 = Ensino Médio Incompleto; 4 = Ensino Médio Completo; 5 = Superior Incompleto; $6=$ Superior Completo; $\%=$ por cento; IPRSS = Índice Percentual de Reconhecimento de Sentenças no Silêncio; IPRSR = Índice Percentual de Reconhecimento de Sentenças no Ruído. 
APÊNDICE G - Comparação da dispersão dos resultados do Índice Percentual de Reconhecimento de Sentenças no Silêncio (IPRSS) em relação ao tempo de privação auditiva, nas 3 fases do estudo.

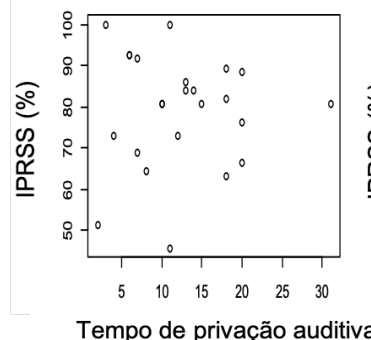

Fase 1: rho (p-valor) $-0,09(0,66)$

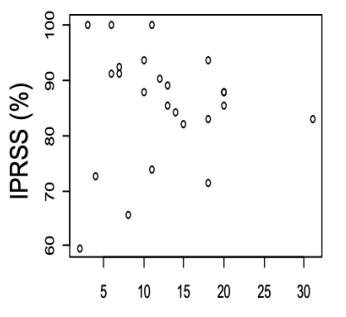

Fase 2: rho (p-valor) $-0,19(0,36)$

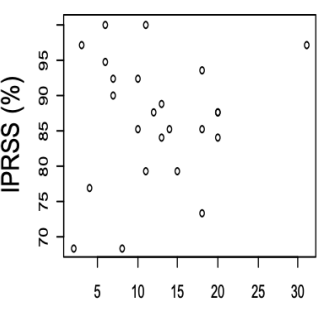

Tempo de privação auditiva

Fase 3: rho (p-valor) $-0,05(0,79)$

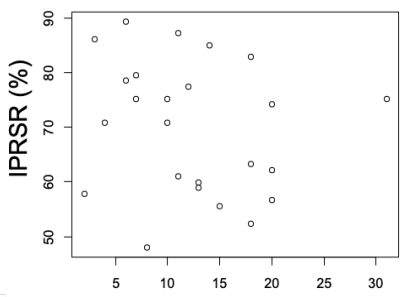

Tempo de privação auditiva

Fase 3 - Com ruído: rho (p-valor) $-0,26(0,21)$

Legenda: \% = por cento; IPRSS = Índice Percentual de Reconhecimento de Sentenças no Silêncio; IPRSR = Índice Percentual de Reconhecimento de Sentenças no Ruído. 
APÊNDICE H - Exemplo dos registros do P300 nas três fases do estudo, com os diferentes estímulos utilizados (tone burst e fala).

Figura 1 - Exemplo de um registro do P300 na fase 1, estímulo tone burst.
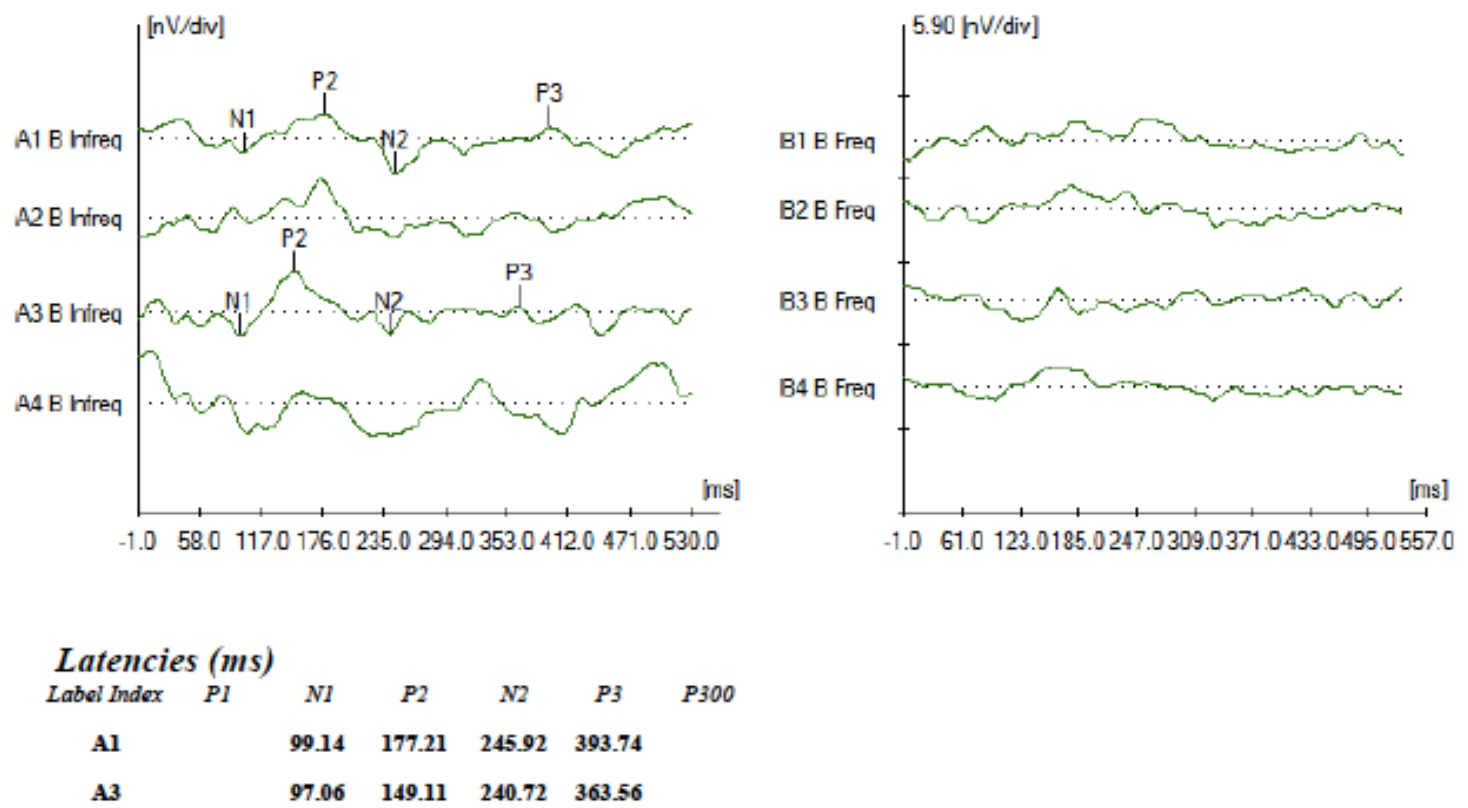

Figura 2 - Exemplo de um registro do P300 na fase 2, estímulo tone burst.
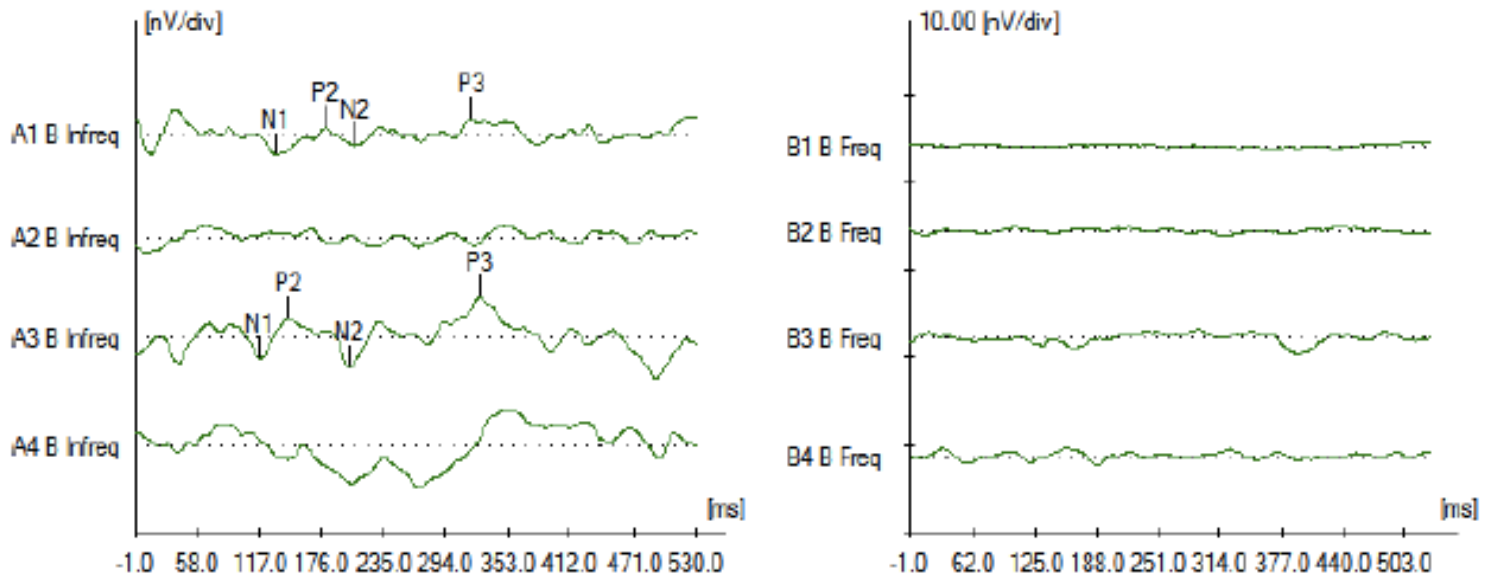

\section{Latencies ( $m s$ )}

$\begin{array}{lllllll}\text { Label Index } & P 1 & N 1 & P 2 & \text { N2 } & P 3 & P 300\end{array}$

Al $\quad \begin{array}{llll}132.45 & 179.30 & 207.40 & 317.75\end{array}$

$\begin{array}{lllll}\text { A3 } & 117.88 & 144.94 & 203.24 & 327.12\end{array}$ 
Figura 3 - Exemplo de um registro do P300 na fase 3, estímulo tone burst.
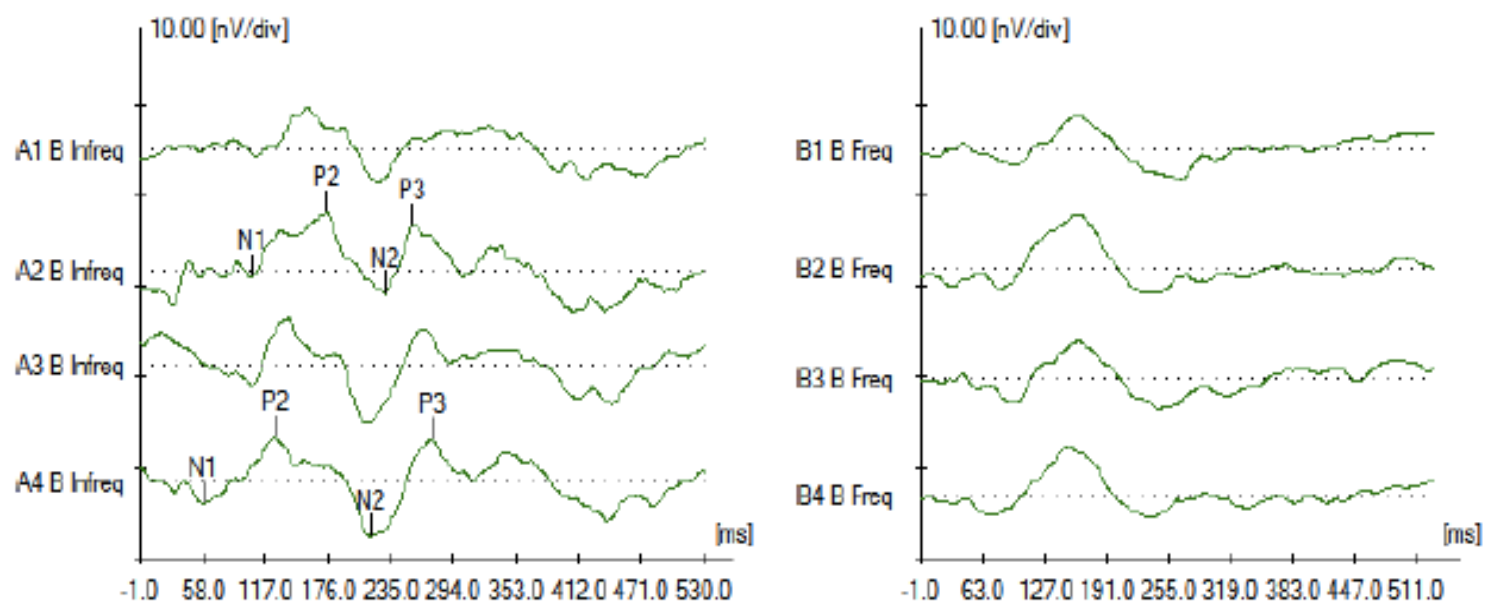

\section{Latencies (ms)}

$\begin{array}{cccccc}\text { Label Index } & P 1 & N 1 & P 2 & N 2 & P 3 \\ \text { A2 } & & 104.34 & 174.09 & 229.26 & 255.29 \\ \text { A4 } & & 58.54 & 126.20 & 215.73 & 274.03\end{array}$

Figura 4 - Exemplo de um registro do P300 na fase 1, estímulo de fala.
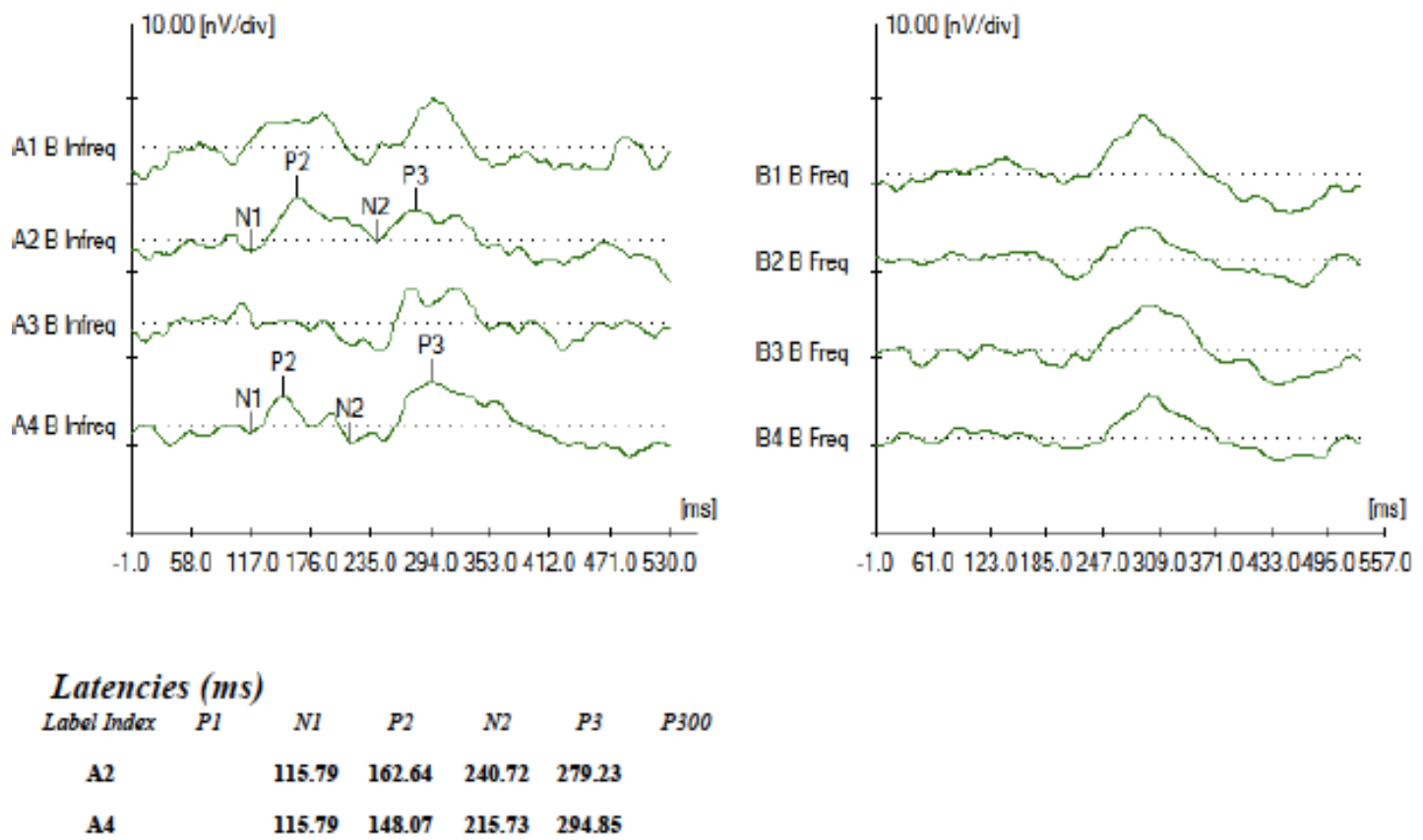
Figura 5 - Exemplo de um registro do P300 na fase 2, estímulo de fala.
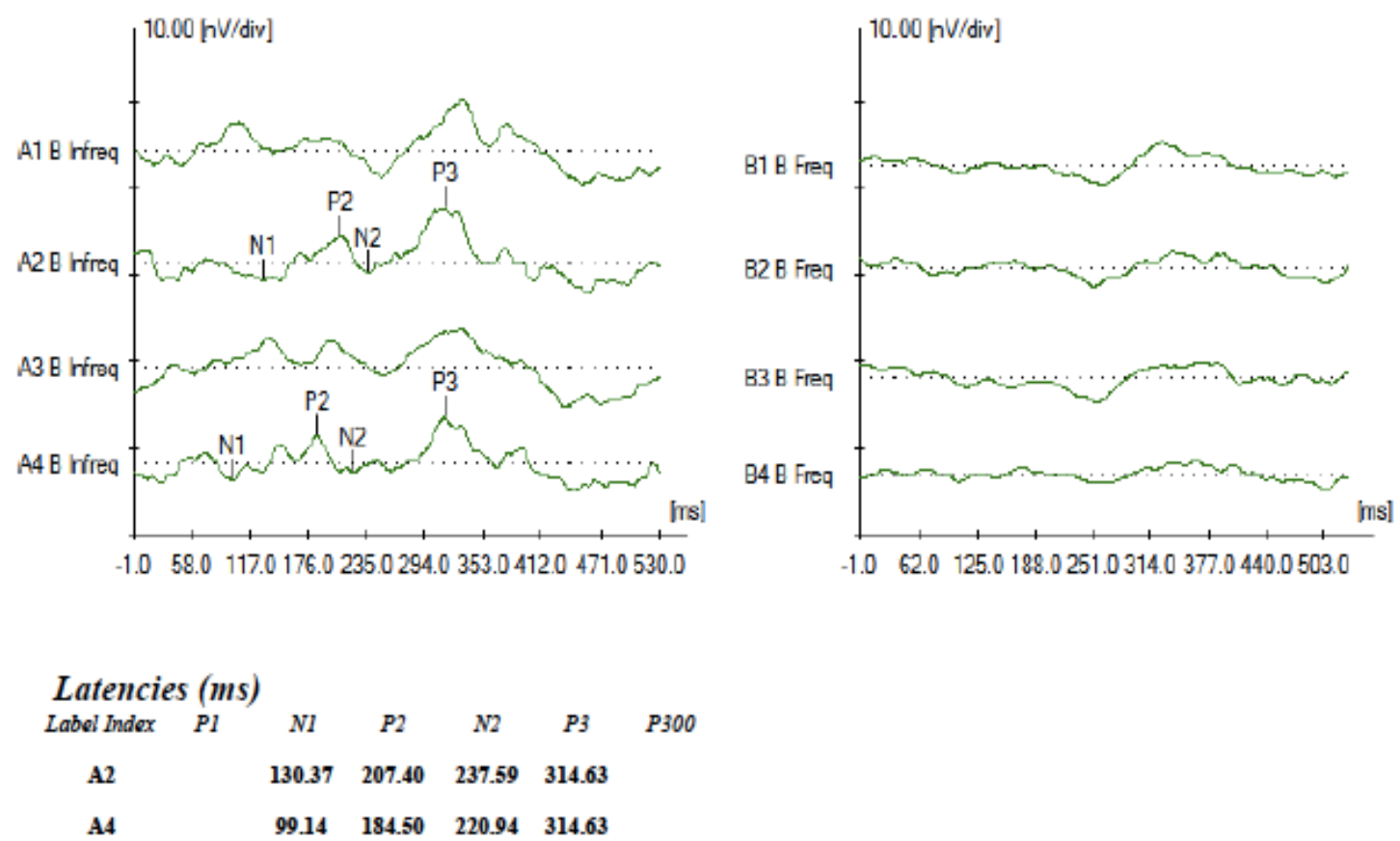

Figura 6 - Exemplo de um registro do P300 na fase 3, estímulo de fala.
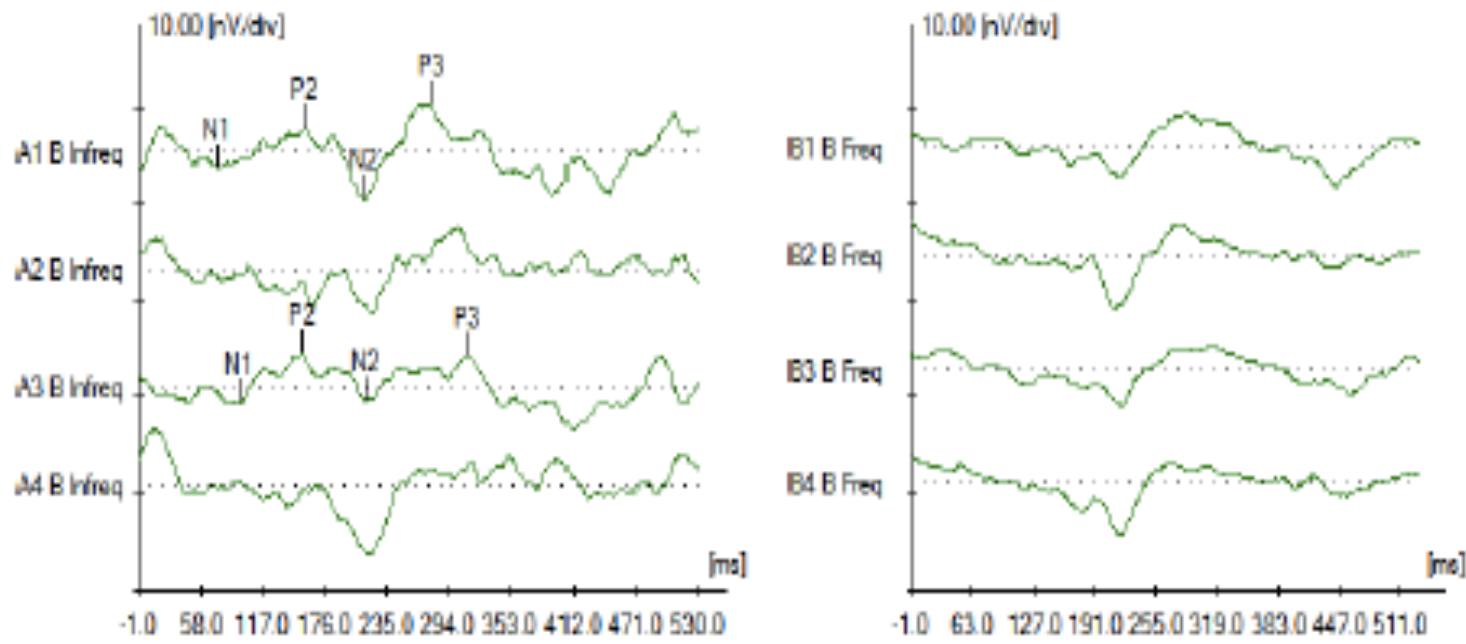

\section{Latencies (ms)}

$\begin{array}{ccccccc}\text { Lobel hadx } & P l & N 1 & P 2 & N 2 & P 3 & P 360 \\ \text { A1 } & & 74.15 & 157.43 & 214.69 & 277.15 & \\ \text { A3 } & & 94.97 & 154.31 & 215.73 & 312.55 & \end{array}$




\section{ANEXOS}

ANEXO A - Parecer do Comitê de Ética em Pesquisa HCRP

HOSPITAL DAS CLÍNICAS DA FACULDADE DE MEDICINA DE RIBEIRÃO PRETO DA UNIVERSIDADE DE SÄO PAULO

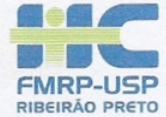

Ribeirão Preto, 09 de agosto de 2017

Oficio $\mathrm{n}^{\circ} 2377 / 2017$

$\mathrm{CEP} / \mathrm{MGV}$

Prezados Senhores,

O trabalho intitulado "AVALIAÇÃO ELETROFISIOLÓGICA (P300) E DE PERCEPÇ̃̃O DE FALA EM INDIVÍDUOS COM PERDA AUDITIVA ANTES E APÓS ADAPTAÇÃo DE PRÓTESES AUDITIVAS" - versão 2.0, de $24 / 07 / 2017$, foi analisado pelo Comitê de Ética em Pesquisa em sua $455^{a}$ Reunião Ordinária, realizada em 07/08/2017 e enquadrado na categoria: APROVADO, bem como o Termo de Consentimento Livre e Esclarecido - versão 2.0, de 24/07/2017 e o Termo de Consentimento Livre e Esclarecido - Grupo Controle - versão 2.0, de 24/07/2017, de acordo com o Processo HCRP nº 8774/2017.

De acordo com Carta Circular n 003/2011/CONEP/CNS, datada de 21/03/2011, o sujeito de pesquisa ou seu representante, quando for o caso, deverá rubricar todas as folhas do Termo de Consentimento Livre e Esclarecido - TCLE apondo sua assinatura na última do referido Termo; o pesquisador responsável deverá da mesma forma, rubricar todas as folhas do Termo de Consentimento Livre e Esclarecido - TCLE - apondo sua assinatura na última página do referido Termo.

Este Comitê segue integralmente a Conferência Internacional de Harmonização de Boas Práticas Clínicas (IGH-GCP), bem como a Resolução $n^{\circ} 466 / 12$ CNS/MS.

Lembramos que devem ser apresentados a este CEP, o Relatório Parcial e o Relatório Final da pesquisa.

Atenciosamente.

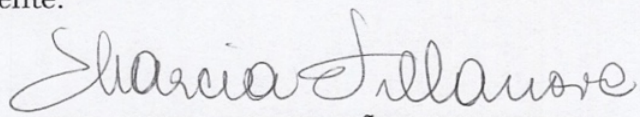

DR ${ }^{a}$. MARCIA GUIMARÃES VILLANOVA

Coordenadora do Comitê de Ética em

Pesquisa do HCRP e da FMRP-USP

Ilustríssimos Senhores

PROF $^{2}$.DR $^{\mathrm{a}}$.ANA CLÁUDIA MIRÂNDOLA BARBOSA REIS

VICTOR GOIRIS CALDERARO

Depto. de Oftalmologia, Otorrinolaringologia e Cirurgia de Cabeça e Pescoço

HOSPITAL DAS CLINICAS DA FACULDADE DE MEDICINA DE RIBEIRĀO PRETO DA UNIVERSIDADE DE SÃO PAULO 14048-900 Ribeirão Preto SP 
ANEXO B - Questionário (Apontador Cognitivo) de 10 Pontos (10-CS) (APOLINARIO et al., 2015) - traduzido para o português brasileiro.

QUESTIONÁRIO (APONTADOR COGNITIVO) DE 10 PONTOS (10-CS)

$>$ QUE ANO É ESSE?

$>$ QUE MÊS É ESTE?

$>$ QUE DIA É HOJE?

$\begin{array}{ll}0 & 1 \\ 0 & 1 \\ 0 & 1\end{array}$

AGORA VOU NOMEAR TRÊS OBJETOS. AGUARDE ATÉ EU DIZER AS TRÊS PALAVRAS E DEPOIS REPITA. LEMBRE-SE O QUE ELES SÃO. VOU LHE PEDIR PARA NOMEÁ-LOS NOVAMENTE EM POUCOS MINUTOS. POR FAVOR, REPITA ESTAS PALAVRAS PARA MIM:

CARRO - VASO - TIJOLO

(pode repetir 3 vezes se necessário, a repetição não é pontuada)

$>\quad$ AGORA ME DIGA OS NOMES DE TODOS OS ANIMAIS QUE VOCÊ PENSAR, O MAIS RÁPIDO POSSÍVEL. EU VOU LHE DAR UM MINUTO PARA CHEGAR A TANTOS ANIMAIS COMO VOCÊ PODE. PRONTO?

$\begin{array}{ll}0-5: & 0 \\ 6-8: & 1 \\ 9-11: & 2 \\ 12-14: & 3 \\ \text { 15 ou mais: } & 4\end{array}$

D AGORA QUAIS ERAM OS TRÊS OBJETOS QUE EU PEDI QUE VOCÊ LEMBRASSE?

$\begin{array}{lll}\text { CARRO } & 0 & 1 \\ \text { VASO } & 0 & 1 \\ \text { TIJOLO } & 0 & 1\end{array}$

10-CS: 
ANEXO C - Listas de Sentenças em Português (COSTA, 2015).

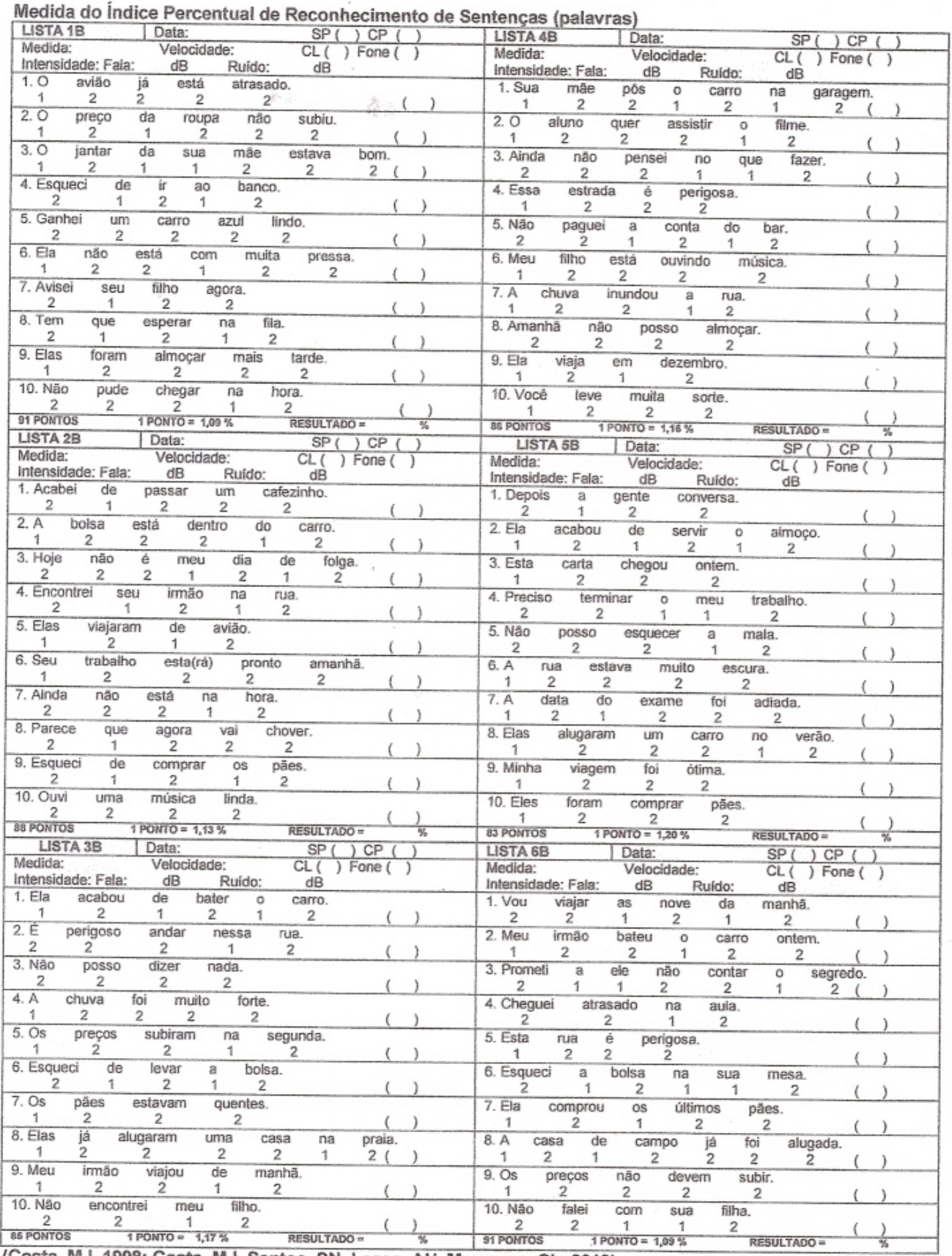

(Costa, MJ, 1998; Costa, MJ, Santos, SN, Lessa, AH, Mezzomo, CL, 2013)

Protocolo elaborado por: Maristela J. Costa e Sinéia N. dos Santos, 2012. 
ANEXO D - Hearing Handicap Inventory for Adults (HHIA) (NEWMAN et al., 1990).

NOME:

DATA:

\begin{tabular}{|c|c|c|c|c|}
\hline & HHIA - PERGUNTAS & $\begin{array}{c}\text { Sim } \\
(4)\end{array}$ & \begin{tabular}{|c|} 
Às vezes \\
$(2)$
\end{tabular} & $\begin{array}{c}\text { Não } \\
\text { (0) }\end{array}$ \\
\hline S-1 & $\begin{array}{l}\text { A dificuldade em ouvir faz você usar o telefone menos vezes do que } \\
\text { gostaria? }\end{array}$ & & & \\
\hline $\mathbf{E}-2$ & $\begin{array}{l}\text { A dificuldade em ouvir faz você se sentir constrangido ou sem jeito } \\
\text { quando é apresentado a pessoas desconhecidas? }\end{array}$ & & & \\
\hline S-3 & A dificuldade em ouvir faz você evitar grupos de pessoas? & & & \\
\hline E-4 & A dificuldade em ouvir faz você ficar irritado? & & & \\
\hline $\mathbf{E}-5$ & $\begin{array}{l}\text { A dificuldade em ouvir faz você se sentir frustrado ou insatisfeito } \\
\text { quando conversa com pessoas da sua família? }\end{array}$ & & & \\
\hline S-6 & $\begin{array}{l}\text { A diminuição da audição causa outras dificuldades quando você vai a } \\
\text { uma festa ou reunião social? }\end{array}$ & & & \\
\hline E-7 & $\begin{array}{l}\text { A dificuldade em ouvir faz você se sentir frustrado ao conversar com } \\
\text { os colegas de trabalho? }\end{array}$ & & & \\
\hline S-8 & Você sente dificuldade em ouvir quando vai ao cinema ou teatro? & & & \\
\hline E-9 & $\begin{array}{l}\text { Você se sente prejudicado ou diminuído devido a sua dificuldade em } \\
\text { ouvir? }\end{array}$ & & & \\
\hline S-10 & $\begin{array}{l}\text { A diminuição da audição causa dificuldades quando visita amigos, } \\
\text { parentes ou vizinhos? }\end{array}$ & & & \\
\hline S-11 & $\begin{array}{l}\text { A dificuldade em ouvir faz com que você tenha problemas para } \\
\text { ouvir/entender os colegas de trabalho? }\end{array}$ & & & \\
\hline E-12 & A dificuldade em ouvir faz você ficar nervoso? & & & \\
\hline $\mathbf{S}-13$ & $\begin{array}{l}\text { A dificuldade em ouvir faz você visitar amigos, parentes ou vizinhos } \\
\text { menos do que gostaria? }\end{array}$ & & & \\
\hline E-14 & $\begin{array}{l}\text { A dificuldade em ouvir faz você ter discussões ou brigas com a sua } \\
\text { família? }\end{array}$ & & & \\
\hline S-15 & $\begin{array}{l}\text { A diminuição da audição causa dificuldades para assistir TV ou ouvir } \\
\text { rádio? }\end{array}$ & & & \\
\hline S-16 & $\begin{array}{l}\text { A dificuldade em ouvir faz com que você saia para fazer compras } \\
\text { menos vezes do que gostaria? }\end{array}$ & & & \\
\hline E-17 & $\begin{array}{l}\text { A dificuldade em ouvir deixa você de alguma maneira chateado ou } \\
\text { aborrecido? }\end{array}$ & & & \\
\hline E-18 & A dificuldade em ouvir faz você preferir ficar sozinho? & & & \\
\hline S-19 & $\begin{array}{l}\text { A dificuldade em ouvir faz você querer conversar menos com as } \\
\text { pessoas da sua família? }\end{array}$ & & & \\
\hline E-20 & $\begin{array}{l}\text { Você acha que a dificuldade em ouvir diminui ou limita de alguma } \\
\text { forma sua vida pessoal ou social? }\end{array}$ & & & \\
\hline S-21 & $\begin{array}{l}\text { A diminuição da audição lhe causa dificuldades quando você está em } \\
\text { um restaurante com familiares ou amigos? }\end{array}$ & & & \\
\hline E-22 & A dificuldade em ouvir faz você se sentir triste ou deprimido? & & & \\
\hline $\mathbf{S}-23$ & $\begin{array}{l}\text { A dificuldade em ouvir faz você assistir TV ou rádio menos vezes do } \\
\text { que gostaria? }\end{array}$ & & & \\
\hline E-24 & $\begin{array}{l}\text { A dificuldade em ouvir faz você se sentir constrangido ou menos à } \\
\text { vontade quando conversa com amigos? }\end{array}$ & & & \\
\hline E-25 & $\begin{array}{l}\text { A dificuldade em ouvir faz você se sentir isolado ou deixado de lado } \\
\text { num grupo de pessoas? }\end{array}$ & & & \\
\hline
\end{tabular}


ANEXO E - Hearing Handicap Inventory for the Elderly (HHIE) (VENTRY; WEINSTEIN, 1982).

NOME:

DATA:

\begin{tabular}{|c|c|c|c|c|}
\hline & HHIE - PERGUNTAS & $\begin{array}{l}\text { Sim } \\
(4)\end{array}$ & $\begin{array}{l}\text { Às vezes } \\
(2)\end{array}$ & $\begin{array}{c}\text { Não } \\
(0)\end{array}$ \\
\hline S-1 & $\begin{array}{l}\text { A dificuldade em ouvir faz você usar o telefone menos vezes do que } \\
\text { gostaria? }\end{array}$ & & & \\
\hline $\mathbf{E - 2}$ & $\begin{array}{l}\text { A dificuldade em ouvir faz você se sentir constrangido ou sem jeito } \\
\text { quando é apresentado a pessoas desconhecidas? }\end{array}$ & & & \\
\hline S-3 & A dificuldade em ouvir faz você evitar grupos de pessoas? & & & \\
\hline E-4 & A dificuldade em ouvir faz você ficar irritado? & & & \\
\hline $\mathbf{E}-5$ & $\begin{array}{l}\text { A dificuldade em ouvir faz você se sentir frustrado ou insatisfeito } \\
\text { quando conversa com pessoas da sua família? }\end{array}$ & & & \\
\hline S-6 & $\begin{array}{l}\text { A diminuição da audição causa outras dificuldades quando você vai a } \\
\text { uma festa ou reunião social? }\end{array}$ & & & \\
\hline E-7 & $\begin{array}{l}\text { A dificuldade em ouvir faz você se sentir "tolo" ou inferiorizado diante } \\
\text { de outras pessoas? }\end{array}$ & & & \\
\hline S-8 & Você sente dificuldade em ouvir quando alguém fala cochichando? & & & \\
\hline E-9 & Você se sente prejudicado ou diminuído devido a dificuldade em ouvir? & & & \\
\hline S-10 & $\begin{array}{l}\text { A diminuição da audição causa dificuldades quando visita amigos, } \\
\text { parentes ou vizinhos? }\end{array}$ & & & \\
\hline S-11 & $\begin{array}{l}\text { A dificuldade em ouvir faz com que você vá a serviços religiosos } \\
\text { menos vezes do que gostaria? }\end{array}$ & & & \\
\hline E-12 & A dificuldade em ouvir faz você ficar nervoso? & & & \\
\hline S-13 & $\begin{array}{l}\text { A dificuldade em ouvir faz você visitar amigos, parentes ou vizinhos } \\
\text { menos do que gostaria? }\end{array}$ & & & \\
\hline E-14 & $\begin{array}{l}\text { A dificuldade em ouvir faz você ter discussões ou brigas com a sua } \\
\text { família? }\end{array}$ & & & \\
\hline S-15 & $\begin{array}{l}\text { A diminuição da audição causa dificuldades para assistir TV ou ouvir } \\
\text { rádio? }\end{array}$ & & & \\
\hline S-16 & $\begin{array}{l}\text { A dificuldade em ouvir faz com que você saia para fazer compras } \\
\text { menos vezes do que gostaria? }\end{array}$ & & & \\
\hline E-17 & $\begin{array}{l}\text { A dificuldade em ouvir deixa você de alguma maneira chateado ou } \\
\text { aborrecido? }\end{array}$ & & & \\
\hline E-18 & A dificuldade em ouvir faz você preferir ficar sozinho? & & & \\
\hline S-19 & $\begin{array}{l}\text { A dificuldade em ouvir faz você querer conversar menos com as } \\
\text { pessoas da sua família? }\end{array}$ & & & \\
\hline E-20 & $\begin{array}{l}\text { Você acha que a dificuldade em ouvir diminui ou limita de alguma } \\
\text { forma sua vida pessoal ou social? }\end{array}$ & & & \\
\hline S-21 & $\begin{array}{l}\text { A diminuição da audição lhe causa dificuldades quando você está em } \\
\text { um restaurante com familiares ou amigos? }\end{array}$ & & & \\
\hline $\mathbf{E - 2 2}$ & A dificuldade em ouvir faz você se sentir triste ou deprimido? & & & \\
\hline S-23 & $\begin{array}{l}\text { A dificuldade em ouvir faz você assistir TV ou rádio menos vezes do } \\
\text { que gostaria? }\end{array}$ & & & \\
\hline E-24 & $\begin{array}{l}\text { A dificuldade em ouvir faz você se sentir constrangido ou menos à } \\
\text { vontade quando conversa com amigos? }\end{array}$ & & & \\
\hline E-25 & $\begin{array}{l}\text { A dificuldade em ouvir faz você se sentir isolado ou "deixado de lado" } \\
\text { num grupo de pessoas? }\end{array}$ & & & \\
\hline
\end{tabular}

